NIST Special Publication 1194

\title{
Benefits and Costs of Energy Standard Adoption for New Residential Buildings: National Summary
}

Joshua Kneifel

Eric O'Rear

This publication is available free of charge from: http://dx.doi.org/10.6028/NIST.SP.1194
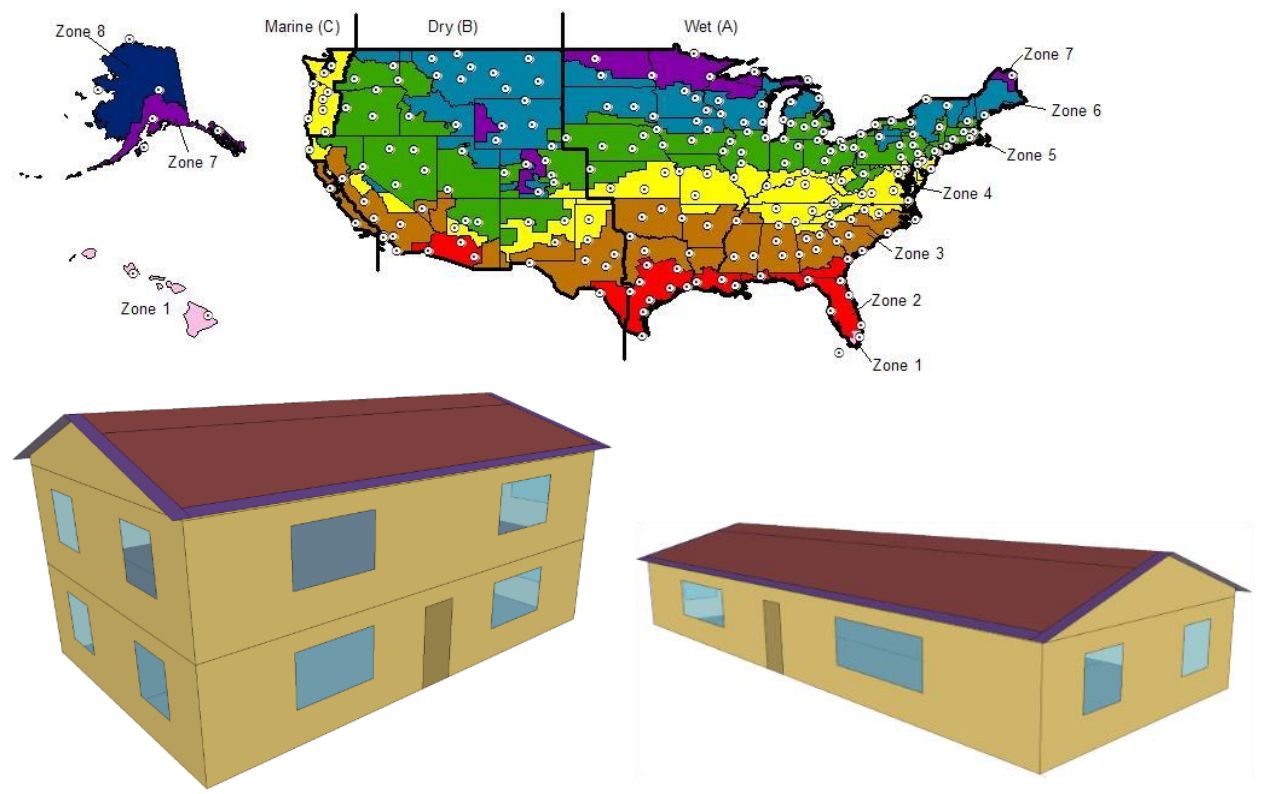

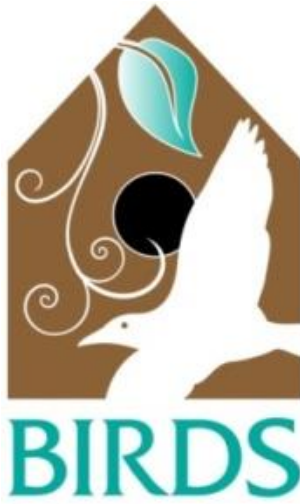

Building Industry Reporting and Design for Sustainability

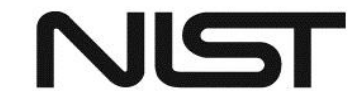

National Institute of Standards and Technology U.S. Department of Commerce 



\title{
NIST Special Publication 1194
}

\section{Benefits and Costs of Energy Standard Adoption for New Residential Buildings: National Summary}

\author{
Joshua Kneifel \\ Eric O'Rear \\ Applied Economics Office \\ Engineering Laboratory
}

This publication is available free of charge from: http://dx.doi.org/10.6028/NIST.SP.1194

June 2015

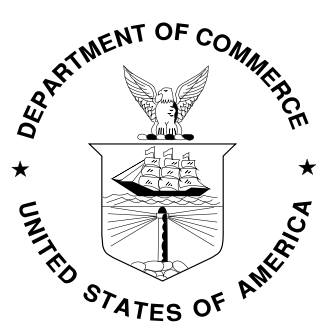

U.S. Department of Commerce Penny Pritzker, Secretary

National Institute of Standards and Technology Willie May, Under Secretary of Commerce for Standards and Technology and Director 
Certain commercial entities, equipment, or materials may be identified in this document in order to describe an experimental procedure or concept adequately. Such identification is not intended to imply recommendation or endorsement by the National Institute of Standards and Technology, nor is it intended to imply that the entities, materials, or equipment are necessarily the best available for the purpose.

National Institute of Standards and Technology Special Publication 1194

Natl. Inst. Stand. Technol. Spec. Publ. 1194, 80 pages (June 2014) http://dx.doi.org/10.6028/NIST.SP.1194

CODEN: NSPUE2 


\begin{abstract}
Energy efficiency requirements in energy codes for residential buildings vary across states, and many states have not yet adopted the latest energy efficiency code edition. As of July 2014, states had adopted energy codes ranging across editions of the International Energy Conservation Code (IECC) (2003, 2006, 2009, and 2012). Some states do not have a code requirement for energy efficiency, leaving it up to the locality or jurisdiction to set its own requirements. This study considers the impacts that the adoption of newer, more stringent energy codes for residential buildings would have on building energy use, operational energy costs, building life-cycle costs, and "cradle-to-grave" life-cycle carbon emissions.

The results of this report are based on analysis of the Building Industry Reporting and Design for Sustainability (BIRDS) new residential database, which includes 9120 whole building energy simulations covering 10 building types in 228 cities across all U.S. states for study periods ranging from 1 year to 40 years. The performance of buildings designed to meet current state energy codes is compared to their performance when meeting new editions of IECC design requirements to determine whether more stringent energy code editions are cost-effective in reducing energy consumption and life-cycle carbon emissions. The estimated savings for each of the building types are aggregated using citylevel new residential building construction data to calculate the magnitude of the incremental savings that a state may realize if it were to adopt a more energy efficient code edition as its state energy code. These state-level estimates are further aggregated to the national level to estimate the potential total impact from nationwide adoption of more stringent energy codes.
\end{abstract}

\title{
Keywords
}

Building economics; economic analysis; life-cycle costing; life-cycle assessment; energy efficiency; residential buildings 


\section{Preface}

This study was conducted by the Applied Economics Office in the Engineering Laboratory (EL) at the National Institute of Standards and Technology (NIST). The study is designed to assess the energy use, life-cycle cost, and life-cycle carbon emissions impacts from the adoption of new state energy codes based on more stringent building energy code editions. The intended audience is researchers and policy makers in the residential building sector, and others interested in residential building energy efficiency.

\section{Disclaimers}

The policy of the National Institute of Standards and Technology is to use metric units in all of its published materials. Because this report is intended for the U.S. construction industry that uses U.S. customary units, it is more practical and less confusing to include U.S. customary units as well as metric units. Measurement values in this report are therefore stated in metric units first, followed by the corresponding values in U.S. customary units within parentheses. 


\section{Acknowledgements}

The authors wish to thank all those who contributed ideas and suggestions for this report. They include Dr. David Butry and Dr. Robert Chapman of EL's Applied Economics Office, Dr. William Healy of EL's Energy and Environment Division, and Dr. Nicos S. Martys of EL's Materials and Structural Systems Division. A special thanks to Brian Presser, Samuel Sharpe, and Priya Lavappa for developing the BIRDS new residential database.

\section{Author Information}

Joshua D. Kneifel

Economist

National Institute of Standards and Technology

Engineering Laboratory

100 Bureau Drive, Mailstop 8603

Gaithersburg, MD 20899-8603

Tel.: 301-975-6857

Email: joshua.kneifel@nist.gov

Eric G. O’Rear

Economist

National Institute of Standards and Technology

Engineering Laboratory

100 Bureau Drive, Mailstop 8603

Gaithersburg, MD 20899-8603

Tel.: 301-975-4570

Email: eric.orear@nist.gov 


\section{Table of Contents}

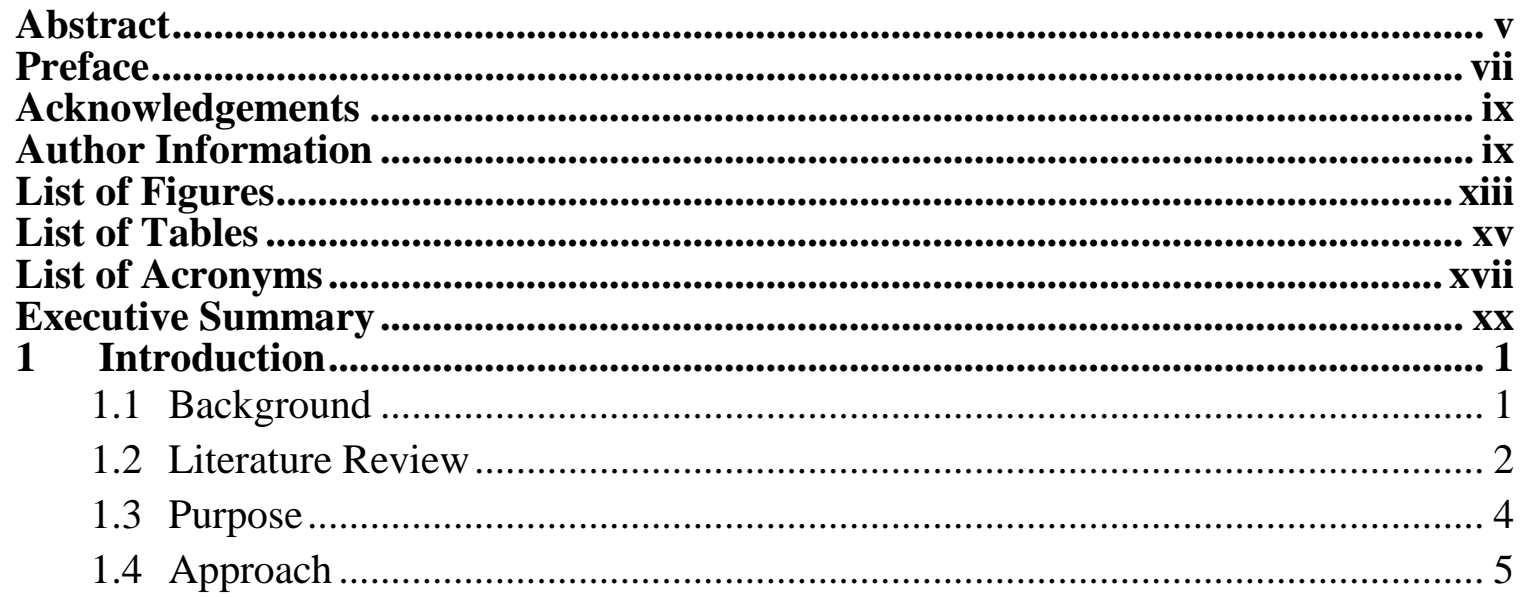

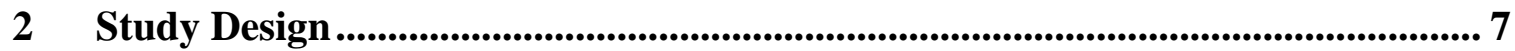



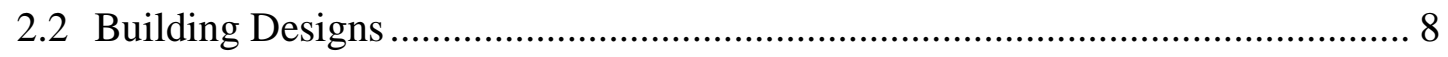

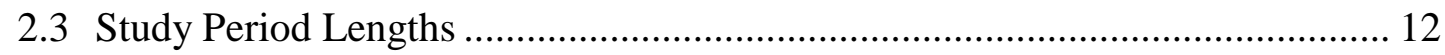

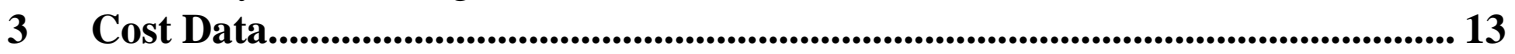

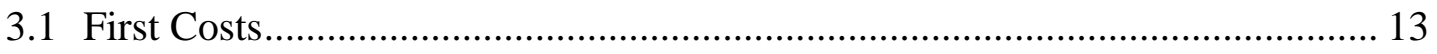

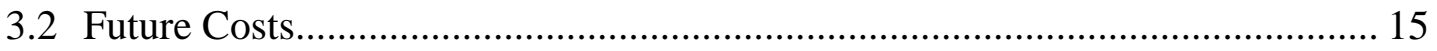

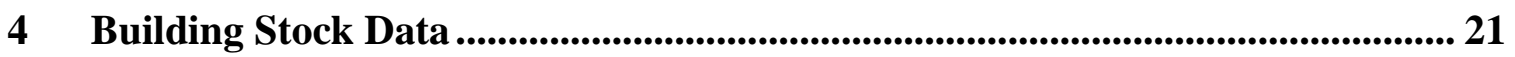

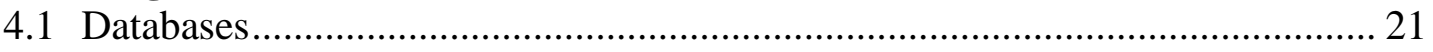

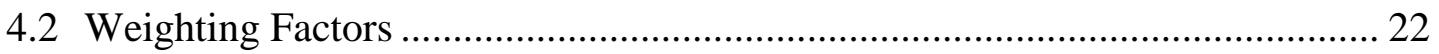

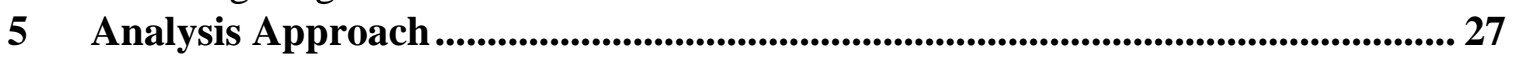

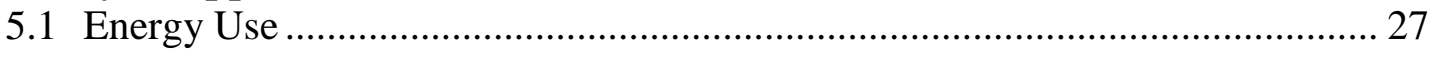

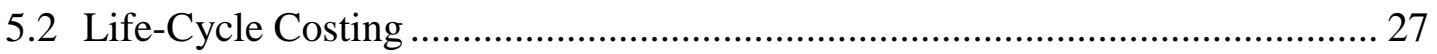

5.3 Environmental Impact Assessment .............................................................. 28

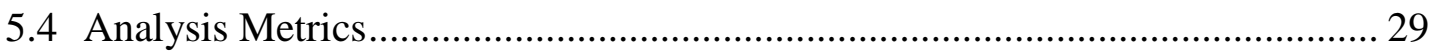

6 Nationwide Impacts of Adopting 2012 IECC Design ........................................ 33

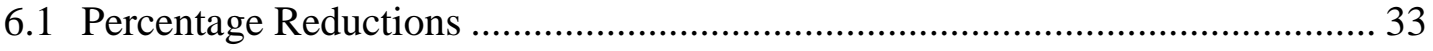

6.1.1 Results by Building Type............................................................... 33

6.1.2 Results by Climate Zone ................................................................. 38

6.1.3 Results by State Energy Code.............................................................. 42

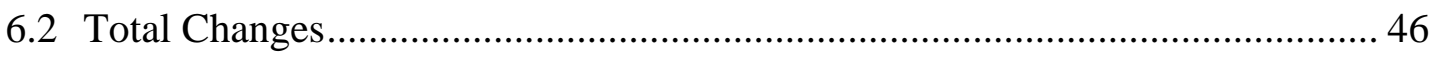

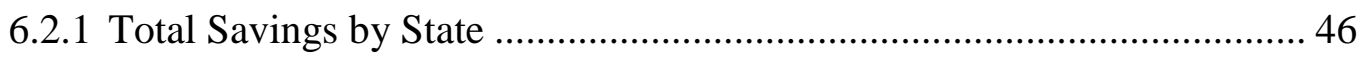

6.2.2 Regional and National Impacts ....................................................... 49

6.3 Savings per Unit of Floor Area ................................................................. 49

6.3.1 State-Level Savings ...................................................................... 49

6.3.1.1 Energy Use and Energy Cost Savings per Unit of Floor Area.. 49

6.3.1.2 Energy Cost Savings per Unit of Energy Savings.................... 50

6.3.1.3 Savings in Life-Cycle Carbon Emissions per Unit of Energy

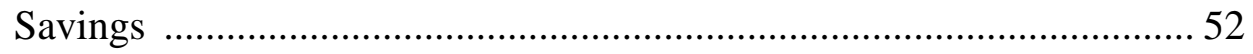

6.3.1.4 Life-Cycle Cost Savings per Unit of Floor Area..................... 53 
6.3.2 Regional and National Savings per Unit of Floor Area ......................... 54

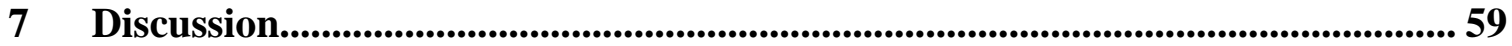

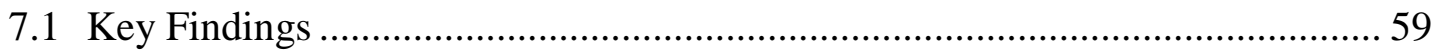

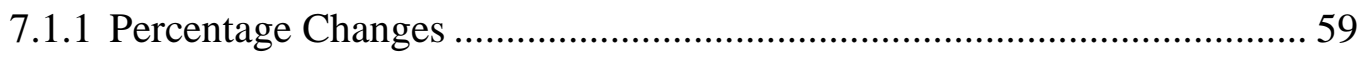

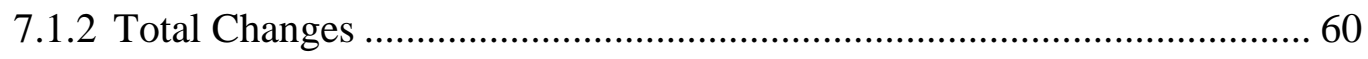

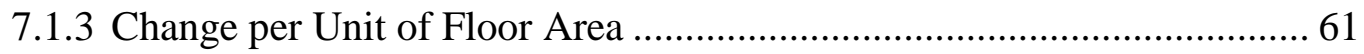

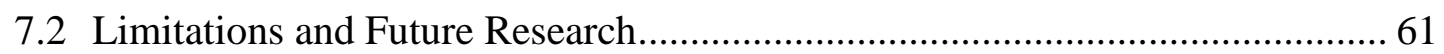

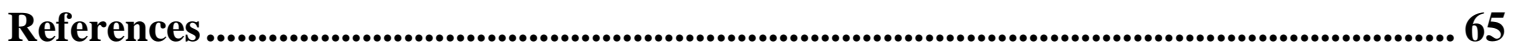

A Building Type, New Construction, and Emissions Rates ............................... 69

B Percentage Changes by State for the Nationwide Adoption of the 2012 IECC 73

C Total Changes from the Nationwide Adoption of the 2012 IECC..................... 75

D Savings per Unit of Floor Area from the Nationwide Adoption of the 2012

IECC.................................................................................................................. 77 


\section{List of Figures}

Figure 2-1 State Residential Energy Codes .............................................................. 10

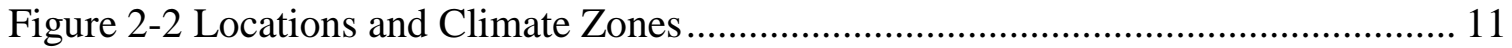

Figure 3-1 Baseline Construction Costs ................................................................. 13

Figure 3-2 Baseline Maintenance, Repair, and Replacement Costs by Year .................. 17

Figure 4-1 Cities and Associated (Colored) County Clusters....................................... 22

Figure 4-2 Data Processing for Weighting Development............................................. 23

Figure 6-1 Average Percentage Reduction in Energy Use, Energy Costs, Life-Cycle

Emissions, and LCC for 1- and 2-Story Homes (10-Year Study Period) ....................... 42

Figure 6-2 Baseline IECC Codes for all U.S. States...................................................... 43

Figure 6-3 Average Percentage Savings by State in (a) Energy Use and (b) Energy Costs

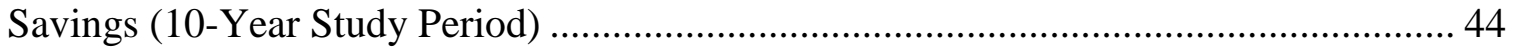

Figure 6-4 Average Percentage Savings in Emissions for all U.S. States (10-Year Study

Period) ......................................................................................................... 45

Figure 6-5 Average Percentage Savings in Life-Cycle Costs for all U.S. States (10-Year

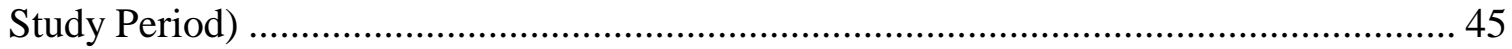

Figure 6-6 Total Average New Residential Floor Area Constructed Annually in Each

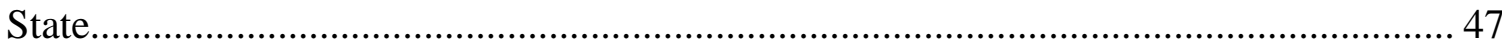

Figure 6-7 Total Savings in Energy Use, Energy Costs, Life-Cycle Carbon Emissions,

and Life-Cycle Costs (10-Year Study Period) .......................................................... 48

Figure 6-8 Energy Savings per Unit of Floor Area by State (10-Year Study Period) ...... 50

Figure 6-9 Energy Cost Savings per Megawatt-Hour Reduced and Weighted Average

Energy Price by State (10-Year Study Period) ....................................................... 51

Figure 6-10 (a) Building America U.S. Climate Regions and (b) the Average Natural Gas

Offset by State (10-Year Study Period).

Figure 6-11 Emissions Savings per MWh Reduced and the Weighted Average Offset of

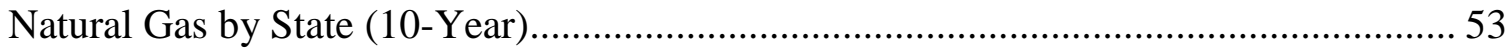

Figure 6-12 Life-Cycle Cost Savings per Unit of Floor Area by State (10-Year)........... 54

Figure A-1 Conditioned Floor Area of New 1-Story Single-Family Housing ................. 69

Figure A-2 Conditioned Floor Area of New 2-Story Single-Family Housing ................ 70 


\section{List of Tables}

Table 2-1 Building Prototype Characteristics ........................................................... 8

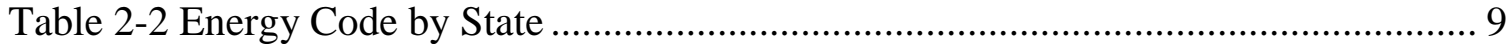

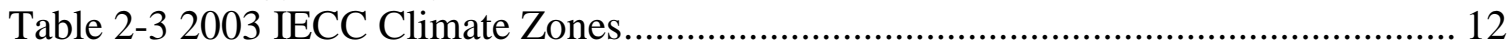

Table 3-1 Energy Efficiency Component Requirements for Alternative Building Designs

Table 3-2 2009 SPV Discount Factors for Future Non-Fuel Costs, 3 \% Real Discount

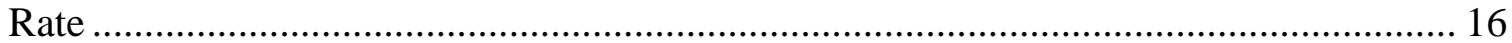

Table 4-1 Percentages of One- and Multi-Story Homes by Census Region.................... 24

Table 4-2 Building Types, Bin Ranges, and Percentage of Each Building Design .......... 24

Table 4-3 Percentage of Each Building Type for One- and Multi-Story Homes (New

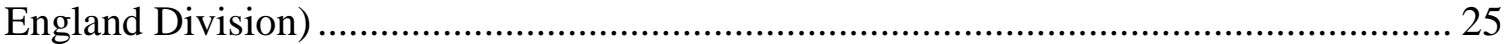

Table 4-4 Percentage of Each Building Type by Census Division ................................ 26

Table 5-1 Greenhouse Gas Global Warming Potentials ............................................... 29

Table 6-1 Nationwide Average Percentage Reduction in Energy Use from Adoption of the 2012 IECC Design by Building Type .................................................................. 34

Table 6-2 Nationwide Average Percentage Reduction in Energy Costs from Adoption of the 2012 IECC Design by Building Type and Study Period Length .............................. 35

Table 6-3 Nationwide Average Percentage Reduction in Life-Cycle Carbon Emissions from Adoption of the 2012 IECC Design by Building Type ........................................ 36 Table 6-4 National Average Percentage Reduction in Life-Cycle Costs from Adoption of the 2012 IECC Design by Building Type and Study Period Length ............................. 37 Table 6-5 Nationwide Average Percentage Reduction in the Four Performance Metrics from Adoption of the 2012 IECC Design by Building Type (10-Year) .......................... 37 Table 6-6 Average Percentage Reduction in Energy Use from Adoption of the 2012 IECC by Climate Zone and Baseline Code for 1- and 2-Story Homes ........................... 39 Table 6-7 Average Percentage Reduction in Energy Costs from Adoption of the 2012 IECC by Climate Zone and Baseline Code for 1- and 2-Story Homes (10-Year Study Period)......

Table 6-8 Average Percentage Reduction in Emissions from Adoption of the 2012 IECC

by Climate Zone and Baseline Code for 1- and 2-Story Homes..................................... 40

Table 6-9 Average Percentage Reduction in Life-Cycle Costs from Adoption of the 2012 IECC by Climate Zone and Baseline Code for 1- and 2-Story Homes (10-Year Study

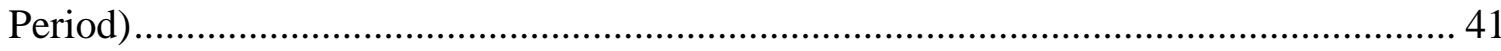

Table 6-10 Total Savings by Census Region from Adoption of the 2012 IECC (10-Year

Study Period)

Table 6-11 Energy Use Reductions per Unit of Newly Constructed Floor Area from Adoption of the 2012 IECC by Census Region (10-Year Study Period) ......................... 54

Table 6-12 Energy Cost Reduction per kWh of Energy Savings from Adoption of the 2012 IECC by Census Region (10-Year)................................................................... 55

Table 6-13 Reduced Carbon Emissions per GWH of Energy Savings from Adoption of the 2012 IECC by Census Region (10-Year Study Period)

Table 6-14 Life-Cycle Cost Savings per Unit of Newly Constructed Floor Area from Adoption of the 2012 IECC by Census Region (10-Year Study Period) ........................ 57

Table A-1 $\mathrm{CO}_{2}, \mathrm{CH}_{4}$, and $\mathrm{N}_{2} \mathrm{O}$ Emissions Rates Electricity Generation by State........... 71 
Table B-1 Total Changes in Fuel Use and the Proportional Changes in Natural Gas Use Relative to 2012 IECC...

Table B-2 Summary of Average Savings in Energy Use, Energy Costs, Carbon Emissions, and Life-Cycle Costs for all U.S. States (10-Year) 74

Table C-1 Total Reductions by State from Adoption of the 2012 IECC (10-Year) ......... 75

Table D-1 Savings in Energy Use per Unit of Floor Area from Adoption of the 2012 IECC (10-Year)

Table D-2 Reduction in Energy Costs per MWh of Reduced Energy Use from Adoption

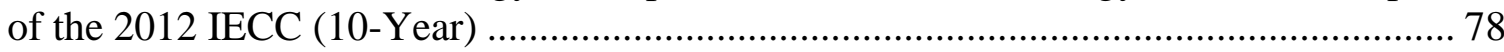
Table D-3 Reduction in Total Carbon Emissions per Unit of Floor Area from Adoption of the 2012 IECC (10-Year). 79 Table D-4 Savings in Life-Cycle Costs per Unit of Floor Area from Adoption of the 2012 IECC (10-Year). 80 


\section{List of Acronyms}

\section{Acronym Definition}

AEO Applied Economics Office

AFUE Annual Fuel Utilization Efficiency

AIRR Adjusted Internal Rate of Return

ASHRAE American Society of Heating, Refrigerating, and Air-Conditioning Engineers

BIRDS Building Industry Reporting and Design for Sustainability

CBECS Commercial Building Energy Consumption Survey

$\mathrm{CH} 4$ Methane

$\mathrm{CO} 2$ Carbon Dioxide

CO2e Carbon Dioxide Equivalent

DOE Department of Energy

EEFG EnergyPlus Example File Generator

eGRID Emissions and Generation Resource Integrated Database

EIA Energy Information Administration

EL Engineering Laboratory

EPA Environmental Protection Agency

FEMP Federal Energy Management Program

FERC Federal Energy Regulatory Commission

HVAC Heating, Ventilating, and Air-Conditioning

I-P Inch-Punds (Customary Units)

IECC International Energy Code Council

ISO International Organization for Standardization

LCA Life-Cycle Assessment

LCC Life-Cycle Cost

LEC Low Energy Case

$\mathrm{MBH}$ thousand Btu per hour

MRR Maintenance, Repair, and Replacement

N2O Nitrous Oxide

NAHB National Association of Home Builders

NERC North American Electric Reliability Corporation

NIST National Institute of Standards and Technology

PNNL Pacific Northwest National Laboratory

ROI Return on Investment

S-I System International (Metric Units)

SEER Seasonal Energy Efficiency Ratio

SHGC Solar Heat Gain Coefficient 
xviii 


\section{Acronym Definition}

SPV Single Present Value

UPV* Uniform Present Value Modified for Fuel Price Escalation 


\section{Executive Summary}

Energy efficiency requirements in energy codes for residential buildings vary across states, and many states have not yet adopted the latest energy efficiency code edition. As of July 2014, states had adopted energy codes ranging across editions of the International Energy Conservation Code (IECC) (2003, 2006, 2009, and 2012). Some states do not have a code requirement for energy efficiency, leaving it up to the locality or jurisdiction to set its own requirements. This study considers the impacts that the adoption of newer, more stringent energy codes for residential buildings would have on building energy use, operational energy costs, building life-cycle costs, and "cradle-to-grave" life-cycle carbon emissions.

The results of this report are based on analysis of the Building Industry Reporting and Design for Sustainability (BIRDS) new residential database, which includes 9120 whole building energy simulations covering 10 building types in 228 cities across all U.S. states for study periods ranging from 1 year to 40 years. The performance of buildings designed to meet current state energy codes is compared to their performance when meeting new editions of IECC design requirements to determine whether more stringent energy code editions are cost-effective in reducing energy consumption and life-cycle carbon emissions.

Assuming a 10-year study period, nationwide adoption of 2012 IECC would lead to significant average percentage reductions in energy consumption $(19.2 \%)$, energy costs $(15.2 \%)$, life-cycle carbon emissions (11.2\%), and life-cycle costs $(1.7 \%)$. The percentage reductions in energy costs are smaller than the percentage reductions in energy consumption because the majority of the reductions are from natural gas, which is cheaper than electricity. The percentage reductions in life-cycle carbon emissions are much lower than the reductions in energy consumption because of two factors. First, the emissions rate is lower for natural gas than for electricity. Since most of the reductions in energy consumption are from natural gas, the emissions reductions are lower. Second, life-cycle carbon emissions include emissions from both the energy consumption of the building and the embodied emissions from the materials used in construction of the building. In order to reduce energy consumption, additional materials must be installed in the building, leading to higher embodied emissions that offset some of the energy-related carbon emissions reductions.

The estimated savings vary by building prototype, baseline code edition of IECC, and climate zone of a building's location. One-story houses realize smaller savings than 2 -story houses with approximately the same conditioned floor area. Two factors could be driving these differences. First, 2-story houses have more volume per unit of floor area, which causes energy use to meet the heating and cooling loads to account for a greater fraction of total energy use. Second, the two-story houses have less window glazing per 
unit of wall area, which could lead to greater savings from changes in requirements for wall insulation. Similar results and interpretations occur for energy costs, life-cycle carbon emissions, and life-cycle costs. On average, locations with older editions of IECC as their baseline code realize slightly greater reductions in energy use, energy costs, and life-cycle carbon emissions. Life-cycle cost savings are greatest for locations with 2003 IECC as the baseline code, on average, followed by 2009 IECC. Although locations with older baseline codes realize greater reductions, on average, this trend does not hold at the climate zone level. In fact, locations with a baseline code of 2003 IECC lead to the greatest reductions in energy use, energy costs, and carbon emissions for only two of eight climate zones. This result may be driven by the change in climate zone definitions from 2003 IECC to 2006 IECC and the resulting changes in building requirements for locations in those climate zones across IECC editions. On average, the percentage reductions in energy use, energy costs, and life-cycle carbon emissions increase as the climate zone gets colder, with a small drop as the climate shifts from primarily cooling to primarily heating loads. Life-cycle cost reductions do not follow the same trend, with Zone 1 realizing greater life-cycle cost reductions than Zone 2, and Zone 6 realizing lower reductions than Zone 5. This deviation may be a result of the differences in the additional investment costs, on average, of meeting the 2012 IECC across climate zones. These same results hold at the state level, with states in colder climates realizing greater reductions in energy use, energy costs, and life-cycle carbon emissions. However, there is some variation in percentage reductions for energy costs and carbon emissions driven by variation in energy prices and electricity-related emissions rates, respectively.

The estimated savings for each of the building types are aggregated using city-level new residential building construction data to calculate the magnitude of the incremental savings that a state may realize if it were to adopt a more energy efficient code edition as its state energy code. The amount of new floor area constructed in a state is the key driver to the magnitude of the estimated reductions in energy use, energy costs, and life-cycle carbon emissions, with Texas and North Carolina realizing the greatest reductions while Alaska and Vermont realize the smallest reductions in energy use, energy costs, life-cycle carbon emissions, and life-cycle costs. These state-level estimates are aggregated to the national level to estimate the potential total impact from nationwide adoption of more stringent energy codes. The impacts aggregated at the national level total $2.4 \mathrm{TWh}$ of energy consumption, $\$ 993$ million in energy costs, 9.3 million metric tons $\mathrm{CO}_{2} \mathrm{e}$ of lifecycle emissions, and \$601 million for one year's worth of construction for a 10-year study period.

After controlling for the amount of newly constructed floor area, the results are similar to the percentage change results. Energy savings per unit of floor area is driven primarily by climate zone. For example, states such as Alaska have the least amount of new construction, but achieve some of the most extensive reductions in energy use per $\mathrm{m}^{2}$ 
$\left(\mathrm{ft}^{2}\right)$. States with greater reductions in total energy use generally realize greater energy cost savings. Other factors such as energy prices and the fuel mix of the total reductions in energy use in a state also impact the magnitude of energy cost savings. Higher energy prices, greater proportions of energy use accounted for by electricity, and smaller shifts in consumption from natural gas to electricity lead to greater reductions in energy costs per unit of floor area. Similarly, higher emissions rates for electricity, greater proportions of energy use accounted for by electricity, and smaller shifts in consumption from natural gas to electricity lead to greater reductions in life-cycle carbon emissions per unit of floor area. Similar to energy use, life-cycle cost savings per unit of floor area are greater for states in colder climate zones.

The analysis in this study is limited in scope and would be strengthened by including sensitivity analysis, expanding the BIRDS database and metrics, and allowing public access to all the results. Environmental assessment could be expanded beyond life-cycle carbon emissions to cover all environmental impact categories. Additional energy efficiency measures, fuel types, discount rates, building constructions (e.g., wall types), and building types (e.g., low-rise apartment building) would also expand the scope of the database. Uncertainty analysis on these factors as well as other factors, such as local energy pricing schedules, jurisdictional code adoptions and enforcement, occupancy and behavior patterns, and financing options, should be considered in future analysis.

Energy, environmental, and economic performance are but three attributes of building performance. The BIRDS model assumes that its building prototypes all meet minimum technical performance requirements. However, there may be significant differences in technical performance not evaluated in BIRDS, such as indoor environmental quality performance, which may affect energy, environmental, and economic considerations.

The extensive BIRDS new residential database can be used to answer many more questions than posed in this report, and will be made available to the public through BIRDS v2.0 that allows others access to the database for their own research on building energy efficiency and sustainability. These improvements are underway, with comprehensive sustainability assessment and more detailed reporting and release of the BIRDS v2.0 software scheduled for September 2015. 
xxiii 


\section{Introduction}

\subsection{Background}

Building stakeholders need practical metrics, data, and tools to support decisions related to sustainable building designs, technologies, standards, and codes. The Engineering Laboratory (EL) of the National Institute of Standards and Technology (NIST) has addressed this high priority national need by extending its metrics and tools for sustainable building products, known as Building for Environmental and Economic Sustainability (BEES), to entire buildings. These entire or "whole" building sustainability metrics have been developed based on innovative extensions to life-cycle assessment (LCA) and life-cycle costing (LCC) approaches involving whole building energy simulations. The measurement system evaluates the sustainability of both the materials and the energy used by a building over time. It assesses the "carbon footprint" of buildings as well as 11 other environmental performance metrics, and integrates economic performance metrics to yield science-based measures of the business case for investment choices in high-performance green buildings.

The approach developed for BEES has now been applied at the whole building level to address building sustainability measurement in a holistic, integrated manner that considers complex interactions among building materials, energy technologies, and systems across dimensions of performance, scale, and time. Building Industry Reporting and Design for Sustainability (BIRDS) applies the new sustainability measurement system to an extensive whole building performance database NIST has compiled for this purpose. The energy, environmental, and cost data in BIRDS measure building operating energy use through detailed energy simulations, building materials use through innovative life-cycle material inventories, and building costs over time. BIRDS v1.0 includes energy, environmental, and cost measurements for 12540 new commercial and non-low-rise residential buildings, covering 11 building prototypes in 228 cities across all U.S. states for 9 study period lengths. See Lippiatt et al. (2013) for additional details.

Similarly, the new residential building database incorporated into BIRDS v2.0 includes energy, environmental, and cost measurements for 9120 new residential buildings, covering 10 single family dwellings ( 51 -story and 52 -story of varying conditioned floor area) in 228 cities across all U.S. states for study period length ranging from 1 year to 40 years. The sustainability performance of buildings designed to meet current state energy codes can be compared to their performance when meeting three alternative building energy code editions to determine the impact of energy efficiency on sustainability performance. The impact of the building location and the investor's time horizon on sustainability performance can also be measured. 


\subsection{Literature Review}

The U.S. Department of Energy (DOE), through DOE-funded national laboratories, is on the forefront of whole building energy simulation development, including reference building prototypes for both new and existing commercial and residential buildings.

To meet statutory requirements, DOE tasks the Pacific Northwest National Laboratory (PNNL) with estimating the energy use and energy cost savings associated with the standard/code building requirements relative to a baseline edition for each new edition of ASHRAE 90.1 for commercial buildings and IECC for residential buildings. PNNL has also begun to incorporate some LCC estimates into their analysis.

Adopting newer editions of ASHRAE 90.1 for new commercial buildings leads to reductions in energy consumption and energy costs. PNNL (2009a) estimates the impacts for each state of adopting ASHRAE 90.1-2007 as the commercial building energy code relative to the state's current energy code, which vary across states. The annual energy use savings and energy cost savings are estimated for three Department of Energy (DOE) benchmark buildings -- a medium-sized office building, a non-refrigerated warehouse, and a mid-rise apartment building--for 97 cities located across the United States. Halverson et al. (2011a) estimates that, on average, adoption of ASHRAE 90.1-2007 reduces site energy by $4.6 \%$ relative to ASHRAE 90.1-2004. Halverson et al. (2011b) estimates an $18.5 \%$ reduction in site energy use, on average, from the adoption of ASHRAE 90.1-2010 relative to ASHRAE 90.1-2007 while Halverson et al. (2014) estimates a $7.6 \%$ reduction from building to meet ASHRAE 90.1-2013 relative to ASHRAE 90.1-2010.

Adopting newer editions of IECC for new residential buildings lead to reductions in energy consumption and energy costs. PNNL (2009b) estimates the impact of adoption of 2009 IECC for residential buildings for each state relative to its current energy code, including a summary of the changes in energy efficiency construction requirements and the estimated energy use and energy cost savings. Lucas et al. (2012) estimates the energy and life-cycle cost savings for adoption of newer editions of the IECC across climates zones for a single-family dwelling and apartment building across different foundation types. Relative to 2006 IECC, the adoption of 2009 IECC and 2012 IECC lead to average reductions in energy costs of $11 \%$ and $32 \%$, respectively. Additionally, all climate zones realize reductions in life-cycle costs with the coldest climate zones realizing the greatest life-cycle cost savings and Zone 1 (maritime climate) realizing greater life-cycle cost savings than zones characterized as having hot-humid, hot-dry, mixed-dry, or mixed-humid climate conditions (Zone 2 through Zone 4). Mendon et al. (2013) estimates the LCC effectiveness of 2009 IECC and 2012 IECC relative to 2006 IECC for 109 U.S. cities. Mendon et al. (2014) is the most recent PNNL analysis, looking 
at the impacts of 2015 IECC, which are found to lead to a minimal reduction $(1.1 \%$ on average) in energy use relative to 2012 IECC.

The National Association of Home Builders (NAHB) Research Center has completed similar analyses as those presented by PNNL. NAHB (2012a) develops a methodology to calculate energy performance in residential buildings, including simulation modeling assumptions for a "standard reference house" based on national average characteristics. NAHB (2012b) and NAHB (2012c) estimate the cost-effectiveness of constructing to meet 2009 IECC and 2012 IECC relative to 2006 IECC, respectively. Constructing to meet 2009 IECC reduces site energy consumption by $10.7 \%$ with an average payback period of 5.6 years. Constructing to meet 2012 IECC reduces site energy consumption by three times that of 2009 IECC (33.9\%), but has a higher average payback period of 10.4 years because the initial additional costs are much higher for building to meet 2012 IECC versus 2009 IECC.

NIST has expanded on the DOE and PNNL research by increasing the number of locations considered in analysis, including life-cycle costing and life-cycle assessment results, and considering a range of study periods. Kneifel (2010) creates a framework to simultaneously analyze the impacts of improving energy efficiency on energy use, energy costs, life-cycle costs, and carbon emissions through an integrated design context for new commercial buildings. The paper compares the savings of constructing 11 prototype commercial buildings to meet the building envelope requirements of ASHRAE 90.1-2007 and a "Low Energy Case," relative to ASHRAE 90.1-2004, for 16 cities in different climate zones across the contiguous United States. The paper finds minimal improvements in energy efficiency from building to meet ASHRAE 90.1-2007 relative to ASHRAE 90.1-2004 while significant savings is found by building to meet the "Low Energy Case." The "Low Energy Case" is often cost-effective on a first cost basis and is always cost-effective over the longer study period lengths.

Kneifel (2011a) expands on the framework and analysis in Kneifel (2010) by analyzing the impact of adopting the building envelope requirements of ASHRAE 90.1-2007 and a "Low Energy Case" relative to ASHRAE 90.1-2004 in terms of energy use, energy costs, energy-related carbon emissions, and life-cycle costs for 228 cities across the U.S. with at least one city in each state. Analysis includes 4 study period lengths $(1,10,25$, and 40 years). The paper finds that, on average, the more energy efficient building designs are cost-effective. However, there is significant variation across states in terms of energy use savings and life-cycle cost-effectiveness driven by both climate and construction costs. There is also significant variation across cities within a state, even cities located within the same climate zone. These variations are a result of differences in local material and labor costs as well as energy costs. 
Kneifel (2013a) analyzes 12540 whole-building energy simulations in the Building Industry Reporting and Design for Sustainability (BIRDS) database covering 11 building types in 228 cities across all U.S. states for 9 study period lengths $(1,5,10,15,20,25$, 30,35 , and 40 years). Current state energy code performance is compared to the performance of alternative ASHRAE 90.1 Standard editions to determine whether more stringent energy standard editions are cost-effective in reducing energy consumption and energy-related carbon emissions. This analysis includes a "Low Energy Case" (LEC) building design based on ASHRAE 189.1-2009, which increases energy efficiency beyond the ASHRAE 90.1-2007 design. Results are analyzed in detail for the ASHRAE 90.1-2007 and LEC designs. Results are aggregated at the state level for seven states (Alaska, Colorado, Florida, Maryland, Oregon, Tennessee, Wisconsin) to estimate the magnitude of total energy use savings, energy cost savings, life-cycle cost savings and energyrelated carbon emissions reductions that could be attained by adoption of a more stringent state energy code for commercial buildings.

Kneifel (2013b), Kneifel (2013c), Kneifel (2013d), and Kneifel (2013e) implement the analysis approach developed in Kneifel (2013a) for an individual state and analyze each state in the Northeast, Midwest, South, and West Census Regions, respectively. The results for each state, both on a percentage and aggregate basis, are compared across the Census Region to determine the driving factors for variation across states in the relative impacts of adopting more stringent state energy codes. The results are aggregated to the Census Region level to estimate the total region-wide impacts.

Kneifel (2013f) analyzes the results developed in Kneifel (2013a, 2013b, 2013c, 2013d, 2013e) from the BIRDS new commercial database, and summarizes the results into the key nationwide trends and important interpretations for energy efficiency in new commercial buildings.

\subsection{Purpose}

The purpose of this study is to use the same methodology as used for the BIRDS new commercial buildings database reports and analyze the results from the BIRDS new residential database, and summarize the results into the key nationwide trends and important interpretations for energy efficiency in new residential buildings. The performance of buildings designed to meet current state energy codes is compared to their performance when meeting newer editions of IECC for residential building requirements to determine whether more stringent energy standard editions are cost-effective in reducing energy consumption and environmental impacts. The estimated savings for each of the building types are aggregated using new residential building construction data to calculate the magnitude of the incremental savings that the nation may realize if its states were to adopt more energy efficient state residential energy codes. 


\subsection{Approach}

This study uses the Building Industry Reporting and Design for Sustainability (BIRDS) new residential database to analyze the benefits and costs of increasing building energy efficiency across the United States. BIRDS is a compilation of whole building energy simulations, building construction cost data, maintenance, repair, and replacement rates and costs, and energy-related carbon emissions data for 10 building prototypes in 228 cities across all U.S. states. The analysis compares energy performance of buildings designed to each state's current energy code for residential buildings to the performance of more energy efficient building designs to determine the energy use savings, energy cost savings, environmental impact reductions, and the associated life-cycle costs resulting from adopting stricter state energy codes.

Results are analyzed both in percentage and total value terms. The percentage savings results allow for direct comparisons across energy standard editions, building types, study period lengths, climate zones, and cities both within each state and across the nation. Results are aggregated to the state and national levels to estimate the magnitude of total energy use savings, energy cost savings, and carbon emissions reductions that could be attained by adoption of more stringent energy codes, and the associated total life-cycle costs.

Results are summarized using both tables and figures. In cases where the material being discussed is of secondary importance, the associated table or figure is placed in the Appendices. The order in which tables and figures appear in the Appendices corresponds to the order in which they are cited in the text. 


\section{Study Design}

The operating energy component of the BIRDS new residential database was built following the framework developed in Kneifel (2010) and further expanded in Kneifel (2013a) and Kneifel (2013b). The BIRDS new residential database includes the results of 9120 whole building energy simulations covering 4 energy efficiency designs for 10 single-family dwellings, 228 cities across the United States, and 40 study period lengths.

\subsection{Building Types}

The building characteristics in Table 2-1 describe the 10 building types included in the BIRDS new residential database, which include 5 1-story and 5 2-story single-family detached homes of varying conditioned floor area to represent the distribution of new home construction in the United States.

The prototype buildings range in size from $111.9 \mathrm{~m}^{2}\left(1205 \mathrm{ft}^{2}\right)$ to $420.2 \mathrm{~m}^{2}\left(4523 \mathrm{ft}^{2}\right)$. The house dimension ratios are the same at approximately $2.56: 1$ and 1.60:1 for the 1 -story and 2-story prototypes, respectively. These alternative building sizes are based on the U.S. Census' Survey of Construction (SOC) database (U.S. Census Bureau 2013). Figure A-1 and Figure A-2 in Appendix A show the percentile breakdown of the size of new single-family detached houses for 1-story and 2-story houses, respectively, both in frequency (left y-axis) and cumulative distribution (right y-axis). ${ }^{1}$ The building sizes selected for the residential prototype sizes attempt to represent the $10^{\text {th }}, 30^{\text {th }}, 50^{\text {th }}, 70^{\text {th }}$, and $90^{\text {th }}$ percentiles for each distribution.

All building prototypes are assumed to have wood-framing, 3 bedrooms, $2.4 \mathrm{~m}(8 \mathrm{ft})$ high

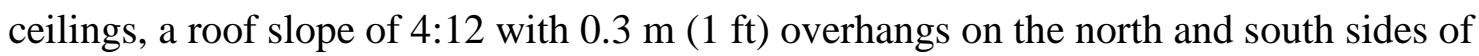
the building, and no garage. The fraction of wall area covered by fenestration ranges from $15 \%$ to $24 \%$.

\footnotetext{
${ }^{1}$ Homes with less than $700 \mathrm{ft}^{2}$ are assumed to have $700 \mathrm{ft}^{2}$.
} 
Table 2-1 Building Prototype Characteristics

\begin{tabular}{|c|c|c|c|}
\hline Floors & $\begin{array}{l}\text { Conditioned Floor Area } \\
\mathbf{m}^{2}\left(\mathbf{f t}^{2}\right)\end{array}$ & $\begin{array}{l}\text { Dimensions } \\
\text { m (ft) }\end{array}$ & Fenestration \\
\hline 1 & $111.9(1205)$ & $\begin{array}{l}6.61 \times 16.89 \\
(21.67 \times 55.42)\end{array}$ & $15 \%$ \\
\hline 1 & $148.6(1600)$ & $\begin{array}{l}7.62 \times 19.51 \\
(25.0 \times 64.0)\end{array}$ & $17 \%$ \\
\hline 1 & $176.6(1901)$ & $\begin{array}{l}8.31 \times 21.26 \\
(27.25 \times 69.75)\end{array}$ & $18 \%$ \\
\hline 1 & $215.8(2323)$ & $\begin{array}{l}9.17 \times 23.53 \\
(30.1 \times 77.21)\end{array}$ & $20 \%$ \\
\hline 1 & $292.8(3152)$ & $\begin{array}{l}10.67 \times 27.43 \\
(35.0 \times 90.0)\end{array}$ & $24 \%$ \\
\hline 2 & $148.8(1602)$ & $\begin{array}{l}6.8 \times 10.9 \\
(22.37 \times 35.8)\end{array}$ & $13 \%$ \\
\hline 2 & $204.9(2205)$ & $\begin{array}{l}8.00 \times 12.80 \\
(26.25 \times 42.0)\end{array}$ & $15 \%$ \\
\hline 2 & $251.2(2704)$ & $\begin{array}{l}8.86 \times 14.17 \\
(29.07 \times 46.5)\end{array}$ & $17 \%$ \\
\hline 2 & $311.0(3348)$ & $\begin{array}{l}9.85 \times 15.78 \\
(32.33 \times 51.78)\end{array}$ & $19 \%$ \\
\hline 2 & $420.2(4523)$ & $\begin{array}{l}11.49 \times 18.29 \\
(37.7 \times 60.0)\end{array}$ & $22 \%$ \\
\hline
\end{tabular}

\subsection{Building Designs}

Current state energy codes are based on different editions of the International Energy Conservation Code (IECC), which have requirements that vary based on a building's characteristics and the climate zone of the location. For the BIRDS new residential database, the $I E C C$-equivalent design is used to meet current state energy codes and to define the alternative building designs. Table 2-2 shows that residential building energy codes as of November 2014 vary by state. It is important to consider that local jurisdictions have adopted energy standard editions that are more stringent than the state energy codes. ${ }^{2}$

\footnotetext{
${ }^{2}$ Local and jurisdictional requirements can be obtained from the Database of State Incentives for Renewables and Efficiency (DSIRE) (NC Clean Energy Technology Center 2015).
} 
Table 2-2 Energy Code by State as of November 2014

\begin{tabular}{|c|c|c|c|c|c|}
\hline Location & Energy Code & Location & Energy Code & Location & Energy Code \\
\hline $\mathrm{AK}$ & None & LA & 2006 & $\mathrm{OH}$ & 2009 \\
\hline AL & 2009 & MA & 2012 & OK & 2006 \\
\hline AR & 2003 & MD & 2012 & OR & 2009 \\
\hline $\mathrm{AZ}$ & None & $\mathrm{ME}$ & None & PA & 2009 \\
\hline $\mathrm{CA}$ & 2012 & MI & 2009 & RI & 2012 \\
\hline $\mathrm{CO}$ & 2003 & $\mathrm{MN}$ & 2006 & SC & 2009 \\
\hline $\mathrm{CT}$ & 2009 & MO & None & SD & None \\
\hline $\mathrm{DE}$ & 2012 & MS & None & $\mathrm{TN}$ & 2006 \\
\hline FL & 2009 & MT & 2009 & $\mathrm{TX}$ & 2009 \\
\hline GA & 2009 & $\mathrm{NC}$ & 2009 & UT & 2009 \\
\hline HI & 2006 & ND & 2009 & VA & 2012 \\
\hline IA & 2012 & $\mathrm{NE}$ & 2009 & VT & 2009 \\
\hline ID & 2009 & $\mathrm{NH}$ & 2009 & WA & 2012 \\
\hline IL & 2012 & NJ & 2009 & WI & 2006 \\
\hline IN & 2009 & NM & 2009 & WV & 2009 \\
\hline KS & None & NV & 2009 & WY & None \\
\hline KY & 2009 & NY & 2009 & & \\
\hline
\end{tabular}

State energy codes vary from no state code to 2003 IECC to 2012 IECC with some regional trends shown in Figure 2-1. The states in the central U.S. tend to wait longer to adopt newer IECC editions. However, there are many cases in which energy codes of neighboring states vary drastically. For example, Missouri has no state energy code while of the 8 surrounding states, 1 has no state energy code, 1 has adopted 2003 IECC, 2 have adopted 2006 IECC, 2 have adopted 2009 IECC, and 2 have adopted 2012 IECC. 


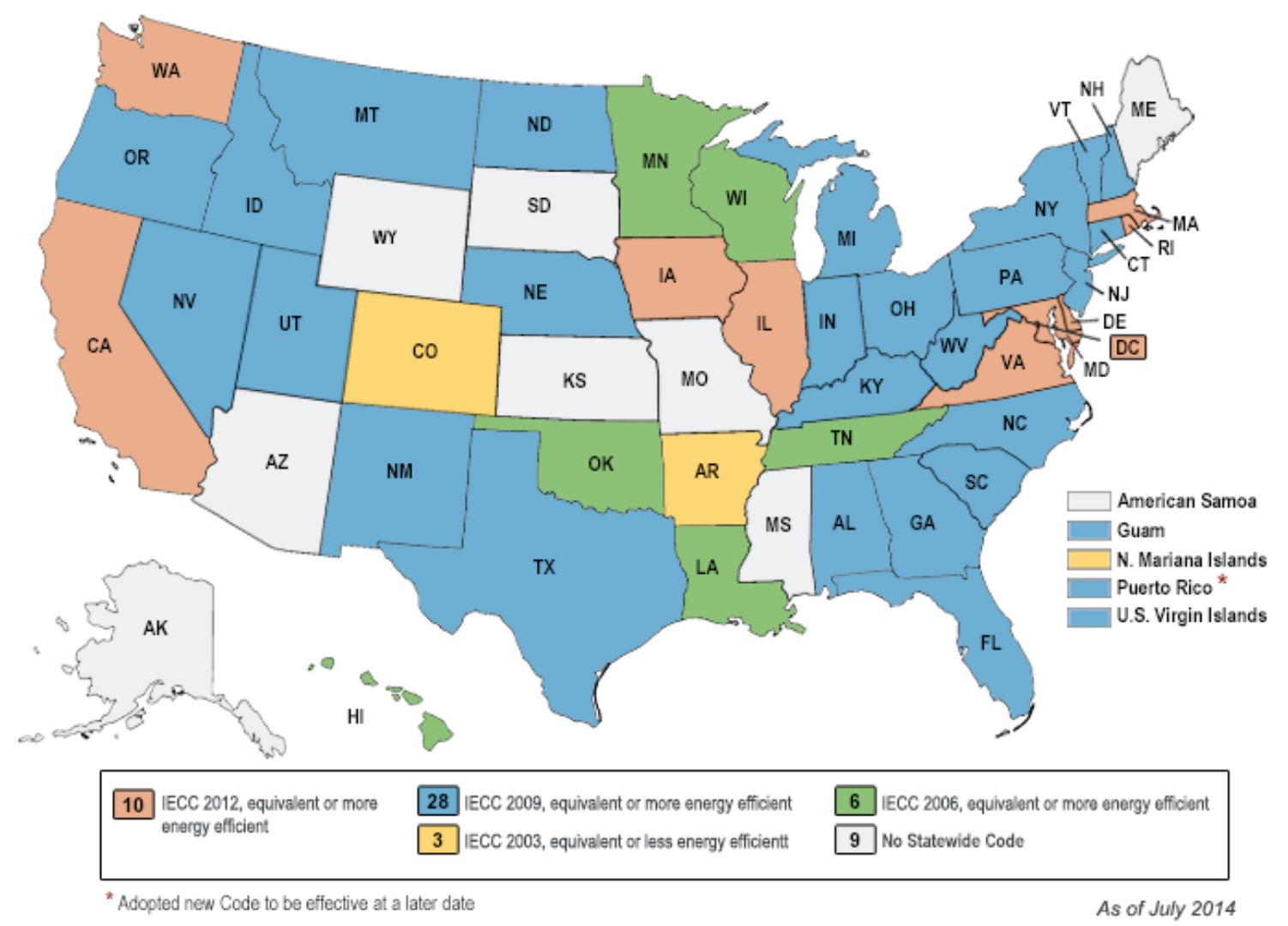

Figure 2-1 State Residential Energy Codes ${ }^{3}$

The prototype buildings are designed to meet the requirements for each of the editions of IECC (2003, 2006, 2009, and 2012) in the 228 cities, which are shown in Figure 2-2 along with current climate zones used in defining IECC building requirements. These cities are selected for three reasons. First, the cities are spread out to represent the entire United States, and represent as many climate zones in each state as possible. Second, the locations cover all the major population centers in the country. Third, multiple locations for a climate zone within a state are included to allow building costs to vary for each building design.

\footnotetext{
${ }^{3}$ Figure was obtained from the Department of Energy (DOE) (2014) in November 2014.
} 

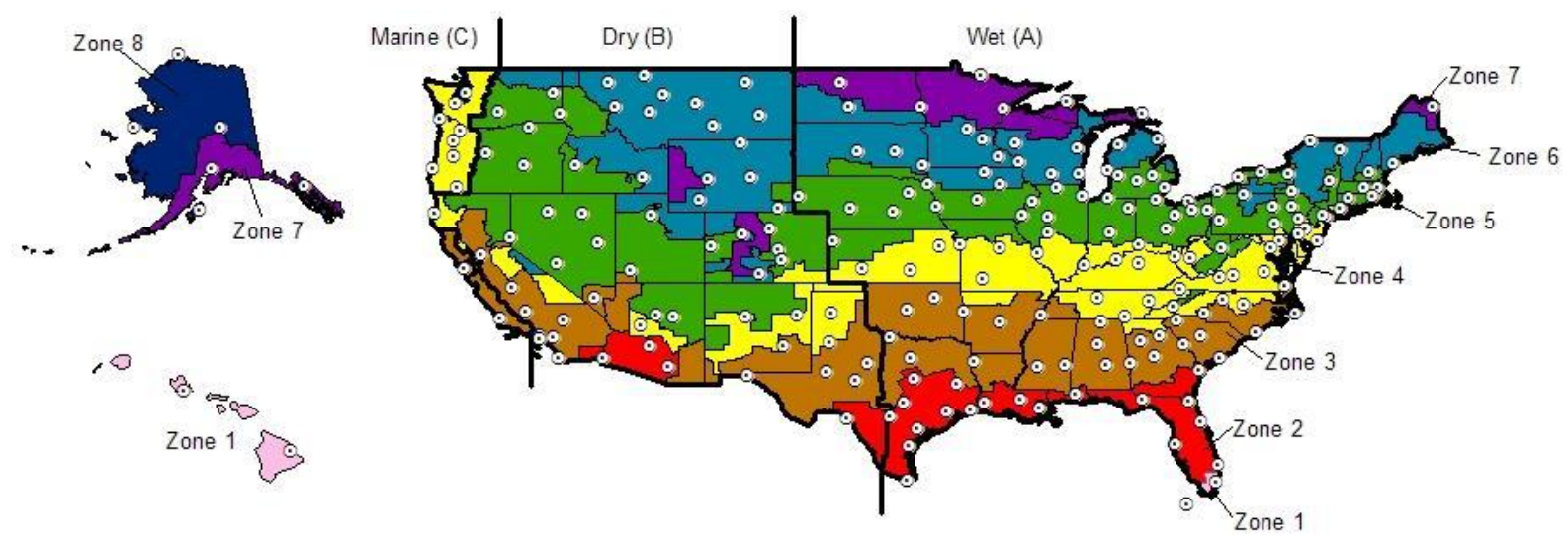

Figure 2-2 Locations and Climate Zones

The climate zones implemented in the IECC were consolidated from the 17 climate zones shown in Table 2-3 for 2003 IECC into 8 climate zones in 2006 IECC. The consolidation is more complex than simply grouping the older climate zones together. The zones in Table 2-3 are based solely on a city's heating degree days at a base of $18^{\circ} \mathrm{C}\left(65^{\circ} \mathrm{F}\right)$ (HDD65) while the zones in Figure 2-2 are based on the combination of a county's heating degree days and cooling degree days at a base of $10^{\circ} \mathrm{C}\left(50^{\circ} \mathrm{F}\right)(\mathrm{CDD} 50)$. The change in the approach results in some cities located in the same climate zone in 2003 IECC being located in a different climate zone in 2006 IECC. The new climate zones are further separated into subzones, "wet," "dry," and "marine," as shown in Figure 2-2, for a total of 16 subzones. 
Table 2-3 2003 IECC Climate Zones

\begin{tabular}{|c|c|}
\hline $\begin{array}{c}\text { Climate Zone } \\
\text { Zone }\end{array}$ & HDD65 \\
\hline 1 & 0 to 499 \\
\hline 2 & 500 to 999 \\
\hline 3 & 1000 to 1499 \\
\hline 4 & 1500 to 1999 \\
\hline 5 & 2000 to 2499 \\
\hline 6 & 2500 to 2999 \\
\hline 7 & 3000 to 3499 \\
\hline 8 & 3500 to 3999 \\
\hline 9 & 4000 to 4499 \\
\hline 10 & 4500 to 4999 \\
\hline 11 & 5000 to 5499 \\
\hline 12 & 5500 to 5999 \\
\hline 13 & 6000 to 6499 \\
\hline 14 & 6500 to 6999 \\
\hline 15 & 7000 to 8499 \\
\hline 16 & 8500 to 8999 \\
\hline 17 & 9000 to 12999 \\
\hline HDD65 $=$ Annual Heating Degree Days base $18^{\circ} \mathrm{C}\left(65^{\circ} \mathrm{F}\right)^{4}$ \\
\hline
\end{tabular}

\subsection{Study Period Lengths}

Forty study period lengths are chosen to represent the wide cross section of potential investment time horizons. A 1-year study period is representative of a developer that intends to sell a property soon after it is constructed. A 5-year to 15-year study period best represents a building owner's time horizon because few owners are concerned about costs realized beyond a decade into the future. The 20 -year to 40 -year study periods better represent institutions, such as colleges, government agencies, or long-term homeowners, because these entities will own buildings for 20 or more years. BIRDS sets the maximum study period at 40 years for consistency with requirements for federal building life-cycle cost analysis defined in the Energy Independence and Security Act of 2007. Beyond 40 years, technological obsolescence becomes an issue, data become too uncertain, and the farther in the future, the less important the costs.

\footnotetext{
${ }^{4}$ A Heating Degree Day of "HDD" is the number of degrees the average temperature is below some specified baseline each day. Generally, the assumed baseline temperature is an indoor temperature of 18 ${ }^{\circ} \mathrm{C}\left(65^{\circ} \mathrm{F}\right)$
} 


\section{Cost Data}

Building construction costs are obtained from two sources: RSMeans (2011) and Faithful + Gould (2012). The baseline costs of each prototypical building is estimated based on the average cost per unit of floor area for "average" construction quality in RSMeans (2011) for 1-story and 2-story single-family dwellings, which is a function of total floor area. Costs are grouped into two categories: first costs that include initial building construction costs and future costs that include operational costs, maintenance, repair, and replacement costs, and building residual value. Both of these cost categories are described below.

\subsection{First Costs}

Figure 3-1 shows that the average cost per unit of floor area decreases as the total floor area increases for both 1- and 2-story single-family dwellings. A power curve is fit to the available data points (base index of the cost per unit of floor area for the 1-story, $148.6 \mathrm{~m}^{2}\left(1000 \mathrm{ft}^{2}\right)$ house $) .^{5}$

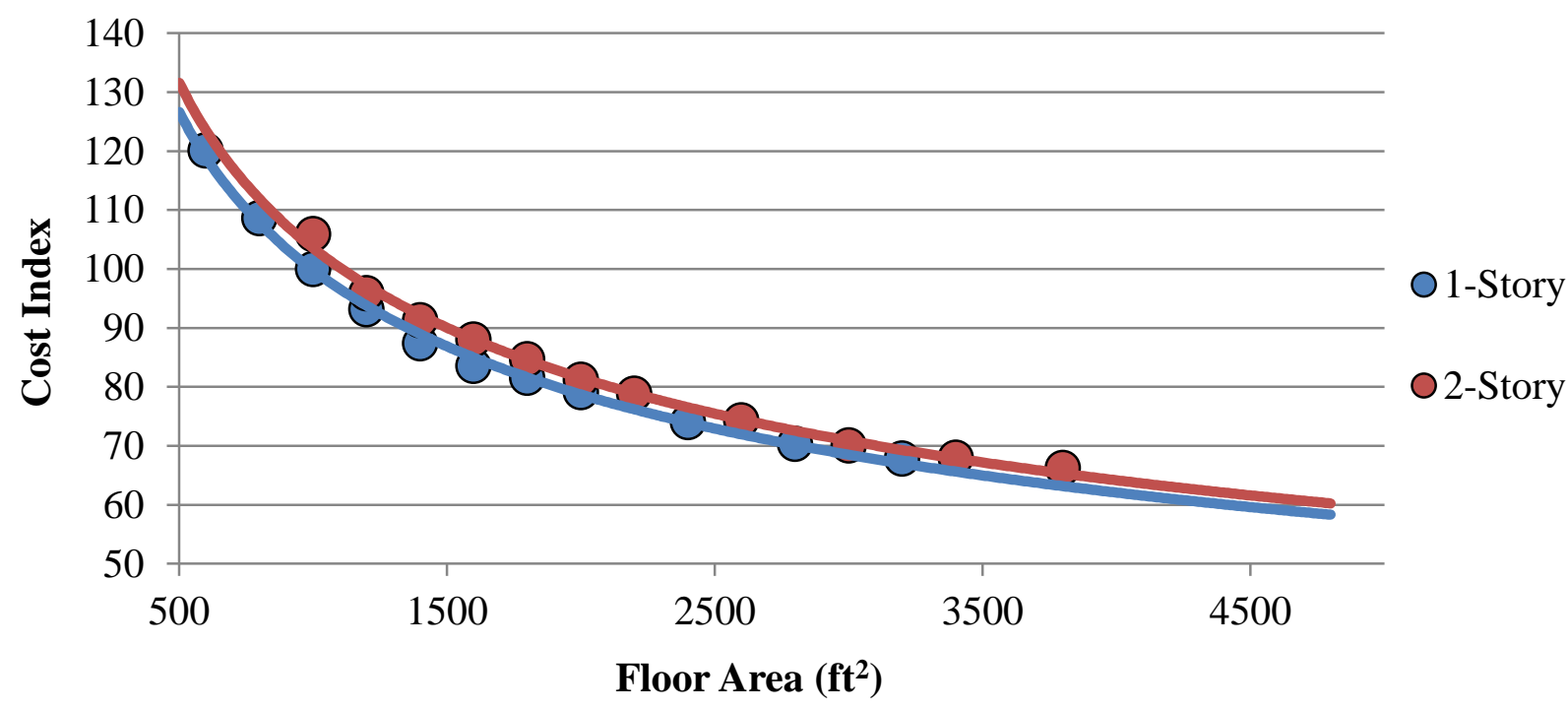

Figure 3-1 Baseline Construction Costs ${ }^{6}$

Incremental cost data from Faithful + Gould (2012) for each required energy efficiency measure are added to the baseline costs used to estimate the total first costs of a building that is compliant with each of the four energy efficiency design alternatives: 2003 IECC, 2006 IECC, 2009 IECC, and 2012 IECC. Six components -- roof insulation, wall insulation, foundation insulation, air sealant, windows, and lighting -- are changed to make the prototypical designs compliant with 2003, 2006, 2009, and 2012 IECC. A

\footnotetext{
${ }^{5}$ Indexed to protect proprietary RSMeans data.

${ }^{6} 1 \mathrm{~m}^{2}=10.764 \mathrm{ft}^{2}$
} 
summary of the requirement ranges (varying climate zone) for each building design are shown in Table 3-1.

The cost data for windows is based on the cost per unit of area for "average casement window across sizes" in the $\mathrm{F}+\mathrm{G}$ database (Faithful+Gould 2012). The lowest cost window that meets the maximum window characteristics (U-factor and solar heat gain coefficient (SHGC)) required by the building design is selected.

There are three different insulation values required for the BIRDS new residential prototypes: wall, ceiling, and foundation. The foundation insulation requirements include two values, the R-value of the insulation and the depth of the insulation. Based on these two values, a cost per linear unit is estimated and multiplied by the total perimeter of the prototype. The cost of ceiling insulation is estimated based on the cost per unit of area for a given R-value multiplied by the area of the top story ceiling. The wall insulation requirements are met using wall cavity insulation or a combination of wall cavity insulation and rigid exterior insulation. Costs per unit of floor area for installed insulation are treated as additive, and are multiplied by the net exterior wall area (gross wall area minus window area) to estimate the total installed cost of the insulation.

Infiltration rates allowed are maximum requirements based on blower door test. The fraction of hard-wired lighting that is high efficiency is adjusted to meet each edition's requirements.

The capacity of the HVAC equipment varies based on the thermal load for a given building prototype, with all equipment meeting minimum federal requirements (SEER 13 for AC unit and $80 \%$ Annual Fuel Utilization Efficiency (AFUE) for gas furnace). Installed costs for $\mathrm{AC}$ units $(2.0,2.5,3.0,4.0$, or 5.0 ton) and furnaces (40 MBH to 50 $\mathrm{MBH}, 60 \mathrm{MBH}$ to $64 \mathrm{MBH}, 78 \mathrm{MBH}$ to $80 \mathrm{MBH}$, and $96 \mathrm{MBH}$ to $100 \mathrm{MBH})$ are selected based on the closest match to the "autosized" system in the $E+$ simulation. ${ }^{7}$

\footnotetext{
${ }^{7} \mathrm{MBH}$ is thousands of BTUs per hour.
} 
Table 3-1 Energy Efficiency Component Requirements for Alternative Building Designs

\begin{tabular}{|c|c|c|c|c|c|c|}
\hline $\begin{array}{l}\text { Design } \\
\text { Comp. }\end{array}$ & Parameter & Units & 2003 IECC & 2006 IECC & 2009 IECC & 2012 IECC \\
\hline $\begin{array}{l}\text { Ceiling } \\
\text { Insulation }\end{array}$ & R-Value & $\begin{array}{l}\mathrm{m}^{2} \cdot \mathrm{K} / \mathrm{W} \\
\left(\mathrm{ft}^{2} \cdot{ }^{\circ} \mathrm{F} \cdot \mathrm{h} / \mathrm{Btu}\right)\end{array}$ & $\begin{array}{c}2.3 \text { to } 8.6 \\
\text { (13.0 to } 49.0)\end{array}$ & $\begin{array}{c}5.3 \text { to } 8.6 \\
\text { (30.0 to } 49.0 \text { ) }\end{array}$ & $\begin{array}{c}5.3 \text { to } 8.6 \\
\text { (30.0 to } 49.0 \text { ) }\end{array}$ & $\begin{array}{c}5.3 \text { to } 8.6 \\
\text { (30.0 to } 49.0 \text { ) }\end{array}$ \\
\hline $\begin{array}{l}\text { Wall } \\
\text { Insulation }\end{array}$ & R-Value & $\begin{array}{l}\mathrm{m}^{2} \cdot \mathrm{K} / \mathrm{W} \\
\left(\mathrm{ft}^{2} \cdot{ }^{\circ} \mathrm{F} \cdot \mathrm{h} / \mathrm{Btu}\right)\end{array}$ & $\begin{array}{c}1.9 \text { to } 3.7 \\
\text { (11.0 to } 21.0)\end{array}$ & $\begin{array}{c}2.3 \text { to } 3.7 \\
(13.0 \text { to } 21.0)\end{array}$ & $\begin{array}{c}2.3 \text { to } 3.7 \\
(13.0 \text { to } 21.0)\end{array}$ & $\begin{array}{l}2.3 \text { to } 3.5+0.9 / 3.7+1.8 \\
(13.0 \text { to } 20+5 / 13+10)\end{array}$ \\
\hline \multirow[t]{2}{*}{$\begin{array}{l}\text { Foundation } \\
\text { Insulation }\end{array}$} & R-value & $\begin{array}{l}\mathrm{m}^{2} \cdot \mathrm{K} / \mathrm{W} \\
\left(\mathrm{ft}^{2 \cdot}{ }^{\circ} \mathrm{F} \cdot \mathrm{h} / \mathrm{Btu}\right)\end{array}$ & $\begin{array}{c}0.0 \text { to } 3.2 \\
(0 \text { to } 18.0)\end{array}$ & $\begin{array}{c}0 \text { to } 1.7 \\
\text { (0 to } 10.0)\end{array}$ & $\begin{array}{c}0 \text { to } 1.7 \\
(0 \text { to } 10.0)\end{array}$ & $\begin{array}{c}0 \text { to } 1.7 \\
(0 \text { to } 10.0)\end{array}$ \\
\hline & Depth & $\mathrm{m}(\mathrm{ft})$ & $\begin{array}{c}0 \text { to } 1.2 \\
(0 \text { to } 4.0)\end{array}$ & $\begin{array}{c}0 \text { to } 1.2 \\
(0 \text { to } 4.0)\end{array}$ & $\begin{array}{c}0 \text { to } 1.2 \\
(0 \text { to } 4.0)\end{array}$ & $\begin{array}{c}0 \text { to } 1.2 \\
(0 \text { to } 4.0)\end{array}$ \\
\hline Infiltration & $\begin{array}{l}\text { Air Changes } \\
\text { Per Hour }\end{array}$ & ACH50 & NR & 7.0 & 7.0 & 3.0 to 5.0 \\
\hline \multirow[t]{2}{*}{ Windows } & U-Factor & $\begin{array}{l}\mathrm{W} /\left(\mathrm{m}^{2} \cdot \mathrm{K}\right) \\
\left(\mathrm{Btu} /\left(\mathrm{h} \cdot \mathrm{ft}^{2} \cdot{ }^{\circ} \mathrm{F}\right)\right.\end{array}$ & $\begin{array}{c}1.99 \text { to } \mathrm{NR} \\
\text { (0.35 to NR) }\end{array}$ & $\begin{array}{l}1.99 \text { to } 6.81 \\
(0.35 \text { to } 1.2)\end{array}$ & $\begin{array}{l}1.99 \text { to } 6.81 \\
(0.35 \text { to } 1.2)\end{array}$ & $\begin{array}{c}1.82 \text { to } \mathrm{NR} \\
(0.32 \text { to } \mathrm{NR})\end{array}$ \\
\hline & SHGC & Fraction & NR & 0.30 to $\mathrm{NR} \dagger$ & 0.30 to $\mathrm{NR} \dagger$ & 0.25 to $\mathrm{NR}$ \\
\hline Lighting & $\begin{array}{l}\text { Fraction } \\
\text { High } \\
\text { Efficiency }\end{array}$ & Fraction & NR & NR & $50 \%$ & $75 \%$ \\
\hline
\end{tabular}

\subsection{Future Costs}

Future costs of a building include maintenance, repair, and replacement (MRR) costs as well as operational energy-related costs from electricity and natural gas consumption. Each of these is discussed below.

Building MRR costs are discounted to equivalent present values using the Single Present Value (SPV) factors for future non-fuel costs reported in Rushing, Kneifel, and Lippiatt (2011). These factors are calculated using the DOE Federal Energy Management Program (FEMP) 2011 real discount rate for federal energy conservation projects (3\%). Table 3-2 reports the SPV factors used to develop the BIRDS new residential database. The MRR costs for each year $\left(C_{M R R, i}\right)$ are multiplied by the SPV for that year and then summed and indexed to determine the total present value MRR costs $\left(C_{M R R}\right)$. 
Table 3-2 2009 SPV Discount Factors for Future Non-Fuel Costs, 3 \% Real Discount Rate

\begin{tabular}{ll} 
Yrs & SPV Factor \\
\hline 1 & 0.971 \\
\hline 2 & 0.943 \\
\hline 3 & 0.915 \\
\hline 4 & 0.888 \\
\hline 5 & 0.863 \\
\hline 6 & 0.837 \\
\hline 7 & 0.813 \\
\hline 8 & 0.789 \\
\hline 9 & 0.766 \\
\hline 10 & 0.744 \\
\hline
\end{tabular}

\begin{tabular}{ll} 
Yrs & SPV Factor \\
\hline 11 & 0.722 \\
\hline 12 & 0.701 \\
\hline 13 & 0.681 \\
\hline 14 & 0.661 \\
\hline 15 & 0.642 \\
\hline 16 & 0.623 \\
\hline 17 & 0.605 \\
\hline 18 & 0.587 \\
\hline 19 & 0.570 \\
\hline 20 & 0.554 \\
\hline
\end{tabular}

\begin{tabular}{lllll} 
Yrs & SPV Factor & & Yrs & SPV Factor \\
\hline 21 & 0.538 & 31 & 0.400 \\
\hline 22 & 0.522 & 32 & 0.388 \\
\hline 23 & 0.507 & 33 & 0.377 \\
\hline 24 & 0.492 & & 34 & 0.366 \\
\hline 25 & 0.478 & 35 & 0.355 \\
\hline 26 & 0.464 & 36 & 0.345 \\
\hline 27 & 0.450 & 37 & 0.335 \\
\hline 28 & 0.437 & 38 & 0.325 \\
\hline 29 & 0.424 & 39 & 0.316 \\
\hline 30 & 0.412 & 40 & 0.307 \\
\hline
\end{tabular}

The electricity and natural gas use predicted by the building's energy simulation is used as the annual energy use of the building for each year of the selected study period. Electricity and natural gas prices are assumed to change over time according to U.S. Energy Information Administration forecasts from 2011 to 2041. These forecasts are embodied in the FEMP Modified Uniform Present Value Discount Factors for energy price estimates (UPV*) reported in Rushing, Kneifel, and Lippiatt (Rushing, Kneifel et al. 2011). ${ }^{8}$ Multiplying the annual electricity costs and natural gas costs by the associated $\mathrm{UPV}^{*}$ value for the study period of interest estimates the present value total electricity costs $\left(C_{\text {Elect }}\right)$ and natural gas costs $\left(C_{\text {Gas }}\right)$. The discount factors vary by Census region, end use, and fuel type.

Total present value future costs $\left(C_{\text {Future }}\right)$ is the sum of present value location-indexed MRR costs and present value energy costs, as shown in the following equation:

$$
C_{\text {Future }}=C_{M R R}+C_{\text {Elect }}+C_{\text {Gas }}
$$

Residential building component and building lifetimes are based on three data sources: NAHB (2007) for building components excluding lighting, U.S. EPA (2012) for light bulbs, and U.S. Census (2011) for building lifetime. A residential building's service lifetime is assumed constant across climate zones at 100 years because, when well maintained, a building can remain in use for up to or beyond 100 years. This assumption is supported by the data in Table C-010AH of the 2011 AHS (Annual Housing Survey), which shows that about half of all owner-occupied housing units are 40 years of age or older and $6 \%$ are 96 years of age or older (U.S. Census Bureau 2011). Additionally, NAHB (2007) estimates the lifetime of a number of house components (e.g., foundations, chimneys) to be greater than 100 years, which implies that the house structure lasts over 100 years. Insulation and air sealants are assumed to have a lifespan greater than 40 years

\footnotetext{
${ }^{8}$ Since the U.S. Energy Information Administration forecasts end at year 30, the escalation rates for years 31-40 are assumed to be the same as for year 30 .
} 
and have no maintenance or repair requirements. Windows have an assumed lifespan of 20 years with costs that vary depending on the required window specifications. Windows are assumed to have no maintenance costs or repair costs. The heating and air conditioning units have assumed lifespans of 15 years while the water heater is assumed to have a lifespan of 10 years. Incandescent and compact fluorescent light (CFL) bulbs are assumed to have lifespans of 1 year and 7 years, respectively (U.S. EPA 2012).

MRR cost data are collected from two sources: U.S. Census Bureau (2011) and Faithful + Gould (2011). The total maintenance and repair costs per square foot of conditioned floor area represent the baseline (non-energy related) MRR costs per unit of floor area, which occur for a building type regardless of the energy efficiency measures incorporated into the design. These data are collected from Table C-12-OO and Table C15-OO in U.S. Census Bureau (2011), which reports median floor area and average maintenance and repair costs per unit of floor area for "Total Owner-Occupied Units" Housing Units and "New Construction the Past 4 Years" Housing Units, respectively. These two data points are used to interpolate and extrapolate for all years considered (1 through 40) as shown in Figure 3-2. These costs are assumed to include all maintenance and repair costs associated with a single-family dwelling.

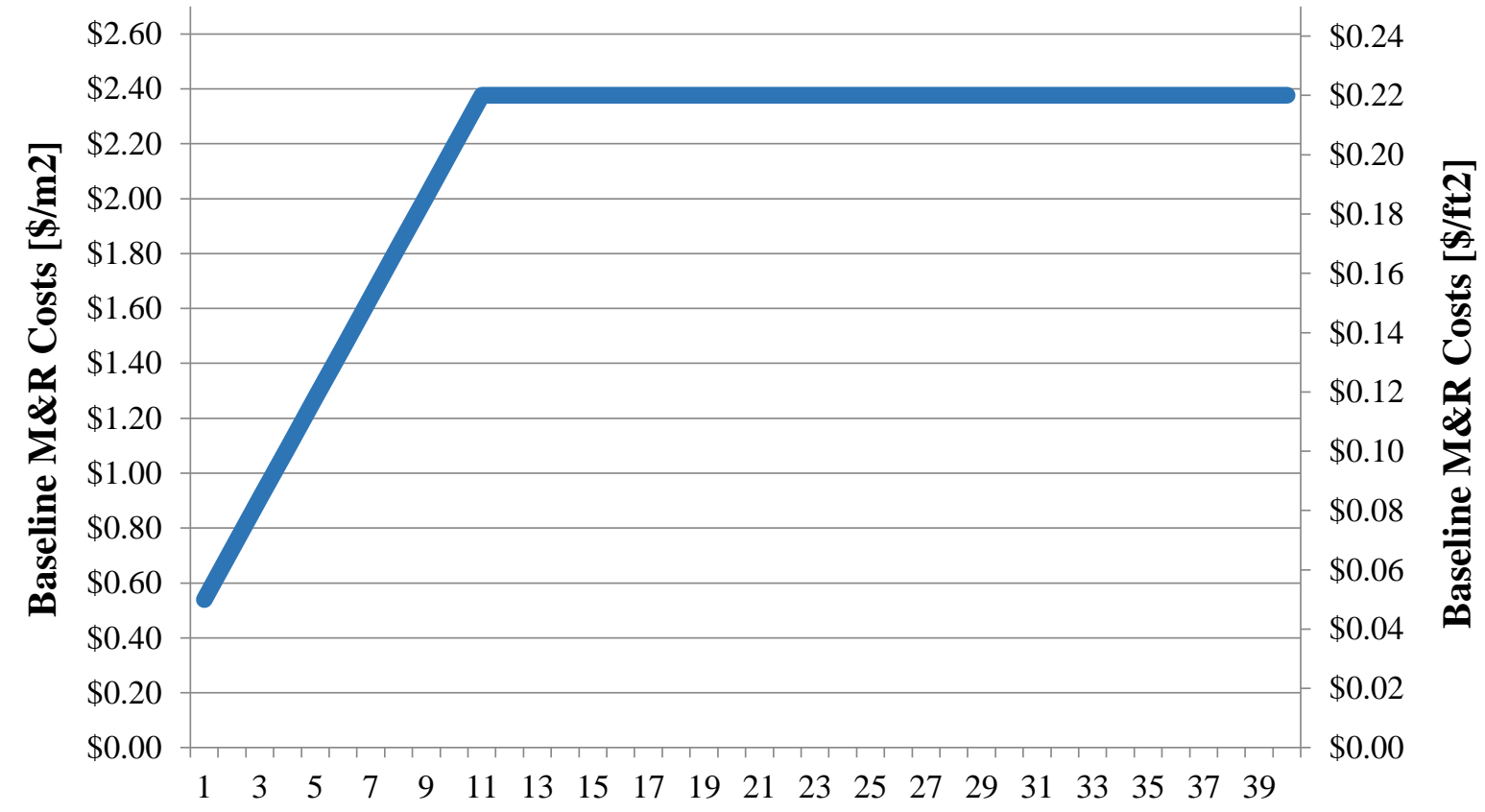

Year

Figure 3-2 Baseline Maintenance, Repair, and Replacement Costs by Year

Faithful and Gould (2011) is the source of replacement costs for the individual components for which costs change across alternative building designs, which in this 
analysis are the HVAC system, lighting, and windows. The replacement cost of windows is assumed to be equal to the initial installation costs of the same window. The cost of replacing CFL light bulbs is greater than the cost of replacing incandescent light bulbs. However, CFLs last 7 times longer than incandescents, which may lead to the total replacement costs of light bulbs over the study period to be lower for the more efficient CFLs. The HVAC system capacity size varies based on the thermal performance of the building design, which results in varying replacement costs because smaller capacity systems are relatively cheaper.

Future MRR costs are discounted to equivalent present values using the Single Present Value (SPV) factors for future non-fuel costs reported in Rushing, Kneifel, and Lippiatt (2011), which are calculated using the U.S. Department of Energy's 2011 real discount rate for energy conservation projects $(3 \%)$.

Annual energy costs are estimated by multiplying annual electricity and natural gas use predicted by the building's energy simulation by the average state retail residential electricity and natural gas prices, respectively. Average state residential electricity and natural gas prices for 2011 are collected from the Energy Information Administration (EIA) Electric Power Annual State Data Tables (U.S. Energy Information Administration (EIA) 2013a) and Natural Gas Navigator (U.S. Energy Information Administration (EIA) $2013 b)$, respectively.

A building's residual value is its value remaining at the end of the study period. In lifecycle costing it is treated as a negative cost item. In BIRDS, it is estimated in four parts, for the building (excluding HVAC, windows, and lighting), HVAC system, windows, and lighting, based on the approach defined in Fuller and Petersen (1996). The building's residual value is calculated as the building's location-indexed first cost multiplied by one minus the ratio of the study period to the service life of the building, discounted from the end of the study period. For example, if a building has first costs (excluding HVAC, windows, and lighting) of $\$ 500000$, a 10 year service life, and the study period length is 100 years, the residual value of the building in year 10 (excluding HVAC, window, and lighting) is $\$ 500000 *\left(1-\frac{10}{100}\right)=\$ 450000$.

Because they may be replaced during the study period, residual values for the HVAC system, windows, and lighting are computed separately. The remaining "life" of the HVAC equipment is determined by taking its service life minus the number of years since its last installation (as of the end of the study period), whether it occurred during building construction or replacement. The ratio of remaining life to service life is multiplied by the location-indexed installed cost of the system and discounted from the end of the study period. For example, assume an HVAC system's installed costs are $\$ 12000$ with a service life of 15 years, and a 20 -year study period length. After one replacement, the system is 5 years old at the end of the study period, leaving 10 years 
remaining in its service life. The residual value in year 20 is $\$ 12000 *\left(1-\frac{10}{15}\right)=$ $\$ 4000$. The residual value for the light bulbs and windows is computed in a similar manner.

The total residual value of the building and its HVAC, windows, and lighting, multiplied by the SPV factor for the number of years in the study period, estimates the present value residual value $\left(C_{\text {Residual }}\right)$. 


\section{Building Stock Data}

Aggregating the savings for newly constructed residential buildings to the state and national levels requires new construction data for each building type within each state. The BIRDS new residential database incorporates 10 prototype buildings (5 1-story, 52 story) of varying floor areas. Certain areas of the country have particular housing characteristics. For example, there is a large prevalence of single-story dwellings in states like Florida while the northeast region of the U.S. is characterized by a significantly greater share of multi-level homes. These differences may have an impact on the level of energy savings resulting from adoption of more efficient state energy codes.

Additionally, each city in a state should not be weighted equally when estimating savings because the amount of new floor area constructed across cities in a state can vary significantly. In order to develop more accurate state-level estimates, the amount of newly constructed floor area in a state should be dissected and associated with the most representative city in a state. Weighting factors are developed to associate the amount of new floor area for each building prototype for each of the 228 cities in the BIRDS new residential database. This chapter will describe the databases and weighting factors developed to allow for aggregate savings estimates.

\subsection{Databases}

Two data sources are required to use the BIRDS new residential database results to develop aggregated savings at the state level, one to determine by much how much to weight each building prototype within a city and another to determine by how much to weight each city within a state.

The United States Census Bureau provides annual microdata based on newly constructed homes. All data is based on a national sample survey of new construction called the Survey of Construction (SOC) (U.S. Census Bureau 2013). Survey responses shed light on close to 60 different characteristics of newly constructed homes in the U.S. The weights used for this analysis are extracted from the 2013 SOC survey by determining the proportion of detached 1-story and 2-story homes relative to all single-family home data points in the sample. We then associate these weights to the 10 prototype homes represented in the BIRDS residential database, with the total new floor area. The building prototype weights are developed at the Census division level.

A newly accessed database from McGraw-Hill Dodge Construction (MHDC) includes newly constructed floor area by year from 1970 to 2012 by county across the entire United States. Kneifel and Butry (2014a) developed an approach to associate the MHDC data for each county in a state to one of the 228 cities included in the BIRDS databases based on distance from the centroid (geometric center of a 2-dimensional region) of the county within the same climate zone as shown in Figure 4-1. The purpose of developing these 
county "clusters" is to associate the new floor area constructed in a county to the most representative city in BIRDS, both in terms of climate and building construction costs.

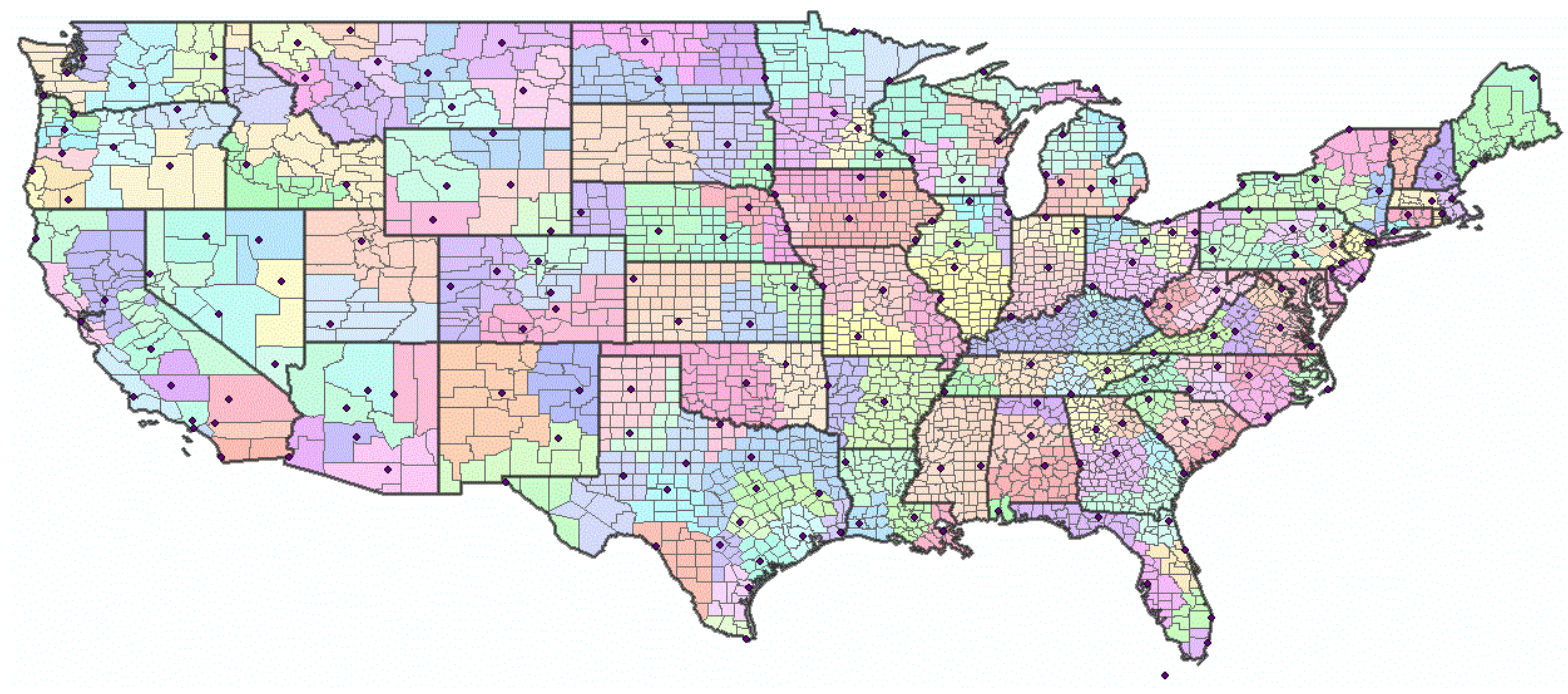

Figure 4-1 Cities and Associated (Colored) County Clusters

The weights developed from the MHDC data for 2012 are used to associate the county "cluster" new floor area to the 10 building prototype results for the city in BIRDS mapped to that particular cluster. The weighting factors are described in detail below.

\subsection{Weighting Factors}

The weighting factors are developed using the combination of the SOC data and MHDC data. Significant data processing is required to create the building prototype-city weights. Figure 4-2 shows how the SOC and MHDC databases are manipulated to develop the desired information. The MHDC data for new residential construction in 2012 is mapped to the county clusters based on the 228 cities in the BIRDS databases, leading to total new residential floor area for each county cluster. The 2013 SOC data is used to allocate the total new floor area from the 2012 MHDC data to the results for each of the building prototypes. 


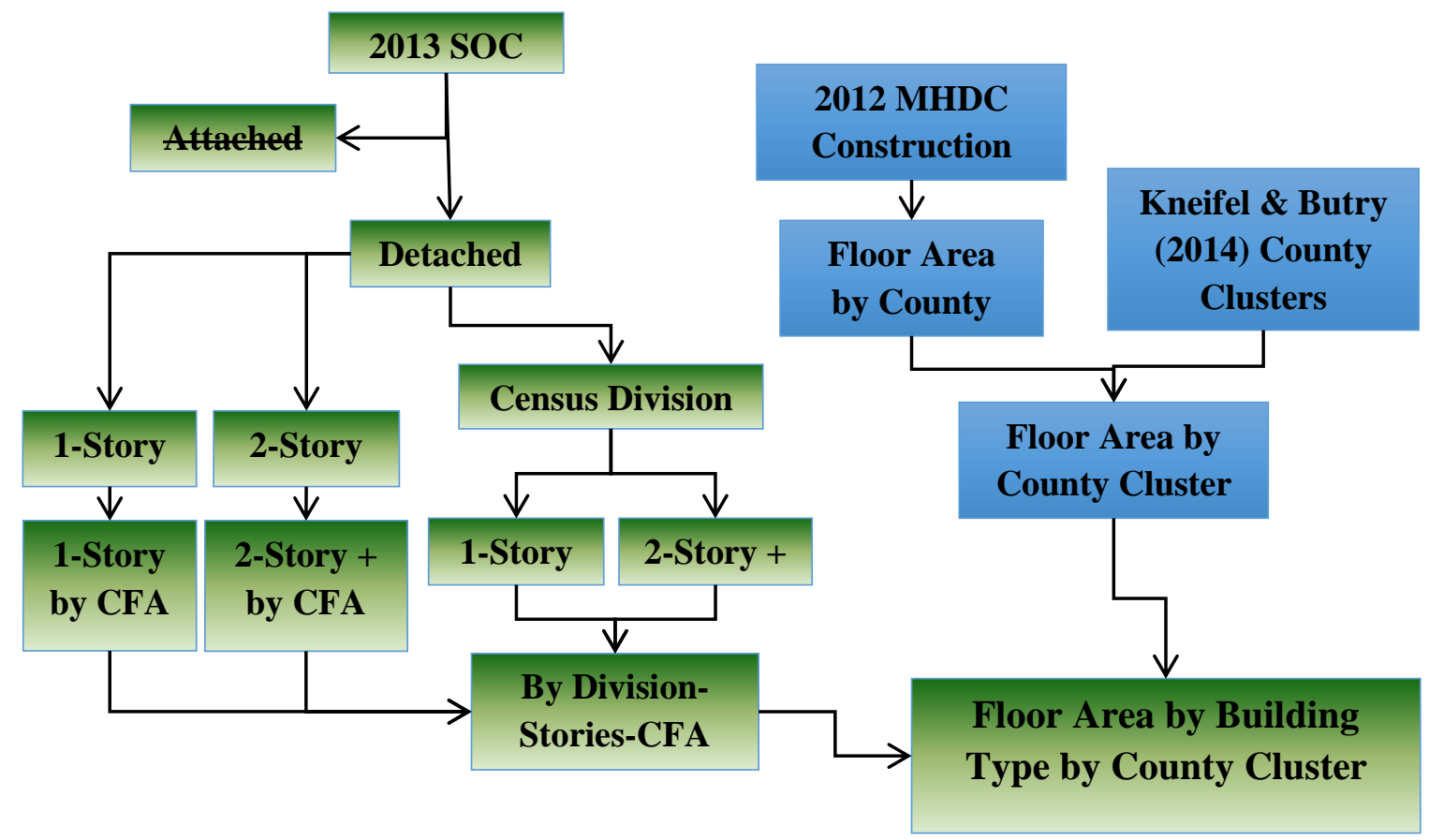

Figure 4-2 Data Processing for Weighting Development

Since this study considers single-family detached dwellings, only detached units are included in the weighting allocation development. Note that $88 \%$ of all new floor area are from detached unit construction with the remaining $12 \%$ of floor area in attached units. The 2013 SOC new floor area data for detached units is used to estimate the fraction of new floor area for a city that should be associated with each of the 10 building prototypes. The prototypes vary in two ways, by number of stories and conditioned floor area (CFA). However, the data that is publically available is at the Census division for floor area by number of stories and national level for floor area by CFA.

The fraction of floor area by number of stories is filtered by Census Division and grouped into two categories: 1-story and 2-story or greater detached housing units. For this study, three-story unit floor area is included in the 2-story unit floor area values because 3-story units are rare, accounting for no more than $4 \%$ of units for any Census division. Table 4-1 shows the resulting percentages of single- and multi-story units across the nine Census divisions, which highlight that new construction in the North Census Region and the Pacific Census Division is primarily units with 2-stories or greater while the new construction in the South Census Region, Midwest Census Region, and Mountain Census Division are about a 50/50 split between 1-story and 2-story or greater units. These trends may be driven by geographic and land availability factors. These fractions will be used to allocate the amount of new floor area to 1-story and 2-story building prototypes for a county cluster based on the Census division in which it is located. 
Table 4-1 Percentages of One- and Multi-Story Homes by Census Region

\begin{tabular}{|l|ll|lll|ll|ll|}
\hline \multicolumn{7}{|c|}{ Regions } \\
\hline & North & & South & & \multicolumn{2}{l|}{ Midwest } & \multicolumn{2}{l|}{ Pacific } \\
\hline \multirow{2}{*}{ Stories } & New & Middle & South & East & West & East & West & Mountain & Pacific \\
& England & Atlantic & Atlantic & South & South & North & North & & \\
$\mathbf{1}$ & $14 \%$ & $23 \%$ & $40 \%$ & $49 \%$ & $55 \%$ & $51 \%$ & $52 \%$ & $49 \%$ & $31 \%$ \\
$\mathbf{2 +}$ & $86 \%$ & $77 \%$ & $60 \%$ & $51 \%$ & $45 \%$ & $49 \%$ & $48 \%$ & $51 \%$ & $69 \%$ \\
\hline
\end{tabular}

The relative percentage of floor area for each building prototype (5 1-story and 5 2-story houses) is based on the national distribution of new floor area by CFA for a unit. The new floor area for detached units in the SOC data ranges from $84 \mathrm{~m}^{2}\left(900 \mathrm{ft}^{2}\right)$ to $743 \mathrm{~m}^{2}(8000$ $\mathrm{ft}^{2}$ ) or greater. The new floor area is filtered into 10 bins based on number of stories and CFA, with each bin associated to a prototype. The percentage of total new floor area that is allocated to each bin by number of stories is shown in Table 4-2.

Table 4-2 Building Types, Bin Ranges, and Percentage of Each Building Design

\begin{tabular}{|c|c|c|c|c|c|}
\hline \multicolumn{3}{|c|}{ 1-Story } & \multicolumn{3}{|c|}{ 2-Story } \\
\hline $\begin{array}{l}\text { Building Type } \\
\mathbf{m}^{2}\left(\mathbf{f t}^{2}\right)\end{array}$ & Bin Range - $\mathbf{m}^{2}\left(\mathbf{f t}^{2}\right)$ & Percentage & $\begin{array}{l}\text { Building Type } \\
\mathbf{m}^{2}\left(\mathbf{f t}^{2}\right)\end{array}$ & Bin Range - $\mathbf{m}^{2}\left(\mathbf{f t}^{2}\right)$ & Percentage \\
\hline $111.9(1205)$ & $\leq 130.1(1400)$ & $13.7 \%$ & $148.8(1602)$ & $\leq 176.5(1900)$ & $10.9 \%$ \\
\hline $148.6(1600)$ & $130.2-167.2(1401-1800)$ & $22.2 \%$ & $204.9(2205)$ & $176.6-232.3(1901-2500)$ & $22.1 \%$ \\
\hline $176.6(1901)$ & $167.3-204.4(1801-2200)$ & $22.5 \%$ & $251.2(2704)$ & $232.4-288.0(2501-3100)$ & $24.0 \%$ \\
\hline $215.8(2323)$ & $204.5-241.5(2201-2600)$ & $15.3 \%$ & $311.0(3348)$ & $288.1-334.5(3101-3600)$ & $17.1 \%$ \\
\hline $292.8(3152)$ & $\geq 241.6(2601)$ & $26.3 \%$ & $420.2(4523)$ & $\geq 334.5(3600+)$ & $25.9 \%$ \\
\hline
\end{tabular}

The Census division-level new floor area weights by number of stories combined with the national-level new floor area weights by building prototype to develop the final weights given to each building type in a county cluster (i.e., city) in a given division. Table 4-3 illustrates the process for calculating this final series of weights using the New England census division as an example. 
Table 4-3 Percentage of Each Building Type for One- and Multi-Story Homes (New England Division)

\begin{tabular}{|c|c|c|}
\hline \multicolumn{3}{|c|}{ Census Division - New England } \\
\hline 1-Story (14\%) & Percentage & Final Weights \\
\hline $111.9(1205)$ & $14 \%$ & $14 \% \cdot 14 \%=2 \%$ \\
\hline $148.6(1600)$ & $22 \%$ & $14 \% \cdot 22 \%=3 \%$ \\
\hline $176.6(1901)$ & $22 \%$ & $14 \% \cdot 22 \%=4 \%$ \\
\hline $215.8(2323)$ & $15 \%$ & $14 \% \cdot 15 \%=2 \%$ \\
\hline $292.8(3152)$ & $26 \%$ & $14 \% \cdot 26 \%=4 \%$ \\
\hline Multi-Story (86\%) & Percentage & Final Weights \\
\hline $148.8(1602)$ & $11 \%$ & $86 \% \cdot 11 \%=9 \%$ \\
\hline $204.9(2205)$ & $22 \%$ & $86 \% \cdot 22 \%=19 \%$ \\
\hline $251.2(2704)$ & $24 \%$ & $86 \% \cdot 24 \%=21 \%$ \\
\hline $311.0(3348)$ & $17 \%$ & $86 \% \cdot 17 \%=15 \%$ \\
\hline $420.2(4523)$ & $26 \%$ & $86 \% \cdot 26 \%=22 \%$ \\
\hline
\end{tabular}

Similar calculations are done to calculate the relative percentage of each building type across all census divisions, which are listed in Table 4-4. The BIRDS database includes the 10 residential prototype buildings in all fifty states. Implementing the division-level weights to the results for each building type is likely to result in varying levels of reductions in energy use, energy costs, life-cycle costs, and life-cycle carbon emissions from adoption of new editions of $I E C C$. 
Table 4-4 Percentage of Each Building Type by Census Division

\begin{tabular}{|c|c|c|c|c|c|c|c|c|c|}
\hline & \multicolumn{2}{|c|}{ North } & \multicolumn{3}{|c|}{ South } & \multicolumn{2}{|c|}{ Midwest } & \multicolumn{2}{|c|}{ Pacific } \\
\hline & $\begin{array}{c}\text { New } \\
\text { England }\end{array}$ & $\begin{array}{l}\text { Middle } \\
\text { Atlantic }\end{array}$ & $\begin{array}{c}\text { South } \\
\text { Atlantic }\end{array}$ & $\begin{array}{c}\text { East } \\
\text { South } \\
\text { Central }\end{array}$ & $\begin{array}{c}\text { West } \\
\text { South } \\
\text { Central }\end{array}$ & $\begin{array}{c}\text { East } \\
\text { North } \\
\text { Central }\end{array}$ & $\begin{array}{c}\text { West } \\
\text { North } \\
\text { Central }\end{array}$ & Mountain & Pacific \\
\hline One-Story & & & & & & & & & \\
\hline 111.9 (1205) & $2 \%$ & $3 \%$ & $5 \%$ & $7 \%$ & $8 \%$ & $7 \%$ & $7 \%$ & $7 \%$ & $4 \%$ \\
\hline $148.6(1600)$ & $3 \%$ & $5 \%$ & $9 \%$ & $11 \%$ & $12 \%$ & $11 \%$ & $12 \%$ & $11 \%$ & $7 \%$ \\
\hline $176.6(1901)$ & $3 \%$ & $5 \%$ & $9 \%$ & $11 \%$ & $12 \%$ & $11 \%$ & $12 \%$ & $11 \%$ & $7 \%$ \\
\hline $215.8(2323)$ & $2 \%$ & $4 \%$ & $6 \%$ & $8 \%$ & $8 \%$ & $8 \%$ & $8 \%$ & $7 \%$ & $5 \%$ \\
\hline $292.8(3152)$ & $4 \%$ & $6 \%$ & $10 \%$ & $13 \%$ & $14 \%$ & $13 \%$ & $14 \%$ & $13 \%$ & $8 \%$ \\
\hline Multi-Story & & & & & & & & & \\
\hline $148.8(1602)$ & $9 \%$ & $8 \%$ & $7 \%$ & $6 \%$ & $5 \%$ & $5 \%$ & $5 \%$ & $6 \%$ & $8 \%$ \\
\hline 204.9 (2205) & $19 \%$ & $17 \%$ & $13 \%$ & $11 \%$ & $10 \%$ & $11 \%$ & $10 \%$ & $11 \%$ & $15 \%$ \\
\hline $251.2(2704)$ & $21 \%$ & $19 \%$ & $14 \%$ & $12 \%$ & $11 \%$ & $12 \%$ & $11 \%$ & $12 \%$ & $17 \%$ \\
\hline $311.0(3348)$ & $15 \%$ & $13 \%$ & $10 \%$ & $9 \%$ & $8 \%$ & $8 \%$ & $8 \%$ & $9 \%$ & $12 \%$ \\
\hline $420.2(4523)$ & $22 \%$ & $20 \%$ & $16 \%$ & $13 \%$ & $12 \%$ & $13 \%$ & $12 \%$ & $13 \%$ & $18 \%$ \\
\hline
\end{tabular}




\section{Analysis Approach}

The analysis in this report compares benefits and costs of the current state energy codes to more stringent alternatives. The relative changes in energy use, energy costs, environmental impacts, and life-cycle costs use the current energy code for a state as the baseline and uses each IECC edition that is newer than the edition required by the current state energy code as an alternative design. The results are considered on both a percentage change and an aggregate change basis.

\subsection{Energy Use}

The analysis uses each state's current energy code as the baseline energy efficiency design. For any state without a state energy code, 2003 IECC is assumed to be the baseline because it represents minimum energy-related industry practices. The baseline for each state is compared to the higher energy efficiency building designs to determine the relative annual energy savings resulting from adopting the alternative code edition as the state's energy code. For example, if a state's energy code has adopted 2006 IECC as its energy code requirements, this baseline energy use is compared to the energy use of all newer energy code editions, 2009 IECC and 2012 IECC.

It is assumed that the building maintains its energy efficiency performance throughout the study period, resulting in energy consumption remaining constant over the entire study period. This assumption is reasonable given the maintenance, repair, and replacement costs included in the analysis to ensure the building and its equipment perform as expected.

\subsection{Life-Cycle Costing}

Life-cycle costing (LCC) takes into account all relevant costs throughout the chosen study period, including construction costs, maintenance, repair, and replacement costs, energy costs, and residual values. A cost's present value (PV) is calculated by discounting its nominal value into today's dollars based on the year the cost occurs and the assumed discount rate. LCC of buildings typically compares the costs for a baseline building design to the costs for alternative, more energy-efficient building designs to determine if future operational savings justify higher initial investments. ${ }^{9}$ For this study, the design based on any IECC edition that is newer than the code edition required by the current state energy code is compared to the baseline state energy code compliant design to determine the changes in life-cycle costs.

\footnotetext{
${ }^{9}$ All life-cycle cost calculations are based on ASTM Standards of Building Economics (2012) and Fuller and Petersen (1996).
} 
Two metrics are used to analyze changes in life-cycle costs: net LCC savings and net LCC savings as a percentage of base case LCC. Net LCC savings is the difference between the base case and alternative design's LCCs.

\subsection{Environmental Impact Assessment}

The BIRDS database expands on Kneifel (2011a) by conducting a life-cycle assessment (LCA) of greenhouse gas emissions for a building across its life-cycle, following guidance in the International Organization for Standardization (ISO) 14040 series of standards for LCA. The analysis quantifies the greenhouse gas emissions from construction of the building, maintenance, repair, and replacement of building components, and operational energy consumption on a cradle-to-grave basis, including emissions from raw materials acquisition, materials processing, generation, transmission, distribution, use, and end-of-life.

The assessment of cradle-to-grave carbon emissions considers a number of greenhouse gases. Carbon dioxide $\left(\mathrm{CO}_{2}\right)$, methane $\left(\mathrm{CH}_{4}\right)$, and nitrous oxide $\left(\mathrm{N}_{2} \mathrm{O}\right)$ are the most prevalent. Both the embodied emissions in the building and its components as well as two types of energy consumption, electricity and natural gas, are included in the assessment. While carbon emissions from natural gas use can be assessed on a national average basis, those from electricity use are highly dependent upon the fuel mixes of regional electricity grids. For this reason, electricity emissions are assessed at the state-level using North American Electric Reliability Corporation (NERC) sub-region level data. ${ }^{10}$ The life-cycle data sets for natural gas production and combustion as well as for all fuel sources in the electricity grid come from the U.S. Life-Cycle Inventory (LCI) database (National Renewable Energy Laboratory (NREL) 2012). The state-level average emissions rates per GWh (MBtu) of electricity generated, as shown in Table A-1 of the Appendix, are obtained from the 2007 Emissions and Generation Resource Integrated Database (Environmental Protection Agency (EPA) 2007), which is a collection of data from the EIA, the Federal Energy Regulatory Commission (FERC), and the Environmental Protection Agency (EPA). ${ }^{11}$

The embodied and operating energy-related greenhouse gas emissions are converted into a common unit of measure called carbon dioxide equivalents $\left(\mathrm{CO}_{2} \mathrm{e}\right)$ using equivalency factors reported in Table 5-1, which represent the global warming potential (GWP) of 1 unit of greenhouse gas relative to that of the same amount of carbon dioxide. For example, 1 unit of methane has 25 times the GWP as the same amount of carbon dioxide, and nitrous oxide has 298 times the GWP as carbon dioxide. The aggregated $\mathrm{CO}_{2} \mathrm{e}$ is

\footnotetext{
${ }^{10}$ For states located in more than one NERC sub-region, a weighted average of emissions rates for the multiple sub-regions is implemented. Source: North American Electric Reliability Corporation (NERC) (2011).

${ }^{11}$ Emissions rates are held constant over all study periods.
} 
calculated by taking the amount of each flow multiplied by its $\mathrm{CO}_{2} \mathrm{e}$ factor, and summing the resulting $\mathrm{CO}_{2}$ equivalencies. The results are analyzed in metric tons of $\mathrm{CO}_{2} \mathrm{e}$ emissions, and will be referred to as "carbon emissions" for the remainder of the report.

\section{Table 5-1 Greenhouse Gas Global Warming Potentials}

\begin{tabular}{ll} 
Environmental Flow & $\mathrm{GWP}\left(\mathrm{CO}_{2} \mathrm{e}\right)$ \\
\hline Carbon Dioxide $\left(\mathrm{CO}_{2}\right)$ & 1 \\
\hline Methane $\left(\mathrm{CH}_{4}\right)$ & 25 \\
\hline Nitrous Oxide $\left(\mathrm{N}_{2} \mathrm{O}\right)$ & 298 \\
\hline Ethane, 1,1-difluoro-, HFC-152a & 124 \\
\hline Ethane, 1,1,1-trichloro-, HCFC-140 & 146 \\
\hline Ethane, 1,1,1,2-tetrafluoro-, HFC-134a & 1430 \\
\hline Ethane, 1,1,2-trichloro-1,2,2-trifluoro-, CFC-113 & 6130 \\
\hline Ethane, 1,2-dichloro-1,1,2,2-tetrafluoro-, CFC-114 & 10000 \\
\hline Ethane, hexafluoro-, HFC-116 & 12200 \\
\hline Methane, bromo-, Halon 1001 & 5 \\
\hline Methane, bromochlorodifluoro-, Halon 1211 & 1890 \\
\hline Methane, bromotrifluoro-, Halon 1301 & 7140 \\
\hline Methane, chlorodifluoro-, HCFC-22 & 1810 \\
\hline Methane, dichloro-, HCC-30 & 9 \\
\hline Methane, dichlorodifluoro-, CFC-12 & 10900 \\
\hline Methane, monochloro-, R-40 & 13 \\
\hline Methane, tetrachloro-, CFC-10 & 1400 \\
\hline Methane, tetrafluoro-, CFC-14 & 7390 \\
\hline Methane, trichlorofluoro-, CFC-11 & 4750 \\
\hline Methane, trifluoro-, HFC-23 & 14800 \\
\hline
\end{tabular}

\subsection{Analysis Metrics}

Three metrics are used to analyze the results: simple percentage changes, aggregate changes, and changes per unit of floor area. The average percentage savings energy use, energy cost, carbon emissions, and LCCs are calculated by taking the average of the percentage savings weighted by new floor area for each single-family detached locationbuilding type combination in the state or nation.

The estimated change in total energy use, energy costs, energy-related carbon emissions, and life-cycle costs for each of the building types is combined with new residential building construction data to calculate the magnitude of the available total savings a state may realize if it were to adopt a more energy efficient standard as its state energy code using the following equation. 


$$
\text { (1) } I_{j}^{k}=\frac{\sum_{i=1}^{10} C F A_{j i} * R_{j i}^{k}}{\sum_{i=1}^{10} F_{j i}}
$$

Where $I_{j}^{k} \quad=$ total change in performance metric $k^{l 2}$ for state $j$

$C F A_{j i}=$ average annual newly constructed floor area for building type $i$ for state $j$

$R_{j i} \quad=$ average change per unit of floor area for building type $i$ for state $j$

$F_{j i} \quad=$ fraction of average annual new floor area represented by building type $i$ for state $j$

For each building type $i$, the average change per unit of floor area for all cities in a state $\left(R_{i}\right)$ is multiplied by the average annual floor area of new construction for 2003 to 2007 for building type $i$ in that state $\left(C F A_{i}\right)$ to estimate the total savings for that building type for that state. The impacts are summed across all ten building prototypes. These impacts are then divided by the amount of average annual new residential floor area represented by the ten building prototypes $(F)$, which scale the results to the statewide impacts of all new residential construction $\left(I_{j}\right)$. Using this approach to estimate the total impacts for a state requires the assumption that the savings realized by the BIRDS building prototypes are representative of new residential building construction as a whole.

The national-level impacts $\left(I_{T}\right)$ are estimated using Equation 2, where the impacts for state $j$ estimated using Equation $1\left(I_{j}\right)$ are summed across all fifty states.

$$
\text { (2) } I_{T}^{k}=\sum_{j=1}^{50}\left(I_{j}^{k}\right)
$$

Where $I_{T}^{k} \quad=$ nationwide total impacts on $k$

$I_{j}^{k} \quad=$ total impacts on $k$ in state $j$

The third metric, change per unit of floor area, allows for comparisons across states to determine which states realize the greatest impacts per unit of construction. Equation 3 shows this calculation, where the total statewide impacts estimated in Equation $1\left(I_{j}\right)$ are divided by the total average annual new floor area for all building types in a state $\left(T C F A_{j}\right)$, providing a means for a cost performance comparison across states.

$$
\text { (3) } A V G I_{j}^{k}=\frac{I_{j}}{T C F A_{j}}
$$

Where $A V G I_{j}^{k}=$ average impact on $k$ per unit of new floor area in state $j$

$I_{j}^{k} \quad=$ total impacts on $k$ in state $j$

$T C F A_{j}=$ total average annual new floor area for all building types in state $j$

\footnotetext{
${ }^{12}$ A change in the performance metric $k$ refers to the change energy use, energy costs, life-cycle costs, or life-cycle carbon emissions.
} 
It is necessary to assume a particular study period length to generate results. Although the annual energy use savings and energy-related carbon emissions reductions, both in percentage and total value terms, are assumed to be the same across study period lengths, the energy costs and life-cycle costs vary with the study period length because costs vary year-over-year. A 10-year study period is used for the majority of this analysis because it is the most realistic investor time frame of the 9 study period length options. 


\section{Nationwide Impacts of Adopting 2012 IECC Design}

This section analyzes the benefits and costs of nationwide adoption of the 2012 IECC for residential buildings relative to currently adopted state energy codes. Benefits are examined across several dimensions (study period, location, and code edition) in order to better understand the full scope of the impacts associated with more energy efficient new single-family dwellings. Changes in annual energy use, energy costs, life-cycle costs, and life-cycle carbon emissions stemming from the adoption of stricter energy codes are expressed in terms of percentage reduction, total reduction, and change per unit of floor area.

\subsection{Percentage Reductions}

Average reductions or percentage change impacts from adopting the 2012 IECC design are estimated for energy use, energy costs, life-cycle carbon emissions, and life-cycle costs. Impacts are evaluated across four dimensions: study period length, building type, climate zone, and state energy code.

\subsubsection{Results by Building Type}

Incorporating 2012 IECC requirements in new residential construction will impact energy consumption, energy costs, life-cycle carbon emissions, and life-cycle costs. The magnitude of these impacts is likely to vary as study period length increases. 1-, 5-, 10-, 20-, and 40-year study period lengths are considered to gain a better understanding of these variations.

Table 6-1 shows the national average percentage reduction in annual energy usage across all U.S. states from nationwide adoption of the 2012 IECC relative to currently adopted state energy codes. Because the BIRDS database assumes that energy efficiency is maintained constant over time, reductions will be consistent across all study period lengths. Percent reductions vary across building types and range from $17.0 \%$ to $21.9 \%$, with a weighted national average reduction of $19.2 \%$. Results in Table 6-1 suggest that the larger the building, the greater the average percentage reduction in energy consumption. Two factors that impact the relative percentage changes are the fraction of energy use associated with meeting heating and cooling loads and the basic geometry of the building, including the glazing (i.e., windows) fraction of wall area. All prototypes assume the same occupancy and equipment operation. As the building increases in size, meeting heating and cooling loads becomes a greater portion of total energy demand. Given a specific amount of total floor area, the heating and cooling loads will be reduced as the exterior surface area of the building decreases. Additionally, less window area (as a percentage of wall area) will lead to greater impacts from greater insulation requirements because the requirement will impact a greater portion of the wall area. As a result, a 2- 
story building will have lower heating and cooling loads than a 1-story building with the same amount of floor area.

Table 6-1 Nationwide Average Percentage Reduction in Energy Use from Adoption of the 2012 IECC Design by Building Type

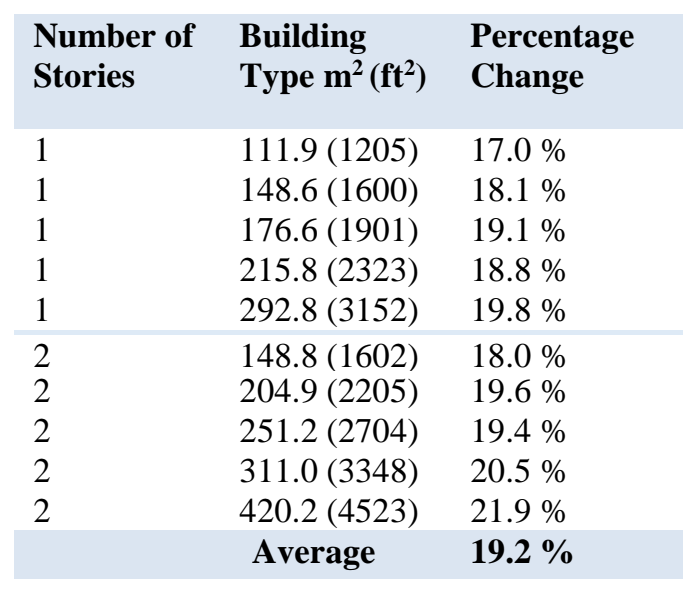

The national average percent changes in energy-related expenditures across each building type and study length are displayed in Table 6-2. There is minimal variation in energy cost savings over time. Percent changes range between $11.8 \%$ and $18.9 \%$ depending on building type and time period. More sizeable reductions (regardless of study period) are witnessed with larger homes (all 2-story and larger single-story homes). Average percent changes across all 10 building types range between $15.1 \%$ for a 1-year study period, and $15.7 \%$ for a 40 -year study period. These marginal changes (percentage terms) in average energy cost reductions are due to the assumed escalation of energy prices in the future (Rushing, Kneifel et al. 2011). Percent changes in energy costs are smaller than the reductions in energy use because majority of the reductions occur for the cheaper of the two primary fuel sources, natural gas. 
Table 6-2 Nationwide Average Percentage Reduction in Energy Costs from Adoption of the 2012 IECC Design by Building Type and Study Period Length

\begin{tabular}{lllllll} 
Stories & Building Type & \multicolumn{7}{l}{ Study Period Length } \\
\cline { 3 - 7 } & $\mathbf{m}^{\mathbf{2}\left(\mathbf{f t}^{2}\right)}$ & $\mathbf{1}$ & $\mathbf{5}$ & $\mathbf{1 0}$ & $\mathbf{2 0}$ & $\mathbf{4 0}$ \\
\hline 1 & $111.9(1205)$ & $11.8 \%$ & $11.8 \%$ & $11.9 \%$ & $12.1 \%$ & $12.4 \%$ \\
1 & $148.6(1600)$ & $13.6 \%$ & $13.6 \%$ & $13.6 \%$ & $13.9 \%$ & $14.2 \%$ \\
1 & $176.6(1901)$ & $14.4 \%$ & $14.3 \%$ & $14.4 \%$ & $14.7 \%$ & $15.1 \%$ \\
1 & $215.8(2323)$ & $15.6 \%$ & $15.5 \%$ & $15.6 \%$ & $15.8 \%$ & $16.2 \%$ \\
1 & $292.8(3152)$ & $16.9 \%$ & $16.9 \%$ & $17.0 \%$ & $17.2 \%$ & $17.5 \%$ \\
\hline 2 & $148.8(1602)$ & $13.3 \%$ & $13.3 \%$ & $13.4 \%$ & $13.6 \%$ & $14.0 \%$ \\
2 & $204.9(2205)$ & $15.2 \%$ & $15.1 \%$ & $15.2 \%$ & $15.4 \%$ & $15.8 \%$ \\
2 & $251.2(2704)$ & $15.5 \%$ & $15.4 \%$ & $15.5 \%$ & $15.8 \%$ & $16.1 \%$ \\
2 & $311.0(3348)$ & $16.7 \%$ & $16.7 \%$ & $16.8 \%$ & $17.0 \%$ & $17.4 \%$ \\
2 & $420.2(4523)$ & $18.2 \%$ & $18.1 \%$ & $18.2 \%$ & $18.5 \%$ & $18.9 \%$ \\
\hline & Average & $\mathbf{1 5 . 1} \%$ & $\mathbf{1 5 . 1} \%$ & $\mathbf{1 5 . 2} \%$ & $\mathbf{1 5 . 4} \%$ & $\mathbf{1 5 . 7} \%$
\end{tabular}

Constructing a residential building to meet 2012 IECC requirements results in fewer total life-cycle carbon emissions than meeting requirements set by current state energy codes based on an older edition of IECC. Table 6-3 shows the nationwide average percent changes in GWP (emissions) for each building type. We stated previously that the national average percentage change in energy use is constant across all study periods, which means that average energy-related carbon emissions are constant. Additionally, the building construction-related emissions are equally associated with years across the study period. National average percent changes range between $8.1 \%$ and $14.5 \%$ depending on the building type, with a nationwide average percentage change of $11.2 \%$. Emissions reductions for each building are directly related to its energy use, with 2-story houses achieving greater reductions in both energy use and emissions than single-story houses of similar size and the largest 2-story prototype attaining the largest average reduction of any building type (14.5\%). These results indicate the importance of considering both energy-related and embodied carbon emissions. 
Table 6-3 Nationwide Average Percentage Reduction in Life-Cycle Carbon Emissions from Adoption of the 2012 IECC Design by Building Type

\begin{tabular}{lll} 
Stories & $\begin{array}{l}\text { Building } \\
\text { Type } \mathbf{~ m}^{\mathbf{2}}\left(\mathbf{f t}^{\mathbf{2}}\right)\end{array}$ & $\begin{array}{l}\text { Percentage } \\
\text { Change }\end{array}$ \\
\hline 1 & $111.9(1205)$ & $8.1 \%$ \\
1 & $148.6(1600)$ & $9.5 \%$ \\
1 & $176.6(1901)$ & $9.7 \%$ \\
1 & $215.8(2323)$ & $10.1 \%$ \\
1 & $292.8(3152)$ & $11.3 \%$ \\
\hline 2 & $148.8(1602)$ & $11.2 \%$ \\
2 & $204.9(2205)$ & $11.9 \%$ \\
2 & $251.2(2704)$ & $12.6 \%$ \\
2 & $311.0(3348)$ & $13.0 \%$ \\
2 & $420.2(4523)$ & $14.5 \%$ \\
& Average & $\mathbf{1 1 . 2} \%$ \\
\hline
\end{tabular}

The average percentage changes in LCC for every building type and study period length are shown in Table 6-4. As expected, there are substantial increases in LCC for a study period of 1 year given the higher initial investment costs required for building a more energy-efficient building. The average percentage change in life-cycle costs decreases as the study period length increases from a $42.0 \%$ increase for a 1-year study period to a $2.9 \%$ decrease for a 40 -year study period. All but 1 building type realizes LCC savings (negative \% change) after five years. On the other hand, all 10 buildings realize average LCC savings for study periods of 10 years or more.

The life-cycle cost increase is large in percentage terms for a 1-year study period because the additional increase in first costs is divided by a relatively small value. For example, assume two building designs: Building A (baseline) has first costs of $\$ 150000$ and annual energy costs of \$2000; Building B has first costs of \$200 000 and annual energy costs of $\$ 1400$. Annual energy costs are reduced by $\$ 600$ (30\%) for an additional first cost of $\$ 50$ 000. The life-cycle costs for each building are as follows assuming a $3 \%$ discount rate and 65 year building lifetime:

$$
\begin{gathered}
L C C_{A}=150000+\left(2000 * \frac{1}{(1.03)^{1}}\right)-\left(150000 * \frac{64}{65} * \frac{1}{(1.03)^{1}}\right)=\$ 8609 \\
L C C_{B}=200000+\left(1400 * \frac{1}{(1.03)^{1}}\right)-\left(200000 * \frac{64}{65} * \frac{1}{(1.03)^{1}}\right)=\$ 10213
\end{gathered}
$$

In this example, the percentage change in life-cycle costs (19\%) is the difference between the life-cycle costs (\$1603) divided by the life-cycle costs for the baseline building design (\$8609). The change in life-cycle costs is small in magnitude, but large in percentage terms. 
Table 6-4 National Average Percentage Reduction in Life-Cycle Costs from Adoption of the 2012 IECC Design by Building Type and Study Period Length

\begin{tabular}{|c|c|c|c|c|c|c|}
\hline \multirow[t]{2}{*}{ Stories } & \multirow{2}{*}{$\begin{array}{l}\text { Building } \\
\text { Type } \mathbf{m}^{2}\left(\mathbf{f t}^{2}\right)\end{array}$} & \multicolumn{5}{|c|}{ Study Period Length } \\
\hline & & 1 & 5 & 10 & 20 & 40 \\
\hline 1 & $111.9(1205)$ & $-17.6 \%$ & $-0.1 \%$ & $1.1 \%$ & $1.8 \%$ & $2.4 \%$ \\
\hline 1 & $148.6(1600)$ & $-16.3 \%$ & $0.5 \%$ & $1.5 \%$ & $2.2 \%$ & $2.7 \%$ \\
\hline 1 & $176.6(1901)$ & $-15.9 \%$ & $0.8 \%$ & $1.7 \%$ & $2.4 \%$ & $2.9 \%$ \\
\hline 1 & $215.8(2323)$ & $-20.9 \%$ & $0.8 \%$ & $1.8 \%$ & $2.5 \%$ & $3.0 \%$ \\
\hline 1 & $292.8(3152)$ & $-27.7 \%$ & $1.0 \%$ & $2.0 \%$ & $2.7 \%$ & $3.2 \%$ \\
\hline 2 & $148.8(1602)$ & $-16.5 \%$ & $0.5 \%$ & $1.4 \%$ & $2.1 \%$ & $2.6 \%$ \\
\hline 2 & $204.9(2205)$ & $-18.3 \%$ & $1.1 \%$ & $1.8 \%$ & $2.4 \%$ & $2.9 \%$ \\
\hline 2 & $251.2(2704)$ & $-24.2 \%$ & $1.2 \%$ & $1.9 \%$ & $2.5 \%$ & $3.0 \%$ \\
\hline 2 & $311.0(3348)$ & $-30.1 \%$ & $1.3 \%$ & $2.1 \%$ & $2.7 \%$ & $3.2 \%$ \\
\hline \multirow[t]{2}{*}{2} & $420.2(4523)$ & $-232.7 \%$ & $1.5 \%$ & $2.3 \%$ & $2.9 \%$ & $3.4 \%$ \\
\hline & Average & $-42.0 \%$ & $0.9 \%$ & $1.7 \%$ & $2.4 \%$ & $2.9 \%$ \\
\hline
\end{tabular}

A snapshot of the average reductions in energy use, energy costs, life-cycle carbon emissions, and LCCs, stemming from nationwide adoption of the 2012 IECC building codes is shown in Table 6-5. Assuming a 10-year study period, findings suggest that relative to all other single-story homes, the largest single-story home $\left(293 \mathrm{~m}^{2}\left[3152 \mathrm{ft}^{2}\right]\right)$ achieves the greatest reductions in the above four metrics, while the smallest $\left(112 \mathrm{~m}^{2}\right.$ [1205 $\left.\mathrm{ft}^{2}\right]$ ) achieves the least. A similar trend is discovered for 2-story homes, where the $420 \mathrm{~m}^{2}\left(4523 \mathrm{ft}^{2}\right)$ home outperformed all 1- and 2-story homes.

\section{Table 6-5 Nationwide Average Percentage Reduction in the Four Performance Metrics from Adoption of the 2012 IECC Design by Building Type (10-Year)}

\begin{tabular}{llllll}
$\begin{array}{l}\text { Number of } \\
\text { Stories }\end{array}$ & Building & \multicolumn{2}{l}{ Percentage Change } & & \\
& Type $\mathbf{~ m}^{\mathbf{2}}\left(\mathbf{f t}^{\mathbf{2}}\right)$ & Energy Use & Energy Costs & GWP & LCC \\
1 & $111.9(1205)$ & $17.0 \%$ & $11.9 \%$ & $8.1 \%$ & $1.1 \%$ \\
1 & $148.6(1600)$ & $18.1 \%$ & $13.6 \%$ & $9.5 \%$ & $1.5 \%$ \\
1 & $176.6(1901)$ & $19.1 \%$ & $14.4 \%$ & $9.7 \%$ & $1.7 \%$ \\
1 & $215.8(2323)$ & $18.8 \%$ & $15.6 \%$ & $10.1 \%$ & $1.8 \%$ \\
1 & $292.8(3152)$ & $19.8 \%$ & $17.0 \%$ & $11.3 \%$ & $2.0 \%$ \\
\hline 2 & $148.8(1602)$ & $18.0 \%$ & $13.4 \%$ & $11.2 \%$ & $1.4 \%$ \\
2 & $204.9(2205)$ & $19.6 \%$ & $15.2 \%$ & $11.9 \%$ & $1.8 \%$ \\
2 & $251.2(2704)$ & $19.4 \%$ & $15.5 \%$ & $12.6 \%$ & $1.9 \%$ \\
2 & $311.0(3348)$ & $20.5 \%$ & $16.8 \%$ & $13.0 \%$ & $2.1 \%$ \\
2 & $420.2(4523)$ & $21.9 \%$ & $18.2 \%$ & $14.5 \%$ & $2.3 \%$ \\
& Average & $\mathbf{1 9 . 2} \%$ & $\mathbf{1 5 . 2} \%$ & $\mathbf{1 1 . 2} \%$ & $\mathbf{1 . 7 \%}$ \\
\hline
\end{tabular}




\subsubsection{Results by Climate Zone}

Considering results by climate zone helps shed some light on the relationship between climate zone and the benefits of nationally adopting 2012 IECC. It was discovered in the previous section that weighting based on newly constructed floor area had only minimal impacts on our results. For the sake of simplicity, changes in energy use, energy costs, emissions, and LCC will be calculated without our series of weights. The assumed study period length is 10 years.

The BIRDS new residential database considers both 1- and 2-story family dwellings. Table 6-6 shows the average percentage change in energy use by climate zone and baseline code (see Figure 2-1) from adoption of the 2012 IECC for both a 1- and 2-story home. Similar trends can be seen in the average energy use reductions across climate zones for both 1- and 2-story homes - the changes in average energy consumption tends to grow larger as the climate zone grows colder. Only in Zone 4 and Zone 5 are exceptions, which realize slightly smaller reductions in energy use than the previous zone, which may be a result of changes in requirements across IECC editions, as displayed in Table 3-1. Average reductions in energy use are greater for 2-story homes in all climate zones.

Table 6-6 reveals an unexpected inconsistency between baseline code and energy savings. Although locations with older baseline codes realize greater reductions, on average (final column), this trend does not hold at the climate zone level. In fact, locations with a baseline code of 2003 IECC lead to the greatest reductions for two climate zones for both 1-story and 2-story houses. Locations with a baseline code of 2006 IECC realize the greatest reductions for four climate zones for 1-story houses and four climate zones for 2-story houses. This result may be driven by the change in climate zone definitions and the resulting changes in building requirements for locations in those climate zones. 
Table 6-6 Average Percentage Reduction in Energy Use from Adoption of the 2012 IECC by Climate Zone and Baseline Code for 1- and 2-Story Homes

(a) Average (1-Story)

Climate Zone

$\begin{array}{lllllllllll} & & \mathbf{1} & \mathbf{2} & \mathbf{3} & \mathbf{4} & \mathbf{5} & \mathbf{6} & \mathbf{7} & \mathbf{8} & \text { All } \\ \text { Baseline } & \mathbf{2 0 0 3} & & 17.2 \% & 21.6 \% & 23.1 \% & 21.5 \% & 22.5 \% & 22.8 \% & 25.0 \% & 22.0 \% \\ \text { Code } & \mathbf{2 0 0 6} & 6.9 \% & 11.4 \% & 23.2 \% & 22.9 \% & & 25.0 \% & 24.7 \% & & 19.0 \% \\ & \mathbf{2 0 0 9} & 5.1 \% & 10.2 \% & 20.4 \% & 23.2 \% & 22.6 \% & 23.0 \% & 23.8 \% & & 18.3 \% \\ & \text { Avg } & \mathbf{6 . 0} \% & \mathbf{1 2 . 9} \% & \mathbf{2 1 . 7} \% & \mathbf{2 3 . 1} \% & \mathbf{2 2 . 0} \% & \mathbf{2 3 . 5} \% & \mathbf{2 3 . 8} \% & \mathbf{2 5 . 0} \% & \mathbf{1 9 . 8} \%\end{array}$

(b) Average (2-Story)

Climate Zone

$\begin{array}{lllllllllll} & & \mathbf{1} & \mathbf{2} & \mathbf{3} & \mathbf{4} & \mathbf{5} & \mathbf{6} & \mathbf{7} & \mathbf{8} & \text { All } \\ \text { Baseline } & \mathbf{2 0 0 3} & & 16.1 \% & 24.3 \% & 25.2 \% & 23.9 \% & 26.5 \% & 26.6 \% & 28.3 \% & 24.4 \% \\ \text { Code } & \mathbf{2 0 0 6} & 9.3 \% & 11.9 \% & 26.0 \% & 25.6 \% & & 28.7 \% & 28.3 \% & & 21.6 \% \\ & \mathbf{2 0 0 9} & 6.6 \% & 10.4 \% & 23.1 \% & 25.7 \% & 24.5 \% & 27.0 \% & 27.3 \% & & 20.6 \% \\ & \text { Avg } & \mathbf{7 . 9} \% & \mathbf{1 2 . 8} \% & \mathbf{2 4 . 5} \% & \mathbf{2 5 . 5} \% & \mathbf{2 4 . 2} \% & \mathbf{2 7 . 4} \% & \mathbf{2 7 . 4} \% & \mathbf{2 8 . 3} \% & \mathbf{2 2 . 3} \%\end{array}$

The BIRDS database assumes that each home consumes two fuel types - natural gas for space and water heating and electricity for all other household demands (e.g., cooling, plug loads, etc.). Pricing and emissions profiles differ for electricity and natural gas. Despite regional variations in energy prices, electricity is often more expensive and associated with more emissions than natural gas. Because of this, changes in energy demands and fuel source mixes in response to 2012 IECC can have a significant impact on energy costs. The first of these can be seen in Table 6-7, which shows the average reductions in energy costs by climate zone and baseline code. Energy cost savings increase from Zone 1 to Zone 3 with the increase in energy use savings, which are primarily from reductions in electricity to meet cooling loads. Average energy cost savings then decrease in magnitude from Zone 3 to Zone 5 as energy use shifts to a more heating dominated climate. The final column unveils a similar trend to that found in Table 6-6 - average reductions are greater for older baseline codes. 
Table 6-7 Average Percentage Reduction in Energy Costs from Adoption of the 2012 IECC by Climate Zone and Baseline Code for 1- and 2-Story Homes (10-Year Study Period)

(a) Average (1-Story)

Climate Zone

$\begin{array}{lllllllllll} & & \mathbf{1} & \mathbf{2} & \mathbf{3} & \mathbf{4} & \mathbf{5} & \mathbf{6} & \mathbf{7} & \mathbf{8} & \text { All } \\ \text { Baseline } & \mathbf{2 0 0 3} & & 17.1 \% & 17.9 \% & 17.8 \% & 16.2 \% & 17.7 \% & 17.0 \% & 19.8 \% & 17.6 \% \\ \text { Code } & \mathbf{2 0 0 6} & 7.5 \% & 10.6 \% & 19.4 \% & 17.4 \% & & 18.4 \% & 19.3 \% & & 15.4 \% \\ & \text { Average } & \mathbf{6 . 4} \% & 8.7 \% & 16.3 \% & 17.7 \% & 16.8 \% & 17.6 \% & 18.0 \% & & 14.3 \% \\ & \text { Ave } & \mathbf{1 2 . 1} \% & \mathbf{1 7 . 9} \% & \mathbf{1 7 . 6} \% & \mathbf{1 6 . 5} \% & \mathbf{1 7 . 9} \% & \mathbf{1 8 . 1} \% & \mathbf{1 9 . 8} \% & \mathbf{1 5 . 8} \%\end{array}$

(b) Average (2-Story)

Climate Zone

\begin{tabular}{|c|c|c|c|c|c|c|c|c|c|c|}
\hline \multirow{5}{*}{$\begin{array}{l}\text { Baseline } \\
\text { Code }\end{array}$} & & 1 & 2 & 3 & 4 & 5 & 6 & 7 & 8 & All \\
\hline & 2003 & & $16.1 \%$ & $20.4 \%$ & $18.9 \%$ & $17.5 \%$ & $20.5 \%$ & $19.8 \%$ & $22.6 \%$ & $19.4 \%$ \\
\hline & 2006 & $10.1 \%$ & $11.6 \%$ & $21.9 \%$ & $19.2 \%$ & & $21.2 \%$ & $22.0 \%$ & & $17.7 \%$ \\
\hline & 2009 & $6.9 \%$ & $9.1 \%$ & $18.4 \%$ & $19.3 \%$ & $17.8 \%$ & $20.6 \%$ & $20.6 \%$ & & $16.1 \%$ \\
\hline & Average & $8.5 \%$ & $12.2 \%$ & $20.2 \%$ & $19.2 \%$ & $17.7 \%$ & $20.8 \%$ & $20.8 \%$ & $22.6 \%$ & $17.7 \%$ \\
\hline
\end{tabular}

Table 6-8 shows that average reductions in $\mathrm{CO}_{2}$ emissions range from $3.9 \%$ to $17.3 \%$ for 1-story houses, and $5.5 \%$ to $20.2 \%$ for 2-story houses. Similar to energy costs, 1 - and 2-story homes in Zone 1 and Zone 8 realize the smallest and largest average reductions, respectively, while Zone 4 and Zone 5 deviate slightly from the trend of increasing reductions with colder climates. Emissions (the energy-related portion) are correlated with energy costs because the same fuel that is more expensive also has a higher emissions rate per unit of energy (electricity).

Table 6-8 Average Percentage Reduction in Emissions from Adoption of the 2012 IECC by Climate Zone and Baseline Code for 1- and 2-Story Homes

(a) Average (1-Story)

Climate Zone

$\begin{array}{lllllllllll} & & \mathbf{1} & \mathbf{2} & \mathbf{3} & \mathbf{4} & \mathbf{5} & \mathbf{6} & \mathbf{7} & \mathbf{8} & \text { All } \\ \text { Baseline } & \mathbf{2 0 0 3} & & 10.9 \% & 12.4 \% & 12.4 \% & 11.8 \% & 12.1 \% & 13.3 \% & 17.3 \% & 12.9 \% \\ \text { Code } & \mathbf{2 0 0 6} & 4.6 \% & 7.1 \% & 14.0 \% & 9.7 \% & & 15.4 \% & 14.4 \% & & 10.9 \% \\ & \text { Average } & 3.2 \% & 7.5 \% & 10.5 \% & 11.0 \% & 13.1 \% & 14.4 \% & 13.6 \% & & 10.5 \% \\ & & \mathbf{8 . 5} \% & \mathbf{1 2 . 3} \% & \mathbf{1 1 . 0} \% & \mathbf{1 2 . 4} \% & \mathbf{1 4 . 0} \% & \mathbf{1 3 . 8} \% & \mathbf{1 7 . 3 \%} & \mathbf{1 1 . 6 \%}\end{array}$

(b) Average (2-Story)

Climate Zone

$\begin{array}{lllllllllll} & & \mathbf{1} & \mathbf{2} & \mathbf{3} & \mathbf{4} & \mathbf{5} & \mathbf{6} & \mathbf{7} & \mathbf{8} & \text { All } \\ \text { Baseline } & \mathbf{2 0 0 3} & & 11.4 \% & 15.1 \% & 14.2 \% & 13.5 \% & 14.6 \% & 15.9 \% & 20.2 \% & 15.0 \% \\ \text { Code } & \mathbf{2 0 0 6} & 6.6 \% & 8.6 \% & 16.8 \% & 11.5 \% & & 18.5 \% & 17.1 \% & & 13.2 \% \\ & \text { Average } & \mathbf{5 . 5} \% & \mathbf{9 . 6} \% & \mathbf{1 4 . 9} \% & \mathbf{1 2 . 8} \% & \mathbf{1 4 . 2} \% & \mathbf{1 6 . 9} \% & \mathbf{1 6 . 4} \% & \mathbf{2 0 . 2} \% & \mathbf{1 3 . 8} \%\end{array}$


The average reductions in LCC for 1- and 2-story single-family dwellings are reported in Table 6-9. Results suggest that it is cost-effective to adopt the 2012 IECC edition across all 8 climate zones (assuming a 10-year study period). Average LCC reductions range from $0.6 \%$ (Zone 2) to $4.4 \%$ (Zone 8 ) for a single-story home. For 2-story homes they range between $1.1 \%$ (Zone 2 ) to $4.6 \%$ (Zone 8 ). Average LCC reductions are noticeably larger for 2-story homes. Previous findings imply that the smallest cutbacks in energy use, energy costs, and emissions occur in Zone 1. However, the percentage reductions in LCC for Zone 1 and Zone 5 are greater than those for Zone 2 and Zone 3 for one-story buildings and Zone 2 through Zone 4 for 2 -story buildings. This deviation may be a result of the differences in the additional investment costs, on average, of meeting the 2012 IECC across climate zones. For example, a house in Zone 2 may be required to make more building envelope improvements than in Zone 1 to meet 2012 IECC. The higher investment costs are not offset by enough energy cost savings in Zone 2 to lead to equivalent percentage reductions in LCCs relative to Zone 1. Zone 5 through Zone 8 generate more sizeable LCC reductions and further reinforces that states located in colder climates collectively benefit more by adopting the 2012 IECC edition than states in warmer climate zones.

\section{Table 6-9 Average Percentage Reduction in Life-Cycle Costs from Adoption of the 2012 IECC by Climate Zone and Baseline Code for 1- and 2-Story Homes (10-Year Study Period)}

(a) Average (1-Story)

Climate Zone

$\begin{array}{lllllllllll} & & \mathbf{1} & \mathbf{2} & \mathbf{3} & \mathbf{4} & \mathbf{5} & \mathbf{6} & \mathbf{7} & \mathbf{8} & \text { All } \\ \text { Baseline } & \mathbf{2 0 0 3} & & 1.4 \% & 1.2 \% & 2.2 \% & 2.6 \% & 2.7 \% & 3.1 \% & 4.4 \% & 2.5 \% \\ \text { Code } & \mathbf{2 0 0 9} & 1.6 \% & -0.4 \% & 0.9 \% & 0.6 \% & & 2.1 \% & 2.2 \% & & 1.2 \% \\ & \text { Average } & 1.1 \% & 0.9 \% & 1.5 \% & 2.2 \% & 3.2 \% & 3.2 \% & 3.4 \% & & 2.2 \% \\ & & & \mathbf{0 . 6} \% & \mathbf{1 . 2} \% & \mathbf{1 . 6} \% & \mathbf{2 . 9} \% & \mathbf{2 . 7} \% & \mathbf{2 . 9} \% & \mathbf{4 . 4} \% & \mathbf{2 . 2} \%\end{array}$

(b) Average (2-Story)

Climate Zone

$\begin{array}{lllllllllll} & & \mathbf{1} & \mathbf{2} & \mathbf{3} & \mathbf{4} & \mathbf{5} & \mathbf{6} & \mathbf{7} & \mathbf{8} & \text { All } \\ \text { Baseline } & \mathbf{2 0 0 3} & & 1.9 \% & 1.6 \% & 2.7 \% & 2.8 \% & 2.7 \% & 3.1 \% & 4.6 \% & 2.8 \% \\ \text { Code } & \mathbf{2 0 0 6} & 2.7 \% & 0.2 \% & 1.5 \% & 1 \% & & 2.5 \% & 2.5 \% & & 1.7 \% \\ & \mathbf{2 0 0 9} & 1.4 \% & 1.2 \% & 1.9 \% & 2.4 \% & 3.4 \% & 3.4 \% & 3.5 \% & & 2.4 \% \\ & \text { Average } & \mathbf{2 . 0} \% & \mathbf{1 . 1} \% & \mathbf{1 . 6} \% & \mathbf{2 . 0} \% & \mathbf{3 . 1} \% & \mathbf{2 . 9} \% & \mathbf{3 . 0} \% & \mathbf{4 . 6} \% & \mathbf{2 . 6} \%\end{array}$

Analysis on a location's climate zone helps clarify the relationship between a state's geographic location and potential savings gained by adopting 2012 IECC. Figure 6-1 summarizes the above tables by showing the total average reductions in energy use, 
energy costs, life-cycle emissions, and LCC for 1- and 2-story homes in each climate zone. Again, 2-story homes realize greater average percentage reductions than 1-story homes in each of the four metrics. The relationship between climate zone and average reductions is revealed, showing that average percentage savings increase as the climate zone grows colder. This holds true except in the mixed climate zones (Zone 4 and Zone 5), where there is a slight dip in the average percentage reductions after Zone 3 in three of the four performance metrics.

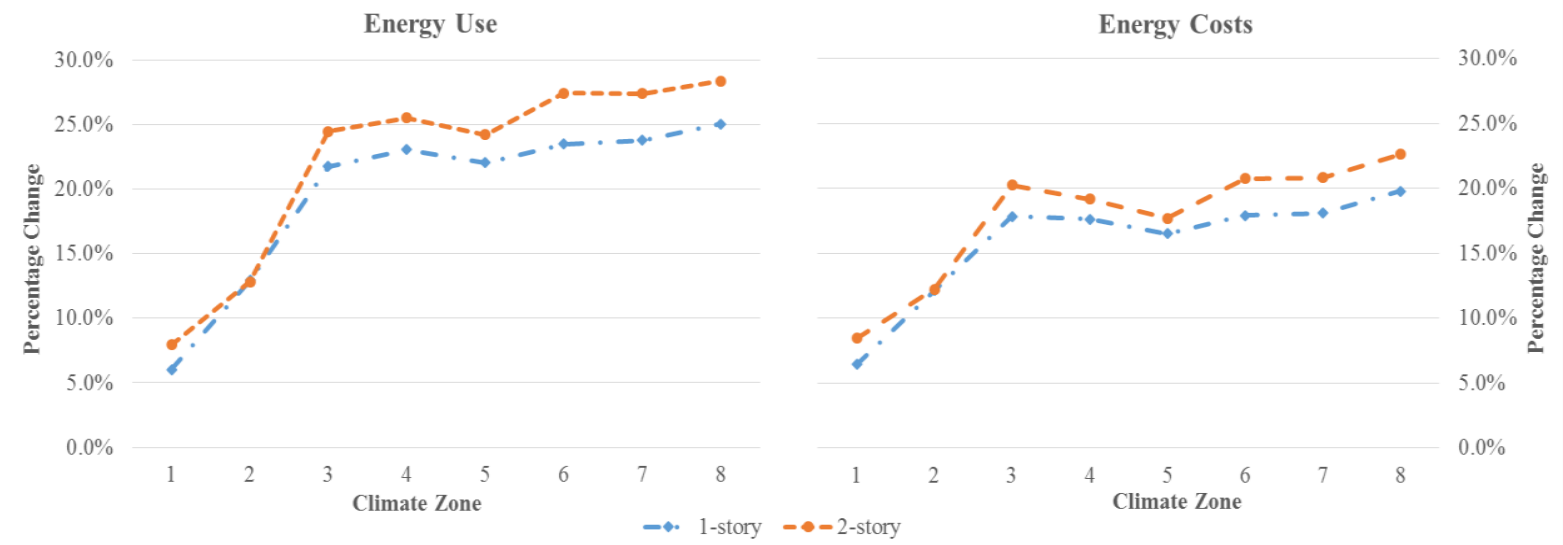

Life-Cycle Carbon Emissions

Life-Cycle Costs

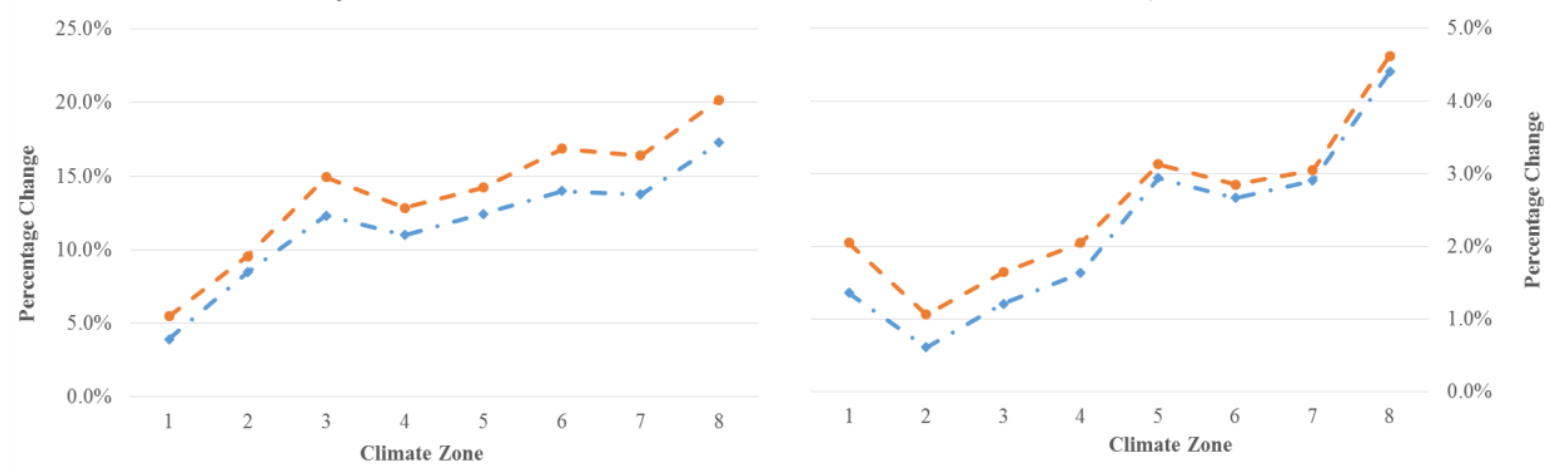

Figure 6-1 Average Percentage Reduction in Energy Use, Energy Costs, Life-Cycle Emissions, and LCC for 1- and 2-Story Homes (10-Year Study Period)

\subsubsection{Results by State Energy Code}

There is an implicit assumption that newer editions of IECC would lead to lower energy consumption. States with older editions of the IECC standards are expected to produce more significant reductions in energy use, energy costs, life-cycle carbon emissions, and life-cycle costs when adopting newer codes. This section analyzes the state-level impacts of 2012 IECC adoption relative to a state's baseline code. States that have already adopted 2012 IECC as of July 2014 are excluded from the analysis. Figure 6-2 shows the assumed baseline IECC edition for each of the fifty states used for this analysis. As of 2014, states such as Alaska and Mississippi have yet to adopt IECC standards statewide, adopting the code only at the local government level or not at all. For this analysis, we 
assume that states like Alaska and Mississippi have adopted the oldest version of the IECC captured in BIRDS, the 2003 IECC.

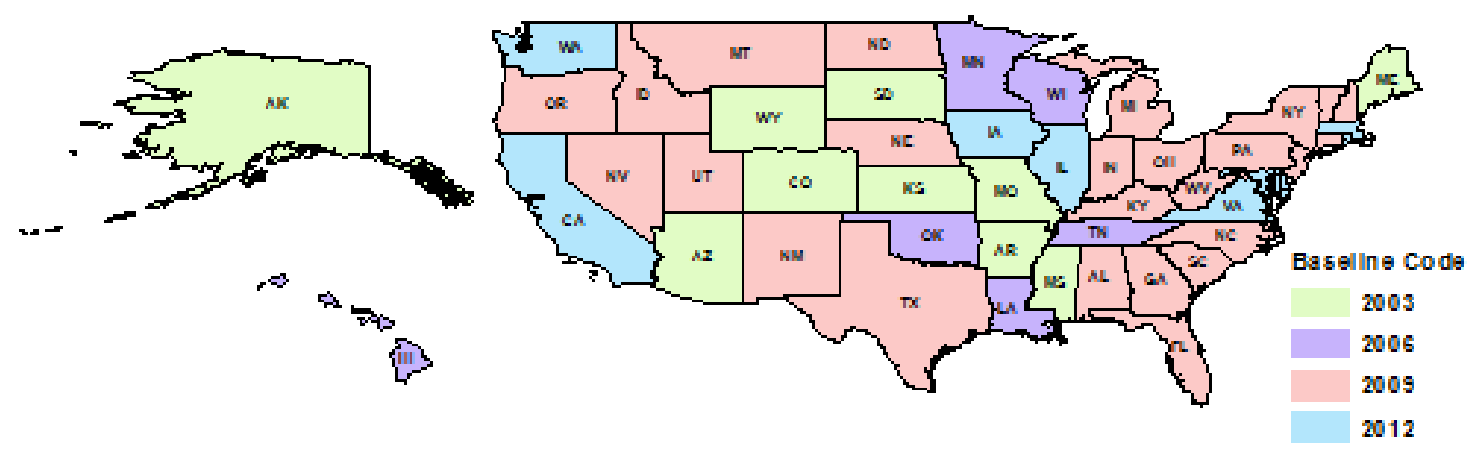

Figure 6-2 Baseline IECC Codes for all U.S. States as of July 2014

Assuming a 10-year study period length, the average percent changes in energy use and energy costs are shown in Figure 6-3. States shaded in grey currently build according to 2012 IECC, so there are no additional savings to be recouped in this study. Cross hatching is used to indicate all states with no code or a code based on 2003 IECC. A total of ten states achieve average reductions of $25 \%$ or more.

Cross-referencing Figure 6-2 (using cross hatching) with Figure 6-3 reveals that there is no direct correlation between code edition and average statewide reductions in energy use. For example, the state of Arizona currently constructs new single-family dwellings based on 2003 IECC codes and achieves an average reduction of $17.5 \%$. On the other hand, New Mexico builds according to 2009 IECC and realizes an average reduction of $23.2 \%$. Both the state-level and previously discussed climate zone-level results reveal that differences are minimal between code edition requirements across 2003 IECC, 2006 IECC, and 2009 IECC. Figure 6-3 reveals the states that realize greater reductions in energy use also realize greater energy cost savings. However, despite a high correlation between energy use and energy costs, there are no states generating energy cost reductions proportional to their reductions in energy use. For example, New Jersey, Wisconsin, and Vermont achieve cost reductions of $19 \%, 20 \%$ and $21 \%$, respectively, despite realizing reductions in energy use by more than $26 \%$ each. The reason for this result is that the reductions in energy demands are primarily driven by reductions in heating load, which is met using natural gas. Since natural gas is the cheaper of the two fuel sources, average percentage reductions in energy costs will be smaller than the changes in energy use. Table B-1 in the appendix further supports this result, showing the total reductions in electricity and natural gas consumption, and the proportional changes in natural gas consumption relative to electricity following the adoption of the 2012 IECC. Every state realizes considerably higher reductions in natural gas demands than 
electricity demands. The large price differential between the two fuels results in less than proportional reductions in energy costs.
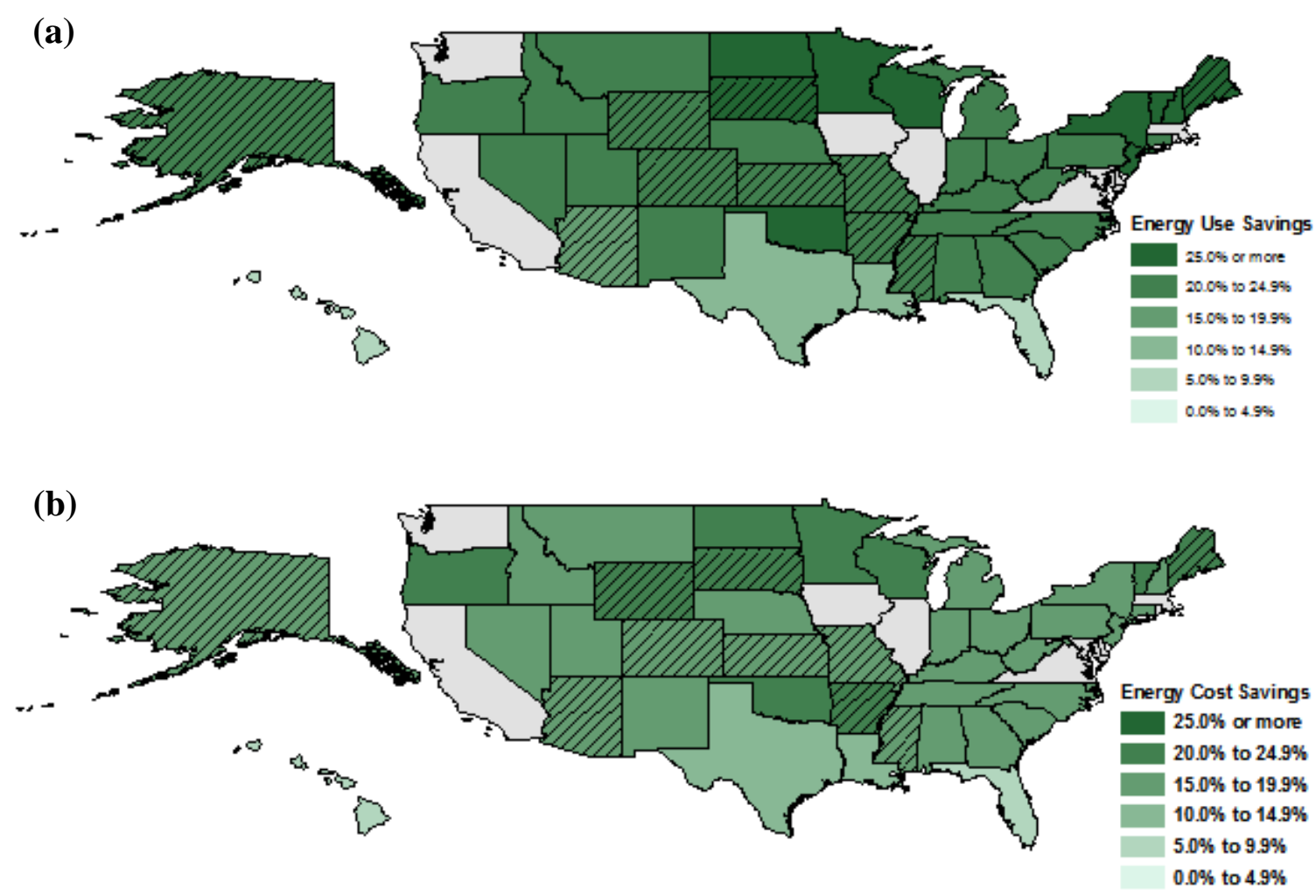

Figure 6-3 Average Percentage Savings by State in (a) Energy Use and (b) Energy Costs Savings (10-Year Study Period)

Percentage reductions in life-cycle emissions shown in Figure 6-4 are highly correlated with reductions in energy use, with states in colder climates realizing greater carbon emission savings. However, the percentage changes in emissions are noticeably smaller than the reductions in energy use. Similar to energy costs, the changing proportions of natural gas in response to the adoption of 2012 IECC is partly responsible for this result. Natural gas emits fewer carbon emissions than electricity, which means that emission reductions associated with operating energy consumption will be smaller than the percentage changes in energy use. Another factor is associated with the embodied energy in the building. 2012 IECC requires additional installed building materials to meet the incorporated energy-efficiency measures. These additional materials increase the overall level of embodied emissions, and as a result, the reduction in carbon emissions associated with less energy consumption will be partially offset by increases in product-related flows - leading to even smaller changes in carbon emissions. States such as Vermont and Wisconsin that were leaders in energy consumption savings continue to be leaders in emissions reductions, but at lower percentage savings relative to energy reductions. 


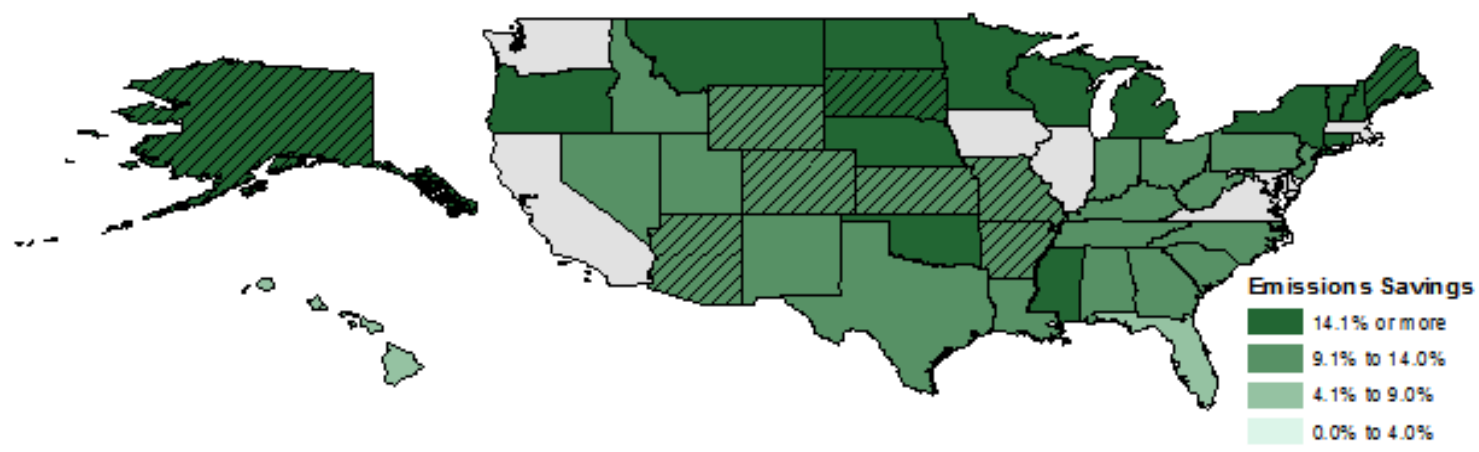

Figure 6-4 Average Percentage Savings in Emissions for all U.S. States (10-Year Study Period)

Figure 6-5 displays the average percentage changes in life-cycle costs for each state assuming a 10-year investor time horizon from nationwide adoption of 2012 IECC. Adoption of 2012 IECC appears to be cost-effective for every state. Louisiana is the only state where life-cycle savings are negative (-0.06\%). Many states with considerable energy cost savings realize greater percentage reductions in overall life-cycle costs. Maine, New Hampshire, and Vermont - for example - are three states that significantly lower their energy use and energy costs relative to all other states, and are the only three states to lower their LCC by more than $4.0 \%$. North Dakota and South Dakota are states that fall below the $4.0 \%$ range despite being leaders in energy cost savings. It is likely that the additional construction costs to meet 2012 IECC offset some of the energy cost savings in these states.

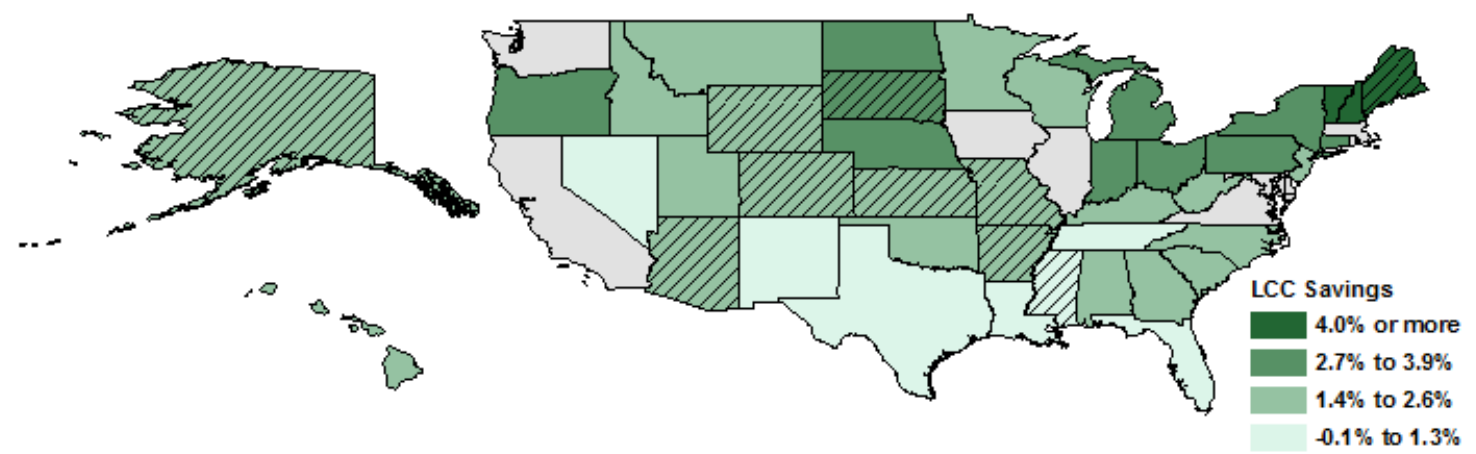

Figure 6-5 Average Percentage Savings in Life-Cycle Costs for all U.S. States (10Year Study Period)

Table B-2 in Appendix B shows the average reductions in energy use, energy costs, emissions, and LCC for a 10-year study period for all U.S. states that have not yet adopted 2012 IECC. The general consensus from the results is that there is no apparent correlation between baseline code edition and the magnitude of average percentage 
reductions in any of the four metrics. For example, Maine achieves almost a $26 \%$ reduction in energy use by switching from 2003 IECC to 2012 IECC. On the other hand, the state of Vermont realizes a very similar level of energy savings even though the state has 2009 IECC as their baseline code. Similar inconsistencies surface with state average reductions in energy costs, life-cycle carbon emissions, and LCC.

As of July 2014, only 10 states build single-family dwellings according to 2012 IECC.

The findings in this section suggest that transitioning to 2012 IECC building codes by the rest of the country will produce cost-effective reductions in energy use and life-cycle carbon emissions for study periods of 10 years or longer. However, there is no definitive relationship between current baseline code edition for a state and potential savings from adopting 2012 IECC. States that have currently adopted older editions of IECC will not necessarily realize the largest average savings in energy use, costs, or emissions, after switching to 2012 IECC.

\subsection{Total Changes}

The above section highlights the average percentage changes in energy use, energy costs, life-cycle carbon emissions, and life-cycle costs. It did not consider the magnitude of the impacts in terms of both total and per unit of floor area. This section uses the total amount of newly constructed floor area for each of the 10 prototype buildings in each state to estimate the magnitude of the total impacts from nationwide adoption of 2012 IECC for residential buildings.

\subsubsection{Total Savings by State}

Controlling for all newly constructed floor area within a state allows us to determine the magnitude of the total impacts from adopting the 2012 IECC nationwide, as well as which states could benefit the most. Absolute changes in the four metrics are calculated using the formulas described in section 5.4.

Figure 6-6 shows the total average amount of new floor area constructed annually (1000

$\mathrm{m}^{2}$ ) for single-family detached homes in each state. Again, states shaded in gray currently have adopted 2012 IECC statewide. The greatest reductions in energy use, energy costs, and life-cycle carbon emissions, are expected to occur in those states with the greatest amount of newly constructed residential floor area (Arizona, Georgia, Florida, North Carolina, and Texas). 

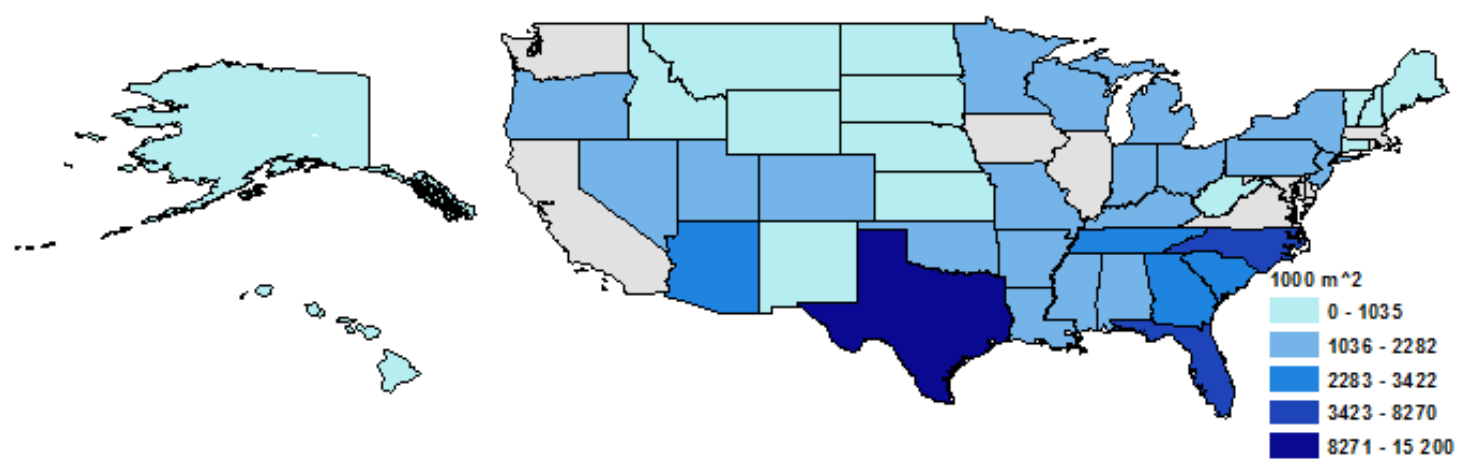

Figure 6-6 Total Average New Residential Floor Area Constructed Annually in Each State

Table C-1 in Appendix C provides a summary of the total savings in energy use, energy costs, LCC, and life-cycle carbon emissions for a single year's worth of construction given the nationwide adoption of the 2012 IECC assuming a 10-year study period. These results are also summarized in Figure 6-7, which shows the total changes in the four metrics across the U.S. Figure 6-7(a) shows that some states realizing significant percent changes in energy use (Texas, North Carolina, and Tennessee) also realize larger changes in total energy consumption. The primary driver behind these reductions is the amount of total new floor area constructed annually. Texas and North Carolina realize the most extensive changes in energy use with reductions of $260 \mathrm{GWh}$ and $189 \mathrm{GWh}$, respectively. Hawaii, Alaska, and Vermont are three states with the least amount of new floor area and only realize $2 \mathrm{GWh}, 5 \mathrm{GWh}$, and $7 \mathrm{GWh}$ in savings, respectively.

Similarly, states with more new residential construction realize greater total changes in energy costs, life-cycle carbon emissions, and LCC. Figure 6-7(b) - (d) show that Texas and North Carolina realize the greatest savings in energy costs, emissions, and LCC. Alaska, Vermont, and New Mexico realize the smallest savings in all three. These findings continue to highlight the significance of energy cost savings in calculating the LCC savings earned by adopting 2012 IECC. 

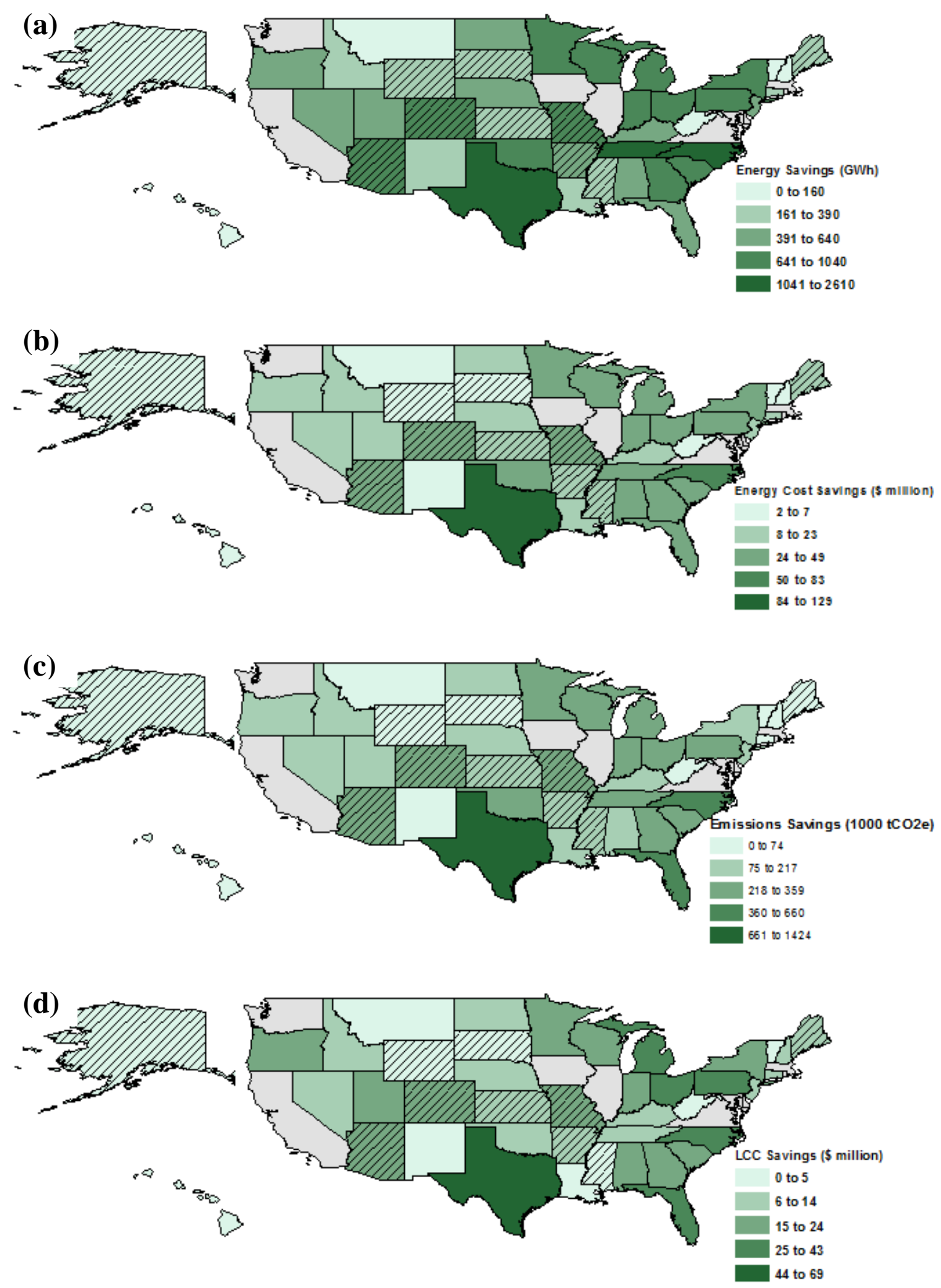

Figure 6-7 Total Savings in Energy Use, Energy Costs, Life-Cycle Carbon Emissions, and Life-Cycle Costs (10-Year Study Period) 


\subsubsection{Regional and National Impacts}

The regional impacts of adopting the 2012 IECC across the nation on energy use, energy costs, LCC, and life-cycle carbon emissions are calculated by summing total changes across all states within each of the four Census Regions. Table 6-10 displays the total changes in the metrics for the four regions under the assumption of a 10-year study period. The South Census Region achieves the greatest reductions in energy use, energy costs, carbon emissions, and LCC. The Northeast region realizes the least. Once again it is shown that total savings are primarily driven by the amount of newly constructed floor area. National adoption of the 2012 IECC leads to reductions of 2.4 TWh in energy use, $\$ 1.0$ billion in energy costs, 9.3 million metric tons in emissions, and $\$ 0.6$ billion in LCC over a 10-year study period.

\section{Table 6-10 Total Savings by Census Region from Adoption of the 2012 IECC (10-Year Study Period)}

\begin{tabular}{|c|c|c|c|c|c|}
\hline $\begin{array}{l}\text { Census } \\
\text { Region }\end{array}$ & $\begin{array}{c}\text { Average New CFA } \\
1000 \mathbf{m}^{2}\left(1000 \mathrm{ft}^{2}\right)\end{array}$ & $\begin{array}{l}\text { Energy Use } \\
\text { (GWh) }\end{array}$ & $\begin{array}{l}\text { Energy Costs } \\
\text { (\$million) }\end{array}$ & $\begin{array}{c}\text { Emissions } \\
\left(1000 \mathrm{tCO}_{2} \mathrm{e}\right)\end{array}$ & $\begin{array}{c}\text { LCC } \\
\text { (\$million) }\end{array}$ \\
\hline Northeast & 5959 (64 146) & 2793 & 112 & 820 & 106 \\
\hline Midwest & 12601 (135 631) & 6627 & 204 & 2125 & 172 \\
\hline South & 49268 (529 922) & 10812 & 513 & 4837 & 344 \\
\hline West & 12603 (135 657) & 4044 & 164 & 1528 & 114 \\
\hline National & 80394 (865 357) & 24277 & 993 & 9311 & 601 \\
\hline
\end{tabular}

\subsection{Savings per Unit of Floor Area}

The total savings estimated in Section 6-2 was driven by the amount of newly constructed floor, making it difficult to analyze the other factors that may be driving variation in the results. This section normalizes the results by estimating the reductions per unit of floor area in order to analyze these other factors.

\subsubsection{State-Level Savings}

The weighted average reductions in energy use are estimated at the city-level and then aggregated to a state-level weighted average using the county clustering approach defined in Section 4.2.

\subsubsection{Energy Use and Energy Cost Savings per Unit of Floor Area}

Aggregate energy savings and energy savings per unit of newly constructed floor area for each state are shown in Table D-1, and are organized by savings per unit of new floor 
area in descending order. Once controlling for the amount of newly constructed building stock, the results are similar to the percentage change results. States such as Alaska have the least amount of new construction but achieve some of the most extensive reductions in energy use per $\mathrm{m}^{2}\left(\mathrm{ft}^{2}\right)$. Energy savings per unit of floor area is driven primarily by climate zone, as shown in Figure 6-8. States located in milder climate zones (Zone 1 through Zone 4) realize smaller reductions in energy use per $\mathrm{m}^{2}\left(\mathrm{ft}^{2}\right)$ than states located in colder climates (Zone 5 through Zone 8).

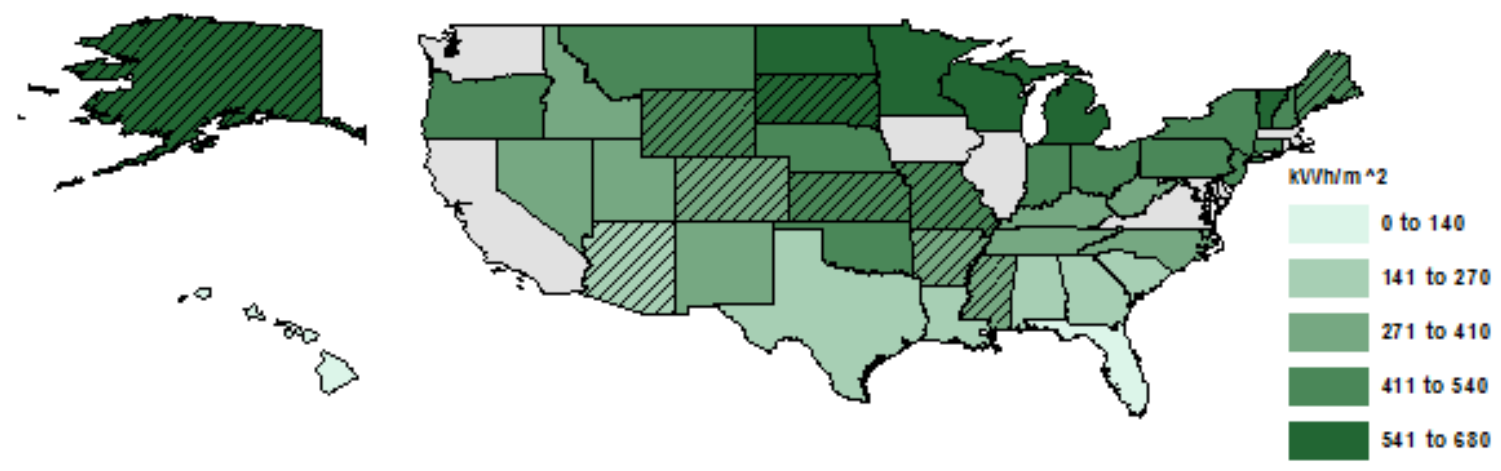

Figure 6-8 Energy Savings per Unit of Floor Area by State (10-Year Study Period)

\subsubsection{Energy Cost Savings per Unit of Energy Savings}

Results from Section 6-2 showed that states with greater reductions in total energy use generally realize greater energy cost savings. Other factors such as energy prices and the fuel mix of the total reductions in energy use in a state also impact the magnitude of energy cost savings. Table D-2 sheds some light on the impacts of energy prices and changes in annual energy consumption on energy cost savings per MWh of energy savings. Listed are the state average electricity and natural gas rates, rate differentials, weighted average energy prices (weighted by the baseline proportions of natural gas and electricity consumed in the state), changes in electricity and natural gas use following nationwide adoption of 2012 IECC, and the resulting energy cost savings per MWh reduced. States with higher average weighted energy prices produce larger energy cost savings per MWh saved. All states - with the exception of Florida and Hawaii - satisfy the majority of their energy needs using natural gas. Large discrepancies in fuel mix proportions, which drive down weighted average energy prices in most states, reveals that energy cost savings are particularly sensitive to changes in natural gas prices.

The relationship between weighted average energy prices and energy cost savings per MWh saved is shown in Figure 6-9. States located in the southern part of the U.S., along the east coast, and Hawaii have both the highest weighted average energy prices and energy cost savings per MWh reduced. Hawaii faces the highest weighted average energy price $(\$ 0.32)$ relative to all other states. Electricity rates in the state are at least two times 
higher than rates in other states, while natural gas rates are at least three times higher. Their uniquely high prices coupled with their heavy dependence on costly electricity results in an exceptionally high weighted average energy price. States in all remaining parts of the U.S. face much lower average energy prices and realize at most moderate cost savings by adopting the 2012 IECC.

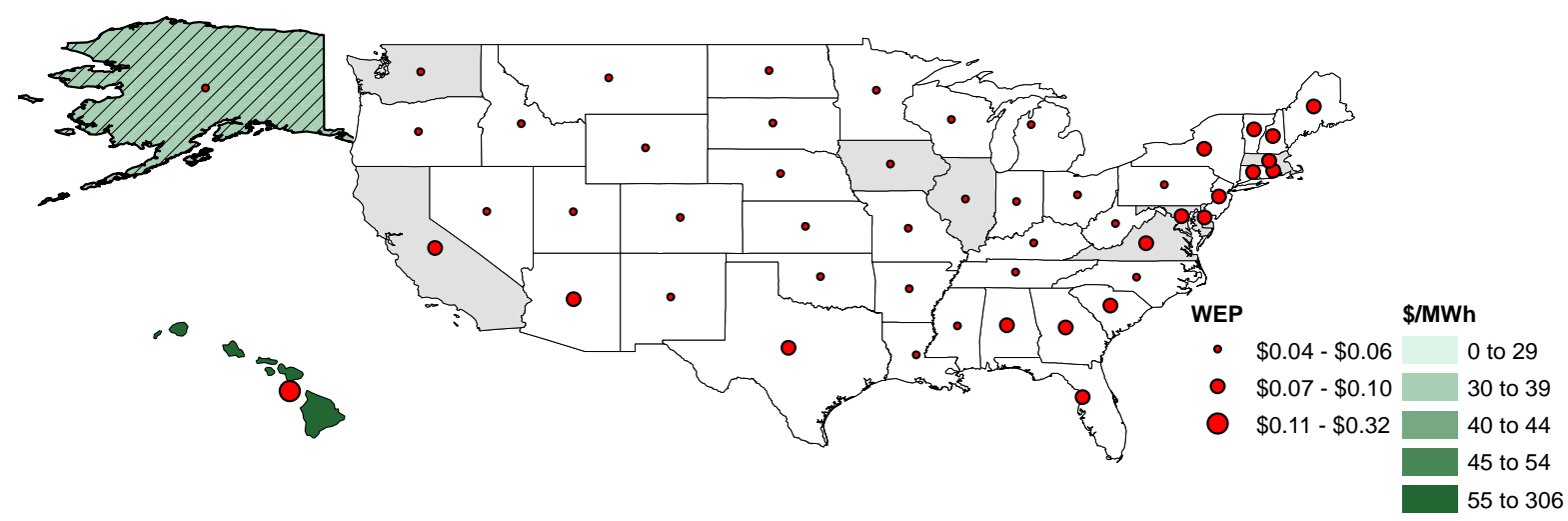

\section{Figure 6-9 Energy Cost Savings per Megawatt-Hour Reduced and Weighted Average Energy Price by State (10-Year Study Period)}

Figure 6-9 suggests that there is some correlation between weighted average energy prices and energy cost savings per MWh saved. From Table D-2, states realizing greater energy cost savings per MWh reduced generally achieve larger cutbacks in electricity use relative to other states. Electricity is more costly per $\mathrm{kWh}$ than natural gas on average, which means that states can recoup greater cost savings per MWh reduced the more they lower their electricity use. The inexpensiveness of natural gas requires that substantial reductions in its use occur in order for there to be significant levels of energy cost savings per unit of energy savings.

Another factor that impacts the energy cost savings is the shift in the fuel mix from natural gas to electricity consumption. The adoption of 2012 IECC leads to reductions in both natural gas and electricity consumption. However, the magnitude of natural gas reductions in most states is greater than that of electricity, increasing the proportion of consumption accounted for by electricity (referred to as an "offset" throughout the remainder of this document). States with a large enough price difference coupled with minor offsets in natural gas can still realize considerable energy cost savings. Large savings may also arise in states with smaller energy price differentials and larger natural gas offsets. The smallest energy cost savings per MWh saved are likely to occur in states with larger energy price differentials and a smaller fraction of natural gas being offset by changes in electricity use.

Figure 6-10 shows the Building America Climate Regions for the Contiguous U.S. (Figure 6-10a) and the average offset (Figure 6-10b), which is the average shift in the 
proportion of consumption from natural gas to electricity in each state from the adoption of 2012 IECC. The smallest offset occurs for Hawaii followed by Alaska, Florida, and Louisiana, which are all states in the hottest (Hawaii, Florida, and Louisiana) and coldest (Alaska) climate zones in the country. These extreme climates have either little, or no, heating or cooling loads and will not shift demands regardless of the efficiency of the building design. The greatest offsets occur in states that are at least partially in the mixed climate zones (ASHRAE Climate Zone 3A (northern portion), Zone 4A, and Zone 4B), which can realize significant shifts from heating to cooling in the transition seasons (spring and fall).

(a)

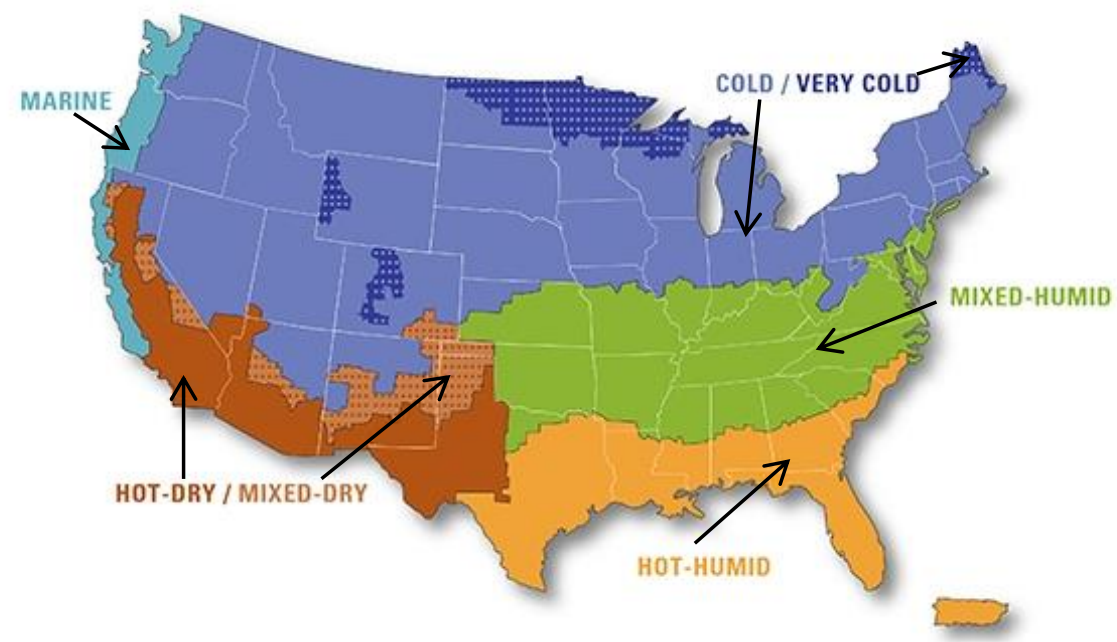

(b)

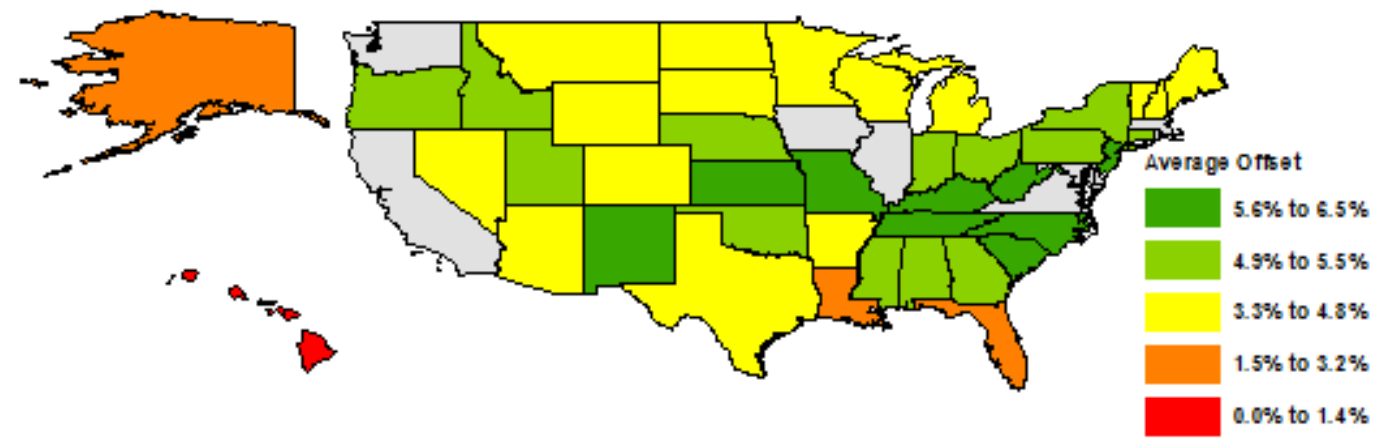

Figure 6-10 (a) Building America U.S. Climate Regions and (b) the Average Natural Gas Offset by State (10-Year Study Period) ${ }^{13}$

\subsubsection{Savings in Life-Cycle Carbon Emissions per Unit of Energy Savings}

It was determined from Figure 6-7 that there is strong correlation between total energy savings and savings in life-cycle carbon emissions. States with the largest reductions in

${ }^{13}$ Source: Building America Climate Region Map (U.S. Department of Energy (DOE) 2015) 
energy use generally produce the largest reductions in emissions. Other factors such as statewide changes in the fuel mix of the energy use savings and changes in the cradle-to-grave construction-related emissions associated with 2012 IECC building efficiency requirement, potentially impact the carbon emissions savings. Table D-3 in the Appendix shows total life-cycle emissions savings, emissions savings per unit of floor area, emission savings per MWh of energy saved, the average proportion of energy consumption represented by natural gas under the baseline energy code, and the weighted average fraction of natural gas offset by changes in electricity consumption in each state. States with a greater proportion of electricity-based energy consumption realize greater reductions per unit of energy reduction, with 8 of the 11 states with the greatest reductions per MWh of energy use savings having natural gas account for less than $60 \%$ of total average energy consumption under their baseline state energy code (bolded in Table D-3). It is also evident that there is a relationship between natural gas offsets and carbon emissions savings per MWh reduced, with 4 of the 5 states that have offsets of less than $4 \%$ (bolded in Table D-3) in those same top 11. For example, the offset for Florida is only $0.9 \%$ and it realizes almost $0.88 \mathrm{tCO}_{2} \mathrm{e}$ savings per MWh reduced. Missouri, however, offsets roughly $6 \%$ of its natural gas for the more carbon intensive electricity and realizes only $0.34 \mathrm{tCO}_{2} \mathrm{e}$ savings per MWh saved after the adoption of the 2012 IECC. This finding is further supported by Figure 6-11, which shows both the average emissions savings per unit of energy saved and the weighted average natural gas offsets in each state. States with higher natural gas offsets generally realize smaller lifecycle carbon emissions savings per MWh saved.

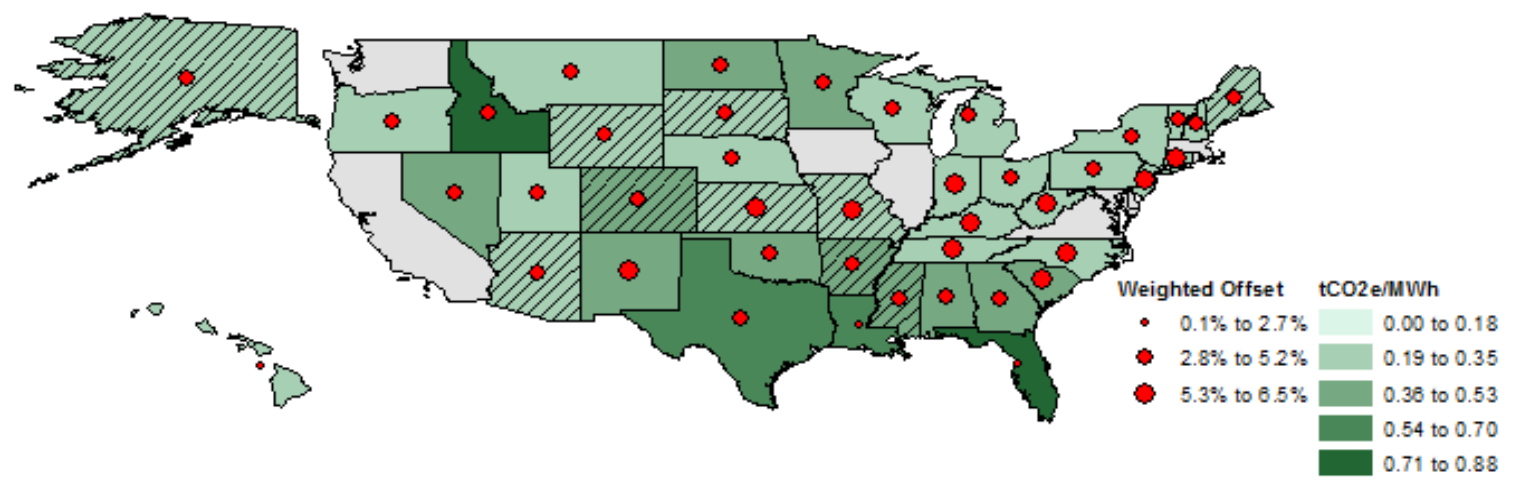

Figure 6-11 Emissions Savings per MWh Reduced and the Weighted Average Offset of Natural Gas by State (10-Year)

\subsubsection{Life-Cycle Cost Savings per Unit of Floor Area}

Changes in LCC per unit of newly constructed floor area are shown in Table D-4. Similar to energy use, climate is a key driver to LCC reductions per unit of floor area. Maine, Vermont, and New York, for example, realize the greatest savings per unit of floor area 
and are located in colder climate zones (Zone 5, Zone 6, or Zone 7). Figure 6-12 shows that LCC savings per $\mathrm{m}^{2}$ grow larger as the climate zone grows colder. Similar to energy costs, Hawaii is the outlier, realizing significant LCC savings per unit of floor area because of its uniquely high energy prices. There is no correlation between LCC savings and state baseline codes.

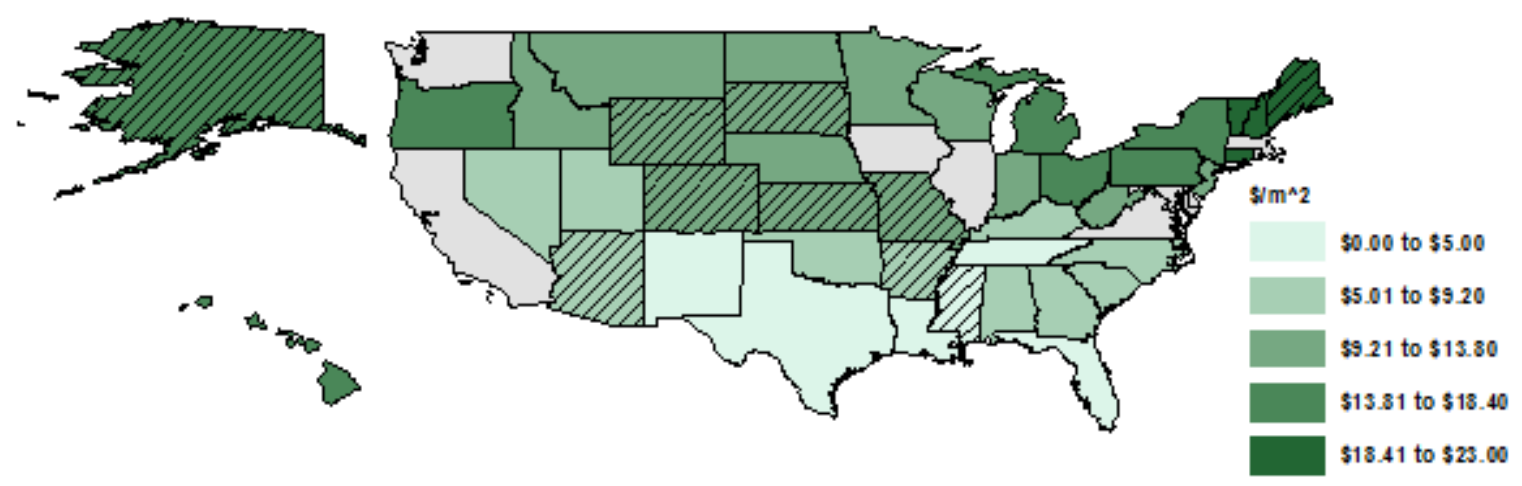

Figure 6-12 Life-Cycle Cost Savings per Unit of Floor Area by State (10-Year)

\subsubsection{Regional and National Savings per Unit of Floor Area}

Table 6-11 shows both the total energy savings and the energy savings per unit of floor area in each of the U.S. Census Regions for a 10-year study period. Total energy use is correlated with the total amount of newly constructed building floor area. Regions with the largest amounts of new CFA realize the largest reductions in annual energy use. This, however, is not the case when comparing average savings per $\mathrm{m}^{2}\left(\mathrm{ft}^{2}\right)$ with the total amount of newly constructed floor area. States located in the Midwest Census Region realize the largest reductions in energy use per unit of floor area, while the South Census Region realizes the least. Nationwide energy savings is approximately $30 \mathrm{kWh} / \mathrm{m}^{2}$ $\left(3 \mathrm{kWh} / \mathrm{ft}^{2}\right)$.

Table 6-11 Energy Use Reductions per Unit of Newly Constructed Floor Area from Adoption of the 2012 IECC by Census Region (10-Year Study Period)

\begin{tabular}{|c|c|c|c|c|}
\hline $\begin{array}{l}\text { Census } \\
\text { Region }\end{array}$ & $\begin{array}{c}\text { Total New CFA } \\
1000 \mathrm{~m}^{2}\left(1000 \mathrm{ft}^{2}\right)\end{array}$ & $\begin{array}{c}\text { Energy Use } \\
\text { (GWh) }\end{array}$ & $\mathrm{kWh} / \mathrm{m}^{2}$ & $\mathbf{k W h} / \mathbf{f t}^{2}$ \\
\hline Northeast & $5959(64$ 146) & 2793 & 469 & 44 \\
\hline Midwest & 12601 (135 631) & 6627 & 526 & 49 \\
\hline South & 49268 (529 922) & 10812 & 220 & 20 \\
\hline West & 12603 (135 657) & 4044 & 321 & 30 \\
\hline Total & 80394 (865 357) & 2428 & 302 & 28 \\
\hline
\end{tabular}


The energy cost savings per kWh of energy savings, electricity rates, natural gas rates, weighted average energy prices, and the percentage offset of natural gas are displayed in Table 6-12. The Northeast Census Region has both the highest average percentage of offset natural gas and average electricity price - realizing the third greatest reduction in energy cost per unit of energy saved behind the South and West Census Regions.

Conversely, the Midwest region has both the second lowest percentage of offset natural gas and electricity prices, and realizes the lowest level of energy cost savings per unit of energy saved with an average reduction of $\$ 0.03$ per $\mathrm{kWh}$.

\section{Table 6-12 Energy Cost Reduction per $\mathrm{kWh}$ of Energy Savings from Adoption of the 2012 IECC by Census Region (10-Year)}

\begin{tabular}{|c|c|c|c|c|c|}
\hline $\begin{array}{l}\text { Census } \\
\text { Region }\end{array}$ & $\begin{array}{l}\text { Offset* } \\
(\%)\end{array}$ & $\begin{array}{c}\text { Electricity Rate* } \\
(\$ / \mathbf{k W h})\end{array}$ & $\begin{array}{l}\text { Natural Gas Rate* } \\
\quad(\$ / \mathbf{k W h})\end{array}$ & $\begin{array}{l}\text { Weighted } \\
\text { Energy Price* } \\
(\$ / k W h)\end{array}$ & $\begin{array}{c}\text { Energy Cost } \\
\text { Reduction } \\
(\$ / \mathbf{k W h})\end{array}$ \\
\hline Northeast & 5.4 & 0.16 & 0.05 & 0.07 & 0.04 \\
\hline Midwest & 4.9 & 0.11 & 0.03 & 0.05 & 0.03 \\
\hline South & 5.1 & 0.10 & 0.04 & 0.07 & 0.05 \\
\hline West & 4.6 & 0.11 & 0.04 & 0.05 & 0.04 \\
\hline Total & 5.0 & 0.11 & 0.04 & 0.06 & 0.04 \\
\hline
\end{tabular}

Table 6-13 shows total life-cycle carbon emissions savings, the weighted average fraction of natural gas offset by changes in electricity use, and the emissions savings per GWh saved across the four Census Regions. Regions with higher natural gas offsets are likely to realize smaller reductions in life-cycle emissions per unit of energy savings. The Northeast Census Region on average has the highest percentage of offset natural gas and achieves the lowest reduction in life-cycle emissions per GWh saved. Meanwhile, the West Census Region realizes the second highest average reduction in emissions per unit of energy savings as a result of having the lowest percentage of offset natural gas. There does exist ambiguity in the relationship between emission reductions per GWh saved and natural gas offsets. For example, the South Census Region exhibits the highest level of life-cycle emissions reduced per GWh of energy reduced despite having the second highest percentage offset of natural gas. This ambiguity is due to the South's warm climate zones, which leads to greater electricity use to meet cooling loads and less natural gas use to meet heating loads. 


\begin{tabular}{|c|c|c|c|c|}
\hline $\begin{array}{l}\text { Census } \\
\text { Region }\end{array}$ & $\begin{array}{c}\text { Emissions } \\
\text { Reduction } \\
(1000 \text { tCO2e })\end{array}$ & $\begin{array}{c}\text { Offset* }^{*} \\
(\%)\end{array}$ & $\begin{array}{c}\text { Weighted Avg. } \\
\text { Electricity Emissions } \\
\text { Rate }\left(\mathrm{tCO}_{2} \mathrm{e} / \mathrm{MWh}\right)\end{array}$ & $\begin{array}{c}\mathrm{CO}_{2} \mathrm{e} \text { Reduction } \\
(\mathrm{t} / \mathrm{GWh})\end{array}$ \\
\hline Northeast & 820 & 5.4 & 620 & 29 \\
\hline Midwest & 2125 & 4.9 & 905 & 32 \\
\hline South & 4837 & 5.1 & 796 & 44 \\
\hline West & 1528 & 4.6 & 687 & 37 \\
\hline Total & 8738 & 5.0 & 788 & 38 \\
\hline
\end{tabular}

Average LCC savings (total and per unit of floor area) and fuel prices (electricity, natural gas, and weighted average) in the four Census Regions are shown in Table 6-14. There appears to be a direct relationship between the LCC savings and the level of energy savings per unit of floor area and regional electricity rates. Regions with greater energy use savings per unit of floor area and higher electricity rates tend to realize greater LCC savings per unit of floor area. The Northeast Region achieves the greatest reduction in LCC per unit of floor area, and has both the second largest reduction in energy use per unit of floor area and the highest average electricity price. Alternatively, the South Census Region achieves the smallest reduction in LCC. Its electricity rates are the lowest of all the regions and its energy savings per unit of floor area are the smallest. Those regions falling in the middle (Midwest and West) have the first and third largest reductions in energy use per unit of floor area, and an average electricity rate $\$ 0.11 / \mathrm{kWh}$. The national average LCC savings per unit of floor area is approximately $\$ 7.47 / \mathrm{m}^{2}$ $\left(\$ 0.69 / \mathrm{ft}^{2}\right)$. Other factors, such as local construction costs, will also have an impact on these regional LCC savings estimates. 
Table 6-14 Life-Cycle Cost Savings per Unit of Newly Constructed Floor Area from Adoption of the 2012 IECC by Census Region (10-Year Study Period)

\begin{tabular}{|c|c|c|c|c|c|c|c|}
\hline $\begin{array}{l}\text { Census } \\
\text { Region }\end{array}$ & $\begin{array}{l}\text { Energy Use } \\
\text { Savings } \\
\left(\mathbf{k W h} / \mathbf{m}^{2}\right)\end{array}$ & $\begin{array}{c}\text { Electricity Rate } \\
(\$ / \mathbf{k W h})^{*}\end{array}$ & $\begin{array}{c}\text { Natural Gas } \\
\text { Rate } \\
(\$ / \mathbf{k W h})^{*}\end{array}$ & $\begin{array}{c}\text { Weighted } \\
\text { Energy Price } \\
(\$ / k W h)^{*}\end{array}$ & $\begin{array}{c}\text { LCC } \\
\text { Savings } \\
\text { (\$million) }\end{array}$ & $\begin{array}{c}\text { LCC } \\
\text { Savings } \\
\left(\$ / \mathbf{m}^{2}\right)\end{array}$ & $\begin{array}{c}\text { LCC } \\
\text { Savings } \\
\left(\$ / \mathbf{f t}^{2}\right)\end{array}$ \\
\hline Northeast & 469 & 0.16 & 0.05 & 0.07 & 91 & 15.30 & 1.42 \\
\hline Midwest & 526 & 0.11 & 0.03 & 0.05 & 155 & 12.26 & 1.14 \\
\hline South & 220 & 0.10 & 0.04 & 0.07 & 241 & 4.90 & 0.45 \\
\hline West & 321 & 0.11 & 0.04 & 0.05 & 114 & 9.03 & 0.84 \\
\hline Total & 302 & 0.11 & 0.04 & 0.06 & 601 & 7.47 & 0.69 \\
\hline
\end{tabular}

*Weighted by energy use savings for a state 


\section{Discussion}

This study analyzes the impacts of adopting the latest, more stringent state energy codes based on the BIRDS new residential database for 10 prototypical building types (woodframed single-family detached buildings) in 228 U.S. locations. Results are summarized at the state, regional, and national levels. This section will discuss key findings, limitations of the research, and recommended directions for future research.

\subsection{Key Findings}

The key findings from this study are analyzed for each sustainability performance metric in terms of percentage change, total change, and change per unit of floor area.

\subsubsection{Percentage Changes}

Assuming a 10-year study period, nationwide adoption of 2012 IECC would lead to significant average percentage reductions in energy consumption $(19.2 \%)$, energy costs $(15.2 \%)$, life-cycle carbon emissions (11.2\%), and life-cycle costs (1.7\%). The percentage reductions in energy costs are smaller than the percentage reductions in energy consumption because the majority of the reductions are from natural gas, which is cheaper than electricity. The percentage reductions in life-cycle carbon emissions are much lower than the reductions in energy consumption because of two factors. First, the emissions rate is lower for natural gas than for electricity. Since most of the reductions in energy consumption are from natural gas, the emissions reductions are lower. Second, life-cycle carbon emissions include emissions from both the energy consumption of the building and the embodied emissions from the materials used in construction of the building. In order to reduce energy consumption, additional materials must be installed in the building, leading to higher embodied emissions that offset some of the energy-related carbon emissions reductions.

The estimated savings vary by building prototype, with 1-story houses realizing smaller savings than 2-story houses with approximately the same conditioned floor area. Two factors could be driving these differences. First, 2-story houses have more volume per

unit of floor area, which causes energy use to meet the heating and cooling loads to account for a greater fraction of total energy use. Second, the two-story houses have less window glazing per unit of wall area, which could lead to greater savings from changes in requirements for wall insulation. Similar results and interpretations occur for energy costs, life-cycle carbon emissions, and life-cycle costs.

The baseline code edition of IECC and climate zone of a location will impact the estimated savings from the adoption of 2012 IECC. On average, locations with older editions of IECC as their baseline code realize slightly greater reductions in energy use, energy costs, and life-cycle carbon emissions. Life-cycle cost savings are greatest for 
locations with 2003 IECC the baseline code, on average, followed by 2009 IECC. Although locations with older baseline codes realize greater reductions, on average, this trend does not hold at the climate zone level. In fact, locations with a baseline code of 2003 IECC lead to the greatest reductions in energy use, energy costs, and carbon emissions for only two of eight climate zones. This result may be driven by the change in climate zone definitions and the resulting changes in building requirements for locations in those climate zones. On average, the percentage reductions in energy use, energy costs, and life-cycle carbon emissions increase as the climate zone gets colder, with a small drop as the climate shifts from primarily cooling to primarily heating loads. Life-cycle cost reductions do not follow the same trend, with Zone 1 realizing greater life-cycle cost reductions than Zone 2, and Zone 6 realizing lower reductions than Zone 5. This deviation may be a result of the differences in the additional investment costs, on average, of meeting the 2012 IECC across climate zones. These same results hold at the state level, with states in colder climates realizing greater reductions in energy use, energy costs, and life-cycle carbon emissions. However, there is some variation in percentage reductions for energy costs and carbon emissions driven by variation in energy prices and electricity-related emissions rates, respectively.

\subsubsection{Total Changes}

Total changes are estimated by using the weighted average change per unit of new floor area and multiplying by the total new floor area for 2012 associated with the city's "county cluster." These cluster-level estimates are aggregated at the state, census region, and national level to determine the magnitude of the impact from nationwide adoption of 2012 IECC. The amount of new floor area constructed in a state is the key driver to the magnitude of the estimated reductions in energy use, energy costs, and life-cycle carbon emissions, with Texas and North Carolina realizing the greatest reductions while Alaska and Vermont realize the smallest reductions in energy use, energy costs, life-cycle carbon emissions, and life-cycle costs.

Similarly, census regions with more constructed new floor area realize greater reductions. The South Census Region realizes savings of 1.1 TWh of energy consumption, $\$ 513$ million in energy costs, 4.8 million $\mathrm{tCO}_{2} \mathrm{e}$ of life-cycle emissions, and $\$ 344$ million for one year's worth of construction for a 10-year study period. The smallest reductions are realized in the Northeast Census Region at $279 \mathrm{GWh}$ of energy consumption, $\$ 112$ million in energy costs, $820000 \mathrm{tCO}_{2} \mathrm{e}$ of life-cycle emissions, and \$106 million for one year's worth of construction for a 10-year study period. The impacts aggregated at the national level total 2.4 TWh of energy consumption, $\$ 993$ million in energy costs, 9.3 million $\mathrm{tCO}_{2} \mathrm{e}$ of life-cycle emissions, and \$601 million for one year's worth of construction for a 10-year study period. 


\subsubsection{Change per Unit of Floor Area}

After controlling for the amount of newly constructed floor area, the results are similar to the percentage change results. Energy savings per unit of floor area are driven primarily by climate zone. For example, states such as Alaska have the least amount of new construction, but achieve some of the most extensive reductions in energy use per $\mathrm{m}^{2}$ $\left(\mathrm{ft}^{2}\right)$. States with greater reductions in total energy use generally realize greater energy cost savings. Other factors such as energy prices and the fuel mix of the total reductions in energy use in a state also impact the magnitude of energy cost savings. Higher energy prices, greater proportions of energy use accounted for by electricity, and smaller shifts in consumption from natural gas to electricity lead to greater reductions in energy costs per unit of floor area. Similarly, higher emissions rates for electricity, greater proportions of energy use accounted for by electricity, and smaller shifts in consumption from natural gas to electricity lead to greater reductions in life-cycle carbon emissions per unit of floor area. Similar to energy use, life-cycle cost savings per unit of floor area are greater for states in colder climate zones.

Savings in energy use per unit of floor area are greater in the colder regions, with the Midwest realizing the greatest savings followed by the Northeast. The savings in energy costs per unit of floor area are greatest for the South Census Region while the savings are smallest for the Midwest. The South has the highest weighted average energy price and a high average offset while the Midwest has the lowest weighted average energy price and a lower offset. The South also realizes the greatest life-cycle carbon emissions savings per unit of floor area because of the region's high proportion of electricity consumption. The Northeast realizes the greatest life-cycle cost savings per unit of floor area while the South has the smallest life-cycle cost savings.

\subsection{Limitations and Future Research}

The analysis in this study is limited in scope and would be strengthened by including sensitivity analysis, expanding the BIRDS database and metrics, and allowing public access to all the results.

Uncertainty analysis is needed for at least three elements of the analysis. First, consider the assumed discount rate. Although $3 \%$ is a reasonable discount rate, in real terms, for federal government investment decisions, it may be too low of a value for an expected real return on an alternative investment in the private sector (Rushing et al. 2011). Sensitivity analysis on the assumed discount rate is needed to determine the robustness of the cost results. Second, the current analysis assumes that building cooling loads are met by equipment running on electricity while space and water heating loads are met by equipment running on natural gas, which is not the typical fuel mix for some areas of the nation. The database should be expanded to include alternative heating fuel source 
options, such as electricity in the South, because the results could be significantly impacted.

Additional data are needed to refine and expand the BIRDS database. The 10 prototypical single-family dwellings analyzed in this study may not be representative of the entire building stock because of the assumed simplicity of the building geometry. For this reason, the results should be considered as general magnitudes for making reasonable comparisons instead of precise quantitative analysis. Future research should include additional prototypes in the database. The state average energy cost rates do not control for local variation in energy tariffs. By using utility-level energy cost data as discussed in Kneifel and Butry (2014b), the accuracy of the estimates in BIRDS could be improved.

BIRDS currently assumes an adoption and enforcement (i.e., commissioning) rate of $100 \%$. Cort and Butner (2012) finds that local adoption of building energy codes varies across states. States with state energy codes have an average adoption rate of $88 \%$ (49\% to $100 \%$ ) while states without a state energy code have an average adoption rate of $52 \%$ ( $3 \%$ to $97 \%$ ). The granularity within each state should be considered to determine how it may impact the current estimates.

Taylor, Fernandez, and Lucas (2012) defines methodology to evaluate the cost-effectiveness of states adopting newer editions of IECC for residential buildings. The main difference between their methodologies and that used in this study is the home purchase financing approach (mortgage versus $100 \%$ cash).

Alternative assumptions should be considered for a number of factors, including foundation type and heating equipment fuel type. An additional building type should be added to the database to account for low-rise multifamily housing units (i.e., low-rise apartment building).

The analysis in this study ignores the impacts that variations in occupancy and behavior patterns, in terms of plug and process load use, thermostat setpoints, and number of occupants, and HVAC equipment efficiency have on the reductions in energy use. Homes with greater plug and process loads will realize smaller percentage changes in energy use because the energy efficiency measures considered in this study focus on the IECC requirements (building envelope and lighting) holding constant the efficiency of other equipment (HVAC equipment and appliances) used in the building and the number of occupants living in the building. Future research should consider the impact that improved equipment efficiency and occupant activity may have on the overall energy savings realized by energy efficiency improvements to buildings.

Analysis based on the energy performance is susceptible to the limitations of current whole building energy simulation models. As the underlying simulation software 
improves in accuracy and uncertainty, the sustainability analysis related to the modeling will improve as well.

Energy, environmental, and economic performance are but three attributes of building performance. The BIRDS model assumes that its building prototypes all meet minimum technical performance requirements. However, there may be significant differences in technical performance not evaluated in BIRDS, such as indoor environmental quality performance, which may affect energy, environmental, and economic considerations.

Finally, a more comprehensive analysis of the environmental performance could be completed. This study applies environmental life cycle assessment methods to estimate the reductions in life-cycle carbon emissions. The BIRDS database could be expanded to the full range of 11 life-cycle environmental impacts covering human health effects, ecological health effects, and resource depletion. 


\section{References}

ASTM International (2012). ASTM Standards on Building Economics: 7th Edition. West Conshohocken, PA, ASTM International.

Cort, K. and R. Butner (2012). An Analysis of Statewide Adoption Rates of Building Energy Code by Local Jurisdictions. Pacific Northwest National Laboratory (PNNL). Richland, WA.

Energy Independence and Security Act (EISA) of 2007, Pub. L. No. 110-140, 2007

Environmental Protection Agency (EPA) (2007). "2007 Emissions and Generation Integrated Database (eGRID2007)." from http://www.epa.gov/cleanenergy/energyresources/egrid/index.html.

Faithful+Gould (2011). Residential Energy Efficiency Measures: Location Factors, National Renewable Energy Laboratory.

Faithful+Gould (2012). Residential Energy Efficiency Measures: Prototype Estimate and Cost Data Revision 6.0, National Renewable Energy Laboratory.

Fuller, S. and S. Petersen (1996). "Life-Cycle Costing Manual for the Federal Energy Management program, 1995 Edition." NIST handbook 135.

Halverson, M., et al. (2011a). ANSI/ASHRAE/IESNA Standard 90.1-2007 Final Determination Quantitative Analysis. Pacific Northwest National Laboratory. Richland, WA.

Halverson, M., et al. (2011b). ANSI/ASHRAE/IESNA Standard 90.1-2010 Final Determination Quantitative Analysis. Pacific Northwest National Laboratory. Richland, WA.

Halverson, M., et al. (2014). ANSI/ASHRAE/IES Standard 90.1-2013 Preliminary Determination: Quantitative Analysis. Pacific Northwest National Laboratory. Richland, WA.

Kneifel, J. (2010). "Life-Cycle Carbon and Cost Analysis of Energy Efficiency Measures in New Commercial Buildings." Energy and Buildings 42(3): 333-340. 
Kneifel, J. (2011a). "Beyond the code: Energy, carbon, and cost savings using conventional technologies." Energy and Buildings 43(4): 951-959.

Kneifel, J. (2013a). "Benefits and Costs of Energy Standard Adoption in New Commercial Buildings." NIST Special Publication 1147.

Kneifel, J. (2013b). "Benefits and Costs of Energy Standard Adoption in New Commercial Buildings: Northeast Census Region." NIST Special Publication 1148-1.

Kneifel, J. (2013c). "Benefits and Costs of Energy Standard Adoption in New Commercial Buildings: Midwest Census Region." NIST Special Publication 1148-2.

Kneifel, J. (2013d). "Benefits and Costs of Energy Standard Adoption in New Commercial Buildings: South Census Region." NIST Special Publication 1148-3.

Kneifel, J. (2013e). "Benefits and Costs of Energy Standard Adoption in New Commercial Buildings: West Census Region." NIST Special Publication 1148-4.

Kneifel, J. (2013f). "Benefits and Costs of Energy Standard Adoption in New Commercial Buildings: National Summary." NIST Special Publication 1161.

Kneifel, J. and D. Butry (2014a). "Impact of More Precise Construction Data on Estimated Savings from Energy Standard Adoption for Commercial Buildings." NIST Special Publication 1178.

Lippiatt, B., et al. (2013). Building Industry Reporting and Design for Sustainability (BIRDS) Technical Manual and User Guide, NIST TN 1814. National Institute of Standards and Technology. Gaithersburg, MD.

Lucas, R., et al. (2012). National Energy and Cost Savings for New Single-and Multifamily Homes: A Comparison of the 2006, 2009, and 2012 Editions of the IECC. Pacific Northwest National Laboratory (PNNL). Richland, WA.

Mendon, V., et al. (2013). Cost-Effectiveness Analysis of the 2009 and 2012 IECC Residential Provisions: Technical Support Document. Pacific Northwest National Laboratory (PNNL). Richland, Washington. 
Mendon, V., et al. (2014). 2015 IECC Determination of Energy Savings: Preliminary Technical Analysis. Pacific Northwest National Laboratory (PNNL). Richland, WA.

National Association of Home Builders (NAHB) Research Center (2012a). Methodology for Calculating Energy Use in Residential Buildings. Upper Marlboro, MD, National Association of Homebuilders.

National Association of Home Builders (NAHB) Research Center (2012b). 2009 IECC Cost Effectiveness Analysis. Upper Marlboro, MD, National Association of Home Builders.

National Association of Home Builders (NAHB) Research Center (2012c). 2012 IECC Cost Effectiveness Analysis. Upper Marlboro, MD, National Association of Home Builders.

National Renewable Energy Laboratory (NREL) (2012). "U.S. Life-Cycle Inventory Database (LCI)." from http://www.nrel.gov/lci/.

NC Clean Energy Technology Center (2015). Database of State Incentives for Renewables and Efficiency (DSIRE): Rules, Regulations, and Policies for Energy Efficiency Database. 2010.

North American Electric Reliability Corporation (NERC) (2011). "Regional Entities." Retrieved December 2011, from http://www.nerc.com/AboutNERC/keyplayers/Pages/Regional-Entities.aspx.

Pacific Northwest National Laboratory (PNNL) (2009a). Impacts of Standard ASHRAE 90.1-2007 for Commercial Buildings at State Level. U.S. Department of Energy Building Energy Codes Program. Richland, WA.

Pacific Northwest National Laboratory (PNNL) (2009b). Impacts of the 2009 IECC for Residential Buildings at State Level. U.S. Department of Energy Building Energy Codes Program. Richland, WA.

RSMeans (2011). "CostWorks Databases." from http://www.meanscostworks.com/.

Rushing, A., et al. (2011). Energy Price Indices and Discount Factors for Life-Cycle Cost Analysis - 2011. Gaithersburg, MD, National Institute of Standards and Technology. 
Taylor, T., et al. (2012). Methodology for Evaluating Cost-Effectiveness of Residential Energy Code Changes. Pacific Northwest National Laboratory (PNNL). Richland, WA.

U.S. Census Bureau (2011). "American Housing Survey (AHS) for the United States, Series H-150, Complete Set of Tables and Standard Errors." from http://www.census.gov/programs-surveys/ahs/.

U.S. Census Bureau (2013). "Survey of Construction, Annual 2013 Characteristics of New Housing." from http://www.census.gov/construction/chars/.

U.S. Department of Energy (DOE) (2014). "Building Energy Codes Program, Status of State Energy Code Adoption." 2014, from http://www.energycodes.gov/adoption/states.

U.S. Department of Energy (DOE) (2015). "Building America Climate Region Map." Retrieved April 4, 2015, from http://energy.gov/eere/buildings/building-america-climatespecific-guidance.

U.S. Energy Information Administration (EIA) (2013a). "Electric Power Annual State Data Tables." 2013, from http://www.eia.doe.gov/fuelelectric.html.

U.S. Energy Information Administration (EIA) (2013b). "Natural Gas Navigator." 2013, from http://www.eia.doe.gov/oil_gas/natural_gas/info_glance/natural_gas.html. 
A Building Type, New Construction, and Emissions Rates

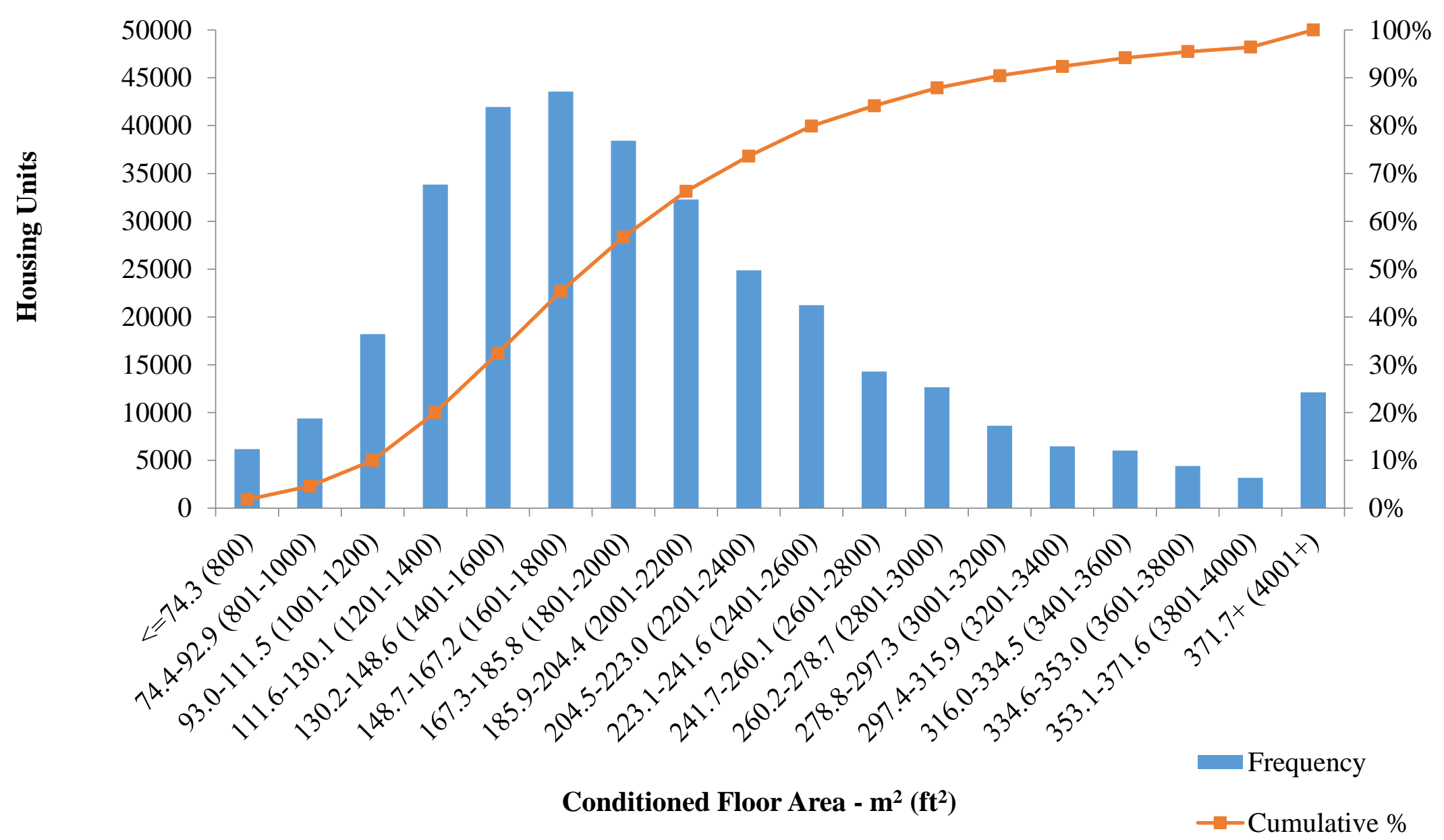

Figure A-1 Conditioned Floor Area of New 1-Story Single-Family Housing 


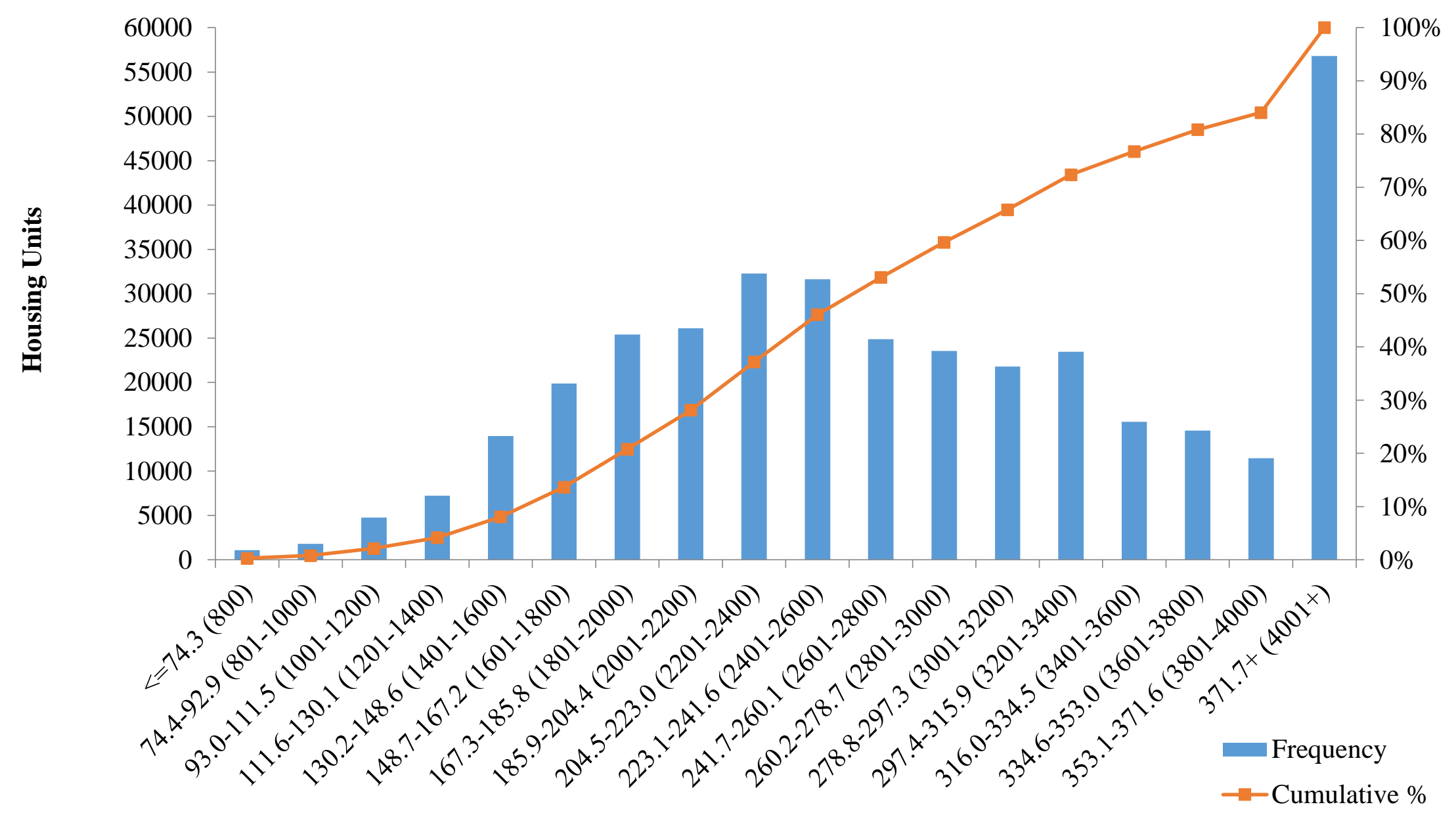

Conditioned Floor Area - $\mathbf{m}^{\mathbf{2}}\left(\mathbf{f t}^{\mathbf{2}}\right)$

Figure A-2 Conditioned Floor Area of New 2-Story Single-Family Housing 
Table A-1 $\mathrm{CO}_{2}, \mathrm{CH}_{4}$, and $\mathrm{N}_{2} \mathrm{O}$ Emissions Rates Electricity Generation by State

\begin{tabular}{|c|c|c|c|}
\hline State & $\begin{array}{l}\mathrm{CO}_{2} \\
(\mathrm{t} / \mathrm{GWh})\end{array}$ & $\begin{array}{l}\text { CH4 } \\
\text { (t/GWh) }\end{array}$ & $\begin{array}{l}\mathrm{N} 2 \mathrm{O} \\
(\mathrm{t} / \mathrm{GWh})\end{array}$ \\
\hline $\mathrm{AK}$ & 603.4 & 57.9 & 1.9 \\
\hline $\mathrm{AL}$ & 804.2 & 42.7 & 0.5 \\
\hline AR & 695.9 & 58.6 & 1.7 \\
\hline $\mathrm{AZ}$ & 746.9 & 53.2 & 1.2 \\
\hline $\mathrm{CA}$ & 450.0 & 45.8 & 1.5 \\
\hline $\mathrm{CO}$ & 938.8 & 54.0 & 0.8 \\
\hline $\mathrm{CT}$ & 550.4 & 47.0 & 1.4 \\
\hline $\mathrm{DE}$ & 618.7 & 33.4 & 0.4 \\
\hline FL & 767.5 & 57.2 & 1.5 \\
\hline GA & 804.2 & 42.7 & 0.5 \\
\hline HI & 807.1 & 28.0 & 0.1 \\
\hline IA & 851.1 & 40.4 & 0.2 \\
\hline ID & 465.6 & 27.6 & 0.4 \\
\hline IL & 948.3 & 44.4 & 0.2 \\
\hline IN & 835.7 & 38.9 & 0.2 \\
\hline $\mathrm{KS}$ & 926.0 & 44.8 & 0.3 \\
\hline KY & 781.9 & 36.9 & 0.2 \\
\hline LA & 719.2 & 59.2 & 1.6 \\
\hline MA & 550.4 & 47.0 & 1.4 \\
\hline MD & 618.7 & 33.4 & 0.4 \\
\hline $\mathrm{ME}$ & 550.4 & 47.0 & 1.4 \\
\hline MI & 861.4 & 46.8 & 0.6 \\
\hline $\mathrm{MN}$ & 851.1 & 40.4 & 0.2 \\
\hline MO & 939.4 & 44.6 & 0.2 \\
\hline MS & 709.8 & 48.3 & 1.0 \\
\hline
\end{tabular}

\begin{tabular}{|c|c|c|c|}
\hline State & $\begin{array}{l}\mathrm{CO}_{2} \\
(\mathrm{t} / \mathrm{GWh})\end{array}$ & $\begin{array}{l}\mathrm{CH} 4 \\
\text { (t/GWh) }\end{array}$ & $\begin{array}{l}\mathrm{N} 2 \mathrm{O} \\
(\mathrm{t} / \mathrm{GWh})\end{array}$ \\
\hline MT & 542.8 & 30.1 & 0.4 \\
\hline $\mathrm{NC}$ & 616.6 & 30.5 & 0.2 \\
\hline ND & 851.1 & 40.4 & 0.2 \\
\hline $\mathrm{NE}$ & 851.1 & 40.4 & 0.2 \\
\hline $\mathrm{NH}$ & 550.4 & 47.0 & 1.4 \\
\hline $\mathrm{NJ}$ & 618.7 & 33.4 & 0.4 \\
\hline NM & 778.5 & 55.3 & 1.3 \\
\hline $\mathrm{NV}$ & 465.6 & 27.6 & 0.4 \\
\hline NY & 480.7 & 32.3 & 0.8 \\
\hline $\mathrm{OH}$ & 835.7 & 38.9 & 0.2 \\
\hline OK & 904.8 & 63.9 & 1.4 \\
\hline OR & 465.6 & 27.6 & 0.4 \\
\hline $\mathrm{PA}$ & 672.9 & 34.7 & 0.4 \\
\hline RI & 550.4 & 47.0 & 1.4 \\
\hline $\mathrm{SC}$ & 616.6 & 30.5 & 0.2 \\
\hline SD & 851.1 & 40.4 & 0.2 \\
\hline $\mathrm{TN}$ & 781.9 & 36.9 & 0.2 \\
\hline $\mathrm{TX}$ & 790.9 & 65.8 & 1.8 \\
\hline UT & 465.6 & 27.6 & 0.4 \\
\hline VA & 689.6 & 33.3 & 0.2 \\
\hline VT & 550.4 & 47.0 & 1.4 \\
\hline WA & 465.6 & 27.6 & 0.4 \\
\hline WI & 860.7 & 44.1 & 0.4 \\
\hline WV & 835.7 & 38.9 & 0.2 \\
\hline WY & 623.7 & 36.4 & 0.5 \\
\hline
\end{tabular}




\section{B Percentage Changes by State for the Nationwide Adoption of the 2012 IECC}

Table B-1 Total Changes in Fuel Use and the Proportional Changes in Natural Gas Use Relative to 2012 IECC

\begin{tabular}{|c|c|c|c|}
\hline State & $\begin{array}{c}\text { Total Change in } \\
\text { Electricity Use }(\mathrm{kWh})\end{array}$ & $\begin{array}{l}\text { Total Change in Natural } \\
\text { Gas Use }(\mathrm{kWh})\end{array}$ & $\begin{array}{c}\text { Proportional Change in } \\
\text { Natural Gas Use Relative } \\
\text { to } 2012(\%)\end{array}$ \\
\hline \multicolumn{4}{|c|}{ Baseline Code - 2003} \\
\hline AK & 518,722 & $11,831,124$ & $-2.7 \%$ \\
\hline $\mathbf{A R}$ & 330,639 & $1,269,709$ & $-4.7 \%$ \\
\hline $\mathbf{A Z}$ & 921,722 & $2,449,190$ & $-3.2 \%$ \\
\hline CO & 434,222 & $5,158,645$ & $-4.6 \%$ \\
\hline KS & 356,833 & $3,769,208$ & $-5.9 \%$ \\
\hline ME & 151,444 & $2,725,539$ & $-4.0 \%$ \\
\hline MO & 352,250 & $3,373,408$ & $-6.0 \%$ \\
\hline MS & 321,417 & 920,328 & $-4.9 \%$ \\
\hline SD & 256,861 & $3,889,825$ & $-4.5 \%$ \\
\hline WY & 373,750 & $5,252,095$ & $-4.3 \%$ \\
\hline \multicolumn{4}{|c|}{ Baseline Code - 2006} \\
\hline HI & 289,250 & 167 & $1.5 \%$ \\
\hline LA & 581,167 & 892,549 & $-2.1 \%$ \\
\hline MN & 419,833 & $7,687,868$ & $-4.0 \%$ \\
\hline OK & 346,083 & $1,646,174$ & $-5.0 \%$ \\
\hline $\mathbf{T N}$ & 551,861 & $3,424,105$ & $-6.5 \%$ \\
\hline WI & 424,472 & $6,652,033$ & $-4.6 \%$ \\
\hline \multicolumn{4}{|c|}{ Baseline Code - 2009} \\
\hline $\mathbf{A L}$ & 404,083 & $1,772,320$ & $-5.4 \%$ \\
\hline CT & 96,194 & $1,938,468$ & $-5.5 \%$ \\
\hline FL & 661,222 & 459,970 & $-0.9 \%$ \\
\hline GA & 645,139 & $2,640,729$ & $-5.4 \%$ \\
\hline ID & 153,694 & $2,568,780$ & $-4.9 \%$ \\
\hline IN & 253,778 & $4,004,026$ & $-5.6 \%$ \\
\hline KY & 204,889 & $2,679,536$ & $-6.6 \%$ \\
\hline MI & 500,139 & $11,002,912$ & $-4.6 \%$ \\
\hline MT & 531,083 & $10,693,172$ & $-4.6 \%$ \\
\hline $\mathrm{NC}$ & 520,694 & $3,689,814$ & $-6.8 \%$ \\
\hline ND & 190,500 & $4,477,969$ & $-4.3 \%$ \\
\hline NE & 324,500 & $5,575,752$ & $-5.2 \%$ \\
\hline NH & 56,222 & $1,103,394$ & $-4.7 \%$ \\
\hline $\mathbf{N J}$ & 139,278 & $2,040,696$ & $-6.7 \%$ \\
\hline NM & 261,694 & $1,912,633$ & $-6.2 \%$ \\
\hline NV & 435,306 & $4,635,394$ & $-4.7 \%$ \\
\hline NY & 387,278 & $8,112,725$ & $-5.2 \%$ \\
\hline OH & 310,750 & $6,284,263$ & $-5.2 \%$ \\
\hline OR & 402,167 & $7,453,577$ & $-5.2 \%$ \\
\hline PA & 418,278 & $7,850,294$ & $-5.3 \%$ \\
\hline SC & 333,917 & $1,463,581$ & $-5.8 \%$ \\
\hline TX & $2,047,444$ & $6,191,258$ & $-4.4 \%$ \\
\hline UT & 104,528 & $1,495,999$ & $-5.1 \%$ \\
\hline VT & 55,944 & $1,223,484$ & $-4.8 \%$ \\
\hline $\mathbf{W V}$ & 178,333 & $2,522,417$ & $-5.9 \%$ \\
\hline
\end{tabular}


Table B-2 Summary of Average Savings in Energy Use, Energy Costs, Carbon Emissions, and Life-Cycle Costs for all U.S. States (10-Year)

\begin{tabular}{|c|c|c|c|c|c|}
\hline \multirow{2}{*}{ State } & \multirow{2}{*}{ Code } & \multicolumn{4}{|c|}{ Percentage Change } \\
\hline & & Energy Use & Energy Costs & Emissions & LCC \\
\hline $\mathbf{A K}$ & 2003 & $-37.2 \%$ & $-17.1 \%$ & $-14.3 \%$ & $-2.5 \%$ \\
\hline $\mathbf{A L}$ & 2003 & $-13.2 \%$ & $-16.7 \%$ & $-11.3 \%$ & $-2.0 \%$ \\
\hline $\mathbf{A R}$ & 2003 & $-23.6 \%$ & $-20.3 \%$ & $-14.0 \%$ & $-1.7 \%$ \\
\hline $\mathbf{A Z}$ & 2003 & $-17.4 \%$ & $-17.0 \%$ & $-11.7 \%$ & $-1.8 \%$ \\
\hline CO & 2003 & $-23.0 \%$ & $-16.5 \%$ & $-13.5 \%$ & $-2.3 \%$ \\
\hline CT & 2003 & $-24.4 \%$ & $-16.8 \%$ & $-15.3 \%$ & $-3.6 \%$ \\
\hline FL & 2003 & $-10.8 \%$ & $-8.2 \%$ & $-7.5 \%$ & $-0.8 \%$ \\
\hline GA & 2003 & $-21.1 \%$ & $-16.7 \%$ & $-11.2 \%$ & $-1.8 \%$ \\
\hline HI & 2003 & $-3.4 \%$ & $-9.3 \%$ & $-6.1 \%$ & $-2.4 \%$ \\
\hline ID & 2003 & $-54.9 \%$ & $-17.3 \%$ & $-12.5 \%$ & $-2.4 \%$ \\
\hline IN & 2006 & $-24.3 \%$ & $-17.4 \%$ & $-13.3 \%$ & $-2.7 \%$ \\
\hline $\mathbf{K S}$ & 2006 & $-24.6 \%$ & $-17.8 \%$ & $-13.5 \%$ & $-2.4 \%$ \\
\hline KY & 2006 & $-17.6 \%$ & $-18.9 \%$ & $-11.1 \%$ & $-1.9 \%$ \\
\hline $\mathbf{L A}$ & 2006 & $-12.8 \%$ & $-12.8 \%$ & $-9.3 \%$ & $-0.1 \%$ \\
\hline ME & 2006 & $-26.0 \%$ & $-20.6 \%$ & $-14.9 \%$ & $-4.2 \%$ \\
\hline MI & 2006 & $-18.7 \%$ & $-17.1 \%$ & $-14.5 \%$ & $-3.5 \%$ \\
\hline MN & 2009 & $-26.3 \%$ & $-19.9 \%$ & $-16.6 \%$ & $-1.9 \%$ \\
\hline MO & 2009 & $-24.0 \%$ & $-18.8 \%$ & $-13.4 \%$ & $-2.3 \%$ \\
\hline MS & 2009 & $-22.3 \%$ & $-18.2 \%$ & $-14.1 \%$ & $-1.0 \%$ \\
\hline MT & 2009 & $-10.6 \%$ & $-18.7 \%$ & $-16.1 \%$ & $-2.5 \%$ \\
\hline $\mathrm{NC}$ & 2009 & $-20.7 \%$ & $-17.8 \%$ & $-10.8 \%$ & $-1.9 \%$ \\
\hline ND & 2009 & $-26.1 \%$ & $-20.3 \%$ & $-16.9 \%$ & $-3.1 \%$ \\
\hline NE & 2009 & $-24.2 \%$ & $-17.8 \%$ & $-15.2 \%$ & $-3.1 \%$ \\
\hline NH & 2009 & $-25.4 \%$ & $-19.3 \%$ & $-16.6 \%$ & $-4.1 \%$ \\
\hline NJ & 2009 & $-27.5 \%$ & $-19.2 \%$ & $-13.4 \%$ & $-2.4 \%$ \\
\hline $\mathbf{N M}$ & 2009 & $-54.3 \%$ & $-16.3 \%$ & $-11.2 \%$ & $-1.1 \%$ \\
\hline NV & 2009 & $-21.5 \%$ & $-17.3 \%$ & $-12.7 \%$ & $-1.3 \%$ \\
\hline NY & 2009 & $-26.2 \%$ & $-18.6 \%$ & $-15.1 \%$ & $-3.9 \%$ \\
\hline $\mathbf{O H}$ & 2009 & $-23.1 \%$ & $-16.6 \%$ & $-13.3 \%$ & $-3.2 \%$ \\
\hline OK & 2009 & $-52.8 \%$ & $-22.0 \%$ & $-16.6 \%$ & $-1.8 \%$ \\
\hline OR & 2009 & $-19.8 \%$ & $-20.2 \%$ & $-15.5 \%$ & $-3.7 \%$ \\
\hline $\mathbf{P A}$ & 2009 & $-24.2 \%$ & $-18.0 \%$ & $-13.8 \%$ & $-3.0 \%$ \\
\hline SC & 2009 & $-33.2 \%$ & $-16.7 \%$ & $-11.5 \%$ & $-1.7 \%$ \\
\hline SD & 2009 & $-25.8 \%$ & $-20.0 \%$ & $-14.3 \%$ & $-3.0 \%$ \\
\hline $\mathbf{T N}$ & 2009 & $-20.7 \%$ & $-18.7 \%$ & $-11.4 \%$ & $-0.9 \%$ \\
\hline $\mathbf{T X}$ & 2009 & $-14.8 \%$ & $-12.0 \%$ & $-9.8 \%$ & $-1.2 \%$ \\
\hline UT & 2009 & $-26.0 \%$ & $-15.6 \%$ & $-13.5 \%$ & $-2.3 \%$ \\
\hline VT & 2009 & $-26.5 \%$ & $-21.1 \%$ & $-17.1 \%$ & $-5.2 \%$ \\
\hline WI & 2009 & $-26.6 \%$ & $-19.5 \%$ & $-16.8 \%$ & $-2.5 \%$ \\
\hline WV & 2009 & $-33.5 \%$ & $-18.5 \%$ & $-11.6 \%$ & $-2.2 \%$ \\
\hline WY & 2009 & $-21.5 \%$ & $-19.6 \%$ & $-13.7 \%$ & $-2.5 \%$ \\
\hline
\end{tabular}




\section{Total Changes from the Nationwide Adoption of the 2012 IECC}

Table C-1 Total Reductions by State from Adoption of the 2012 IECC (10-Year)

\begin{tabular}{|c|c|c|c|c|c|c|}
\hline State & Code & $\begin{array}{c}\text { Average Annual New Floor Area } \\
\qquad 1000 \mathrm{~m}^{2}\left(1000 \mathrm{ft}^{2}\right)\end{array}$ & $\begin{array}{c}\text { Energy Use } \\
\text { (million kWh) }\end{array}$ & $\begin{array}{l}\text { Energy Costs } \\
\text { (\$million) }\end{array}$ & $\begin{array}{c}\text { Emissions } \\
\left(1000 \mathrm{tCO}_{2} \mathrm{e}\right)\end{array}$ & $\begin{array}{c}\text { LCC } \\
\text { (\$million) }\end{array}$ \\
\hline TX & 2009 & 15189 & 2607 & 129 & 1424.4 & 69.3 \\
\hline FL & 2009 & 8264 & 620 & 48.8 & 545.4 & 26.3 \\
\hline $\mathrm{NC}$ & 2009 & 6346 & 1893 & 83 & 659.6 & 42.9 \\
\hline GA & 2009 & 3419 & 880 & 45.7 & 358.9 & 24.3 \\
\hline $\mathbf{A Z}$ & 2003 & 3345 & 642 & 46.3 & 355.3 & 23.8 \\
\hline TN & 2006 & 2962 & 1042 & 39.3 & 328.9 & 9.2 \\
\hline SC & 2009 & 2895 & 749 & 35.8 & 276.4 & 16.8 \\
\hline LA & 2006 & 2280 & 351 & 18 & 191.7 & -0.1 \\
\hline CO & 2003 & 2267 & 917 & 26.6 & 332.8 & 21.3 \\
\hline $\mathbf{A L}$ & 2009 & 2260 & 578 & 31 & 217.0 & 17.6 \\
\hline PA & 2009 & 2036 & 838 & 32.8 & 264.6 & 28.3 \\
\hline $\mathbf{O H}$ & 2009 & 1845 & 840 & 27.3 & 274.1 & 26.6 \\
\hline MO & 2003 & 1820 & 749 & 28.6 & 252.5 & 18.3 \\
\hline IN & 2009 & 1800 & 850 & 24.8 & 272.2 & 20.9 \\
\hline OK & 2006 & 1719 & 757 & 29.7 & 325.2 & 11.1 \\
\hline MI & 2009 & 1647 & 900 & 28.6 & 285.0 & 26.7 \\
\hline UT & 2009 & 1647 & 576 & 16.1 & 193.3 & 15 \\
\hline MN & 2006 & 1504 & 1017 & 27.9 & 320.4 & 14.5 \\
\hline NV & 2009 & 1457 & 398 & 19.1 & 157.7 & 8.6 \\
\hline NY & 2009 & 1428 & 741 & 27.5 & 202.3 & 23.5 \\
\hline WI & 2006 & 1345 & 836 & 26.9 & 278.1 & 16 \\
\hline $\mathbf{A R}$ & 2003 & 1256 & 437 & 18.3 & 173.2 & 7.8 \\
\hline MS & 2003 & 1187 & 323 & 14.2 & 172.4 & 4.2 \\
\hline NJ & 2009 & 1181 & 560 & 23.1 & 155.4 & 14.4 \\
\hline OR & 2009 & 1180 & 539 & 21 & 170.0 & 20.2 \\
\hline KY & 2009 & 1152 & 455 & 15.7 & 127.4 & 8.7 \\
\hline ID & 2009 & 1010 & 387 & 10.9 & 138.2 & 9.8 \\
\hline NE & 2009 & 810 & 405 & 11.3 & 128.8 & 10.7 \\
\hline ND & 2009 & 706 & 476 & 11.6 & 132.2 & 9.2 \\
\hline KS & 2003 & 698 & 298 & 10 & 108.0 & 6.6 \\
\hline NM & 2009 & 645 & 203 & 7 & 56.4 & 2.7 \\
\hline ME & 2003 & 451 & 240 & 10.5 & 64.3 & 8.5 \\
\hline CT & 2009 & 435 & 190 & 8.2 & 61.2 & 8 \\
\hline SD & 2003 & 425 & 256 & 7 & 73.7 & 5 \\
\hline HI & 2006 & 358 & 230 & 7.2 & 19.4 & 5.1 \\
\hline WY & 2003 & 343 & 170 & 4.9 & 46.9 & 3.2 \\
\hline NH & 2009 & 306 & 155 & 6.8 & 50.4 & 5.7 \\
\hline WV & 2009 & 302 & 119 & 4.2 & 36.8 & 2.9 \\
\hline MT & 2009 & 275 & 138 & 3.9 & 44.5 & 2.9 \\
\hline VT & 2009 & 123 & 69 & 3.3 & 22.0 & 2.8 \\
\hline AK & 2003 & 76 & 50 & 1.6 & 13.8 & 1.1 \\
\hline
\end{tabular}




\section{Savings per Unit of Floor Area from the Nationwide Adoption of the 2012 IECC}

Table D-1 Savings in Energy Use per Unit of Floor Area from Adoption of the 2012 IECC (10-Year)

\begin{tabular}{|c|c|c|c|c|c|}
\hline State & Climte Zone(s) & $\begin{array}{l}\text { Average Annual New Floor Area } \\
\qquad 1000 \mathrm{~m}^{2}\left(1000 \mathrm{ft}^{2}\right)\end{array}$ & $\begin{array}{l}\text { Energy Savings } \\
\text { (GWh) }\end{array}$ & $\mathbf{k W h} / \mathbf{m}^{2}$ & $k W h / f^{2}$ \\
\hline $\mathrm{MN}$ & 6,7 & 1504 (16 191) & 1017 & 675.9 & 62.8 \\
\hline ND & 6,7 & 706 (7599) & 476 & 674.3 & 62.6 \\
\hline $\mathrm{AK}$ & 7,8 & $76(822)$ & 50 & 649.1 & 60.3 \\
\hline WI & 6 & $1345(14479)$ & 836 & 621.8 & 57.8 \\
\hline SD & 6 & 443 (4766) & 256 & 603.2 & 56.0 \\
\hline VT & 6 & $123(1322)$ & 69 & 560.7 & 52.1 \\
\hline MI & $5,6,7$ & $1647(17731)$ & 900 & 546.1 & 50.7 \\
\hline ME & 6,7 & $452(4862)$ & 240 & 532.7 & 49.5 \\
\hline NY & 5,6 & 1428 (15 374) & 741 & 518.9 & 48.2 \\
\hline $\mathrm{NH}$ & 6 & $306(3291)$ & 155 & 508.5 & 47.2 \\
\hline MT & 6 & $275(2960)$ & 138 & 503.1 & 46.7 \\
\hline $\mathrm{NE}$ & 5 & $810(8715)$ & 405 & 500.8 & 46.5 \\
\hline WY & 6 & $343(3696)$ & 170 & 496.6 & 46.1 \\
\hline NJ & 4 & $1181(12707)$ & 560 & 474.1 & 44.0 \\
\hline IN & 4,5 & $1800(19380)$ & 850 & 472.1 & 43.9 \\
\hline OR & 4,5 & $1180(12706)$ & 539 & 456.6 & 42.4 \\
\hline $\mathrm{OH}$ & 5 & $1845(19858)$ & 840 & 455.3 & 42.3 \\
\hline OK & 3 & $1719(18506)$ & 757 & 440.5 & 40.9 \\
\hline $\mathrm{CT}$ & 5 & 435 (4683) & 190 & 435.8 & 40.5 \\
\hline $\mathrm{KS}$ & 4,5 & $698(7513)$ & 298 & 426.4 & 39.6 \\
\hline PA & $4,5,6$ & $2036(21911)$ & 838 & 411.8 & 38.3 \\
\hline MO & 4 & $1820(19588)$ & 749 & 411.5 & 38.2 \\
\hline $\mathrm{CO}$ & 5,6 & $2267(24396)$ & 917 & 404.8 & 37.6 \\
\hline KY & 4 & $1152(12405)$ & 455 & 395.2 & 36.7 \\
\hline WV & 4,5 & 302 (3249) & 119 & 394.5 & 36.7 \\
\hline ID & 5,6 & $1010(10872)$ & 387 & 383.0 & 35.6 \\
\hline $\mathrm{TN}$ & 3,4 & $2962(31879)$ & 1042 & 351.9 & 32.7 \\
\hline UT & 5 & $1647(17728)$ & 576 & 349.6 & 32.5 \\
\hline $\mathrm{AR}$ & 3 & $1256(13515)$ & 437 & 348.1 & 32.3 \\
\hline NM & 3,4 & 645 (6942) & 203 & 314.3 & 29.2 \\
\hline $\mathrm{NC}$ & 3,4 & $6346(68311)$ & 1893 & 298.3 & 27.7 \\
\hline NV & 3 & $1457(15678)$ & 398 & 273.2 & 25.4 \\
\hline MS & 3 & $1187(12775)$ & 323 & 272.4 & 25.3 \\
\hline $\mathrm{SC}$ & 3 & 2895 (31 159) & 749 & 258.6 & 24.0 \\
\hline GA & 2,3 & $3419(36807)$ & 880 & 257.4 & 23.9 \\
\hline $\mathrm{AL}$ & 2,3 & $2260(24324)$ & 578 & 255.9 & 23.8 \\
\hline $\mathrm{AZ}$ & 4,5 & $3345(36001)$ & 642 & 192.0 & 17.8 \\
\hline TX & $2,3,4$ & $15189(163491)$ & 2607 & 171.6 & 15.9 \\
\hline LA & 2,3 & $2280(24545)$ & 351 & 153.9 & 14.3 \\
\hline FL & 1,2 & 8264 (88 955) & 620 & 75.1 & 7.0 \\
\hline $\mathrm{HI}$ & 1 & $358(3855)$ & 23 & 65.4 & 6.1 \\
\hline
\end{tabular}


Table D-2 Reduction in Energy Costs per MWh of Reduced Energy Use from Adoption of the 2012 IECC (10-Year)

\begin{tabular}{|c|c|c|c|c|c|c|c|}
\hline State & $\begin{array}{c}\text { Electricity } \\
\text { Rate } \\
(\$ / \mathbf{k W h})\end{array}$ & $\begin{array}{c}\text { Natural Gas } \\
\text { Rate }(\$ / k W h)\end{array}$ & $\begin{array}{c}\text { Price } \\
\text { Differential } \\
(\$ / k W h)\end{array}$ & $\begin{array}{c}\text { Weighted } \\
\text { Energy Price } \\
(\$ / \mathbf{k W h})\end{array}$ & $\begin{array}{c}\text { Change in } \\
\text { Electricity Use }\end{array}$ & $\begin{array}{l}\text { Change in } \\
\text { Natural } \\
\text { Gas Use }\end{array}$ & $\begin{array}{l}\text { Energy Cost } \\
\text { Reduction } \\
\text { (\$/MWh) }\end{array}$ \\
\hline HI & $\$ 0.35$ & $\$ 0.19$ & $\$ 0.16$ & $\$ 0.32$ & 289,250 & 167 & $\$ 305$ \\
\hline FL & $\$ 0.12$ & $\$ 0.06$ & $\$ 0.05$ & $\$ 0.10$ & 661,222 & 459,970 & $\$ 79$ \\
\hline $\mathbf{A Z}$ & $\$ 0.11$ & $\$ 0.05$ & $\$ 0.06$ & $\$ 0.08$ & 921,722 & $2,449,190$ & $\$ 72$ \\
\hline $\mathbf{A L}$ & $\$ 0.11$ & $\$ 0.05$ & $\$ 0.06$ & $\$ 0.08$ & 404,083 & $1,772,320$ & $\$ 54$ \\
\hline GA & $\$ 0.11$ & $\$ 0.05$ & $\$ 0.06$ & $\$ 0.07$ & 645,139 & $2,640,729$ & $\$ 52$ \\
\hline $\mathbf{L A}$ & $\$ 0.09$ & $\$ 0.04$ & $\$ 0.05$ & $\$ 0.06$ & 581,167 & 892,549 & $\$ 51$ \\
\hline VT & $\$ 0.16$ & $\$ 0.06$ & $\$ 0.11$ & $\$ 0.07$ & 55,944 & $1,223,484$ & $\$ 48$ \\
\hline $\mathbf{T X}$ & $\$ 0.11$ & $\$ 0.04$ & $\$ 0.08$ & $\$ 0.07$ & $2,047,444$ & $6,191,258$ & $\$ 49$ \\
\hline SC & $\$ 0.11$ & $\$ 0.04$ & $\$ 0.07$ & $\$ 0.07$ & 333,917 & $1,463,581$ & $\$ 48$ \\
\hline NV & $\$ 0.12$ & $\$ 0.04$ & $\$ 0.08$ & $\$ 0.06$ & 435,306 & $4,635,394$ & $\$ 48$ \\
\hline NH & $\$ 0.17$ & $\$ 0.05$ & $\$ 0.12$ & $\$ 0.07$ & 56,222 & $1,103,394$ & $\$ 44$ \\
\hline $\mathrm{NC}$ & $\$ 0.10$ & $\$ 0.04$ & $\$ 0.06$ & $\$ 0.06$ & 520,694 & $3,689,814$ & $\$ 44$ \\
\hline ME & $\$ 0.15$ & $\$ 0.05$ & $\$ 0.11$ & $\$ 0.07$ & 151,444 & $2,725,539$ & $\$ 44$ \\
\hline CT & $\$ 0.18$ & $\$ 0.05$ & $\$ 0.13$ & $\$ 0.07$ & 96,194 & $1,938,468$ & $\$ 43$ \\
\hline $\mathbf{N Y}$ & $\$ 0.18$ & $\$ 0.05$ & $\$ 0.14$ & $\$ 0.07$ & 387,278 & $8,112,725$ & $\$ 37$ \\
\hline MS & $\$ 0.10$ & $\$ 0.03$ & $\$ 0.07$ & $\$ 0.06$ & 321,417 & 920,328 & $\$ 44$ \\
\hline $\mathbf{N J}$ & $\$ 0.16$ & $\$ 0.04$ & $\$ 0.12$ & $\$ 0.07$ & 139,278 & $2,040,696$ & $\$ 41$ \\
\hline $\mathbf{A R}$ & $\$ 0.09$ & $\$ 0.04$ & $\$ 0.05$ & $\$ 0.06$ & 330,639 & $1,269,709$ & $\$ 42$ \\
\hline PA & $\$ 0.13$ & $\$ 0.04$ & $\$ 0.09$ & $\$ 0.06$ & 418,278 & $7,850,294$ & $\$ 39$ \\
\hline OK & $\$ 0.09$ & $\$ 0.04$ & $\$ 0.06$ & $\$ 0.05$ & 346,083 & $1,646,174$ & $\$ 39$ \\
\hline OR & $\$ 0.10$ & $\$ 0.04$ & $\$ 0.05$ & $\$ 0.06$ & 402,167 & $7,453,577$ & $\$ 39$ \\
\hline MO & $\$ 0.10$ & $\$ 0.04$ & $\$ 0.06$ & $\$ 0.06$ & 352,250 & $3,373,408$ & $\$ 38$ \\
\hline TN & $\$ 0.10$ & $\$ 0.03$ & $\$ 0.07$ & $\$ 0.06$ & 551,861 & $3,424,105$ & $\$ 38$ \\
\hline WV & $\$ 0.09$ & $\$ 0.04$ & $\$ 0.06$ & $\$ 0.05$ & 178,333 & $2,522,417$ & $\$ 35$ \\
\hline KY & $\$ 0.09$ & $\$ 0.04$ & $\$ 0.06$ & $\$ 0.05$ & 204,889 & $2,679,536$ & $\$ 35$ \\
\hline NM & $\$ 0.11$ & $\$ 0.03$ & $\$ 0.08$ & $\$ 0.06$ & 261,694 & $1,912,633$ & $\$ 35$ \\
\hline KS & $\$ 0.11$ & $\$ 0.03$ & $\$ 0.07$ & $\$ 0.05$ & 356,833 & $3,769,208$ & $\$ 34$ \\
\hline $\mathbf{O H}$ & $\$ 0.11$ & $\$ 0.04$ & $\$ 0.08$ & $\$ 0.05$ & 310,750 & $6,284,263$ & $\$ 32$ \\
\hline MI & $\$ 0.13$ & $\$ 0.04$ & $\$ 0.10$ & $\$ 0.05$ & 500,139 & $11,002,912$ & $\$ 32$ \\
\hline WI & $\$ 0.13$ & $\$ 0.03$ & $\$ 0.10$ & $\$ 0.05$ & 424,472 & $6,652,033$ & $\$ 32$ \\
\hline $\mathbf{A K}$ & $\$ 0.18$ & $\$ 0.03$ & $\$ 0.15$ & $\$ 0.05$ & 518,722 & $11,831,124$ & $\$ 32$ \\
\hline IN & $\$ 0.10$ & $\$ 0.03$ & $\$ 0.07$ & $\$ 0.05$ & 253,778 & $4,004,026$ & $\$ 29$ \\
\hline $\mathrm{CO}$ & $\$ 0.11$ & $\$ 0.03$ & $\$ 0.09$ & $\$ 0.05$ & 434,222 & $5,158,645$ & $\$ 29$ \\
\hline WY & $\$ 0.09$ & $\$ 0.03$ & $\$ 0.06$ & $\$ 0.04$ & 373,750 & $5,252,095$ & $\$ 28$ \\
\hline MT & $\$ 0.10$ & $\$ 0.03$ & $\$ 0.07$ & $\$ 0.04$ & 531,083 & $10,693,172$ & $\$ 28$ \\
\hline $\mathbf{N E}$ & $\$ 0.09$ & $\$ 0.03$ & $\$ 0.06$ & $\$ 0.04$ & 324,500 & $5,575,752$ & $\$ 28$ \\
\hline ID & $\$ 0.08$ & $\$ 0.03$ & $\$ 0.05$ & $\$ 0.04$ & 153,694 & $2,568,780$ & $\$ 28$ \\
\hline UT & $\$ 0.09$ & $\$ 0.03$ & $\$ 0.06$ & $\$ 0.04$ & 104,528 & $1,495,999$ & $\$ 28$ \\
\hline MN & $\$ 0.11$ & $\$ 0.03$ & $\$ 0.08$ & $\$ 0.04$ & 419,833 & $7,687,868$ & $\$ 27$ \\
\hline SD & $\$ 0.09$ & $\$ 0.03$ & $\$ 0.06$ & $\$ 0.04$ & 256,861 & $3,889,825$ & $\$ 27$ \\
\hline ND & $\$ 0.09$ & $\$ 0.03$ & $\$ 0.06$ & $\$ 0.04$ & 190,500 & $4,477,969$ & $\$ 24$ \\
\hline
\end{tabular}


Table D-3 Reduction in Total Carbon Emissions per Unit of Floor Area from Adoption of the 2012 IECC (10-Year)

\begin{tabular}{|c|c|c|c|c|c|c|}
\hline State & $1000 \mathrm{tCO}_{2} \mathrm{e}$ & $\mathrm{kg} \mathrm{CO}{ }_{2} \mathrm{e} / \mathrm{m}^{2}$ & $\mathrm{~kg} \mathrm{CO} \mathrm{e}_{2} / \mathrm{ft}^{2}$ & $\mathrm{tCO}_{2} \mathrm{e} / \mathrm{MWh}$ & $\begin{array}{c}\text { Baseline Prop. } \\
\text { Nat. Gas }\end{array}$ & Offset (\%) \\
\hline FL & 542.9 & 6.1 & 65.7 & 0.88 & $30.80 \%$ & $-0.90 \%$ \\
\hline HI & 9.3 & 2.4 & 26 & 0.83 & $16.40 \%$ & $1.50 \%$ \\
\hline $\mathbf{T X}$ & 1420 & 8.7 & 93.5 & 0.55 & $53.90 \%$ & $-4.40 \%$ \\
\hline $\mathbf{A Z}$ & 320.5 & 8.9 & 95.8 & 0.55 & $59.10 \%$ & $-3.20 \%$ \\
\hline LA & 125.5 & 5.1 & 55 & 0.55 & $48.70 \%$ & $-2.10 \%$ \\
\hline MS & 149.4 & 11.7 & 125.9 & 0.53 & $57.10 \%$ & $-4.90 \%$ \\
\hline OK & 275.4 & 14.9 & 160.2 & 0.43 & $68.40 \%$ & $-5.00 \%$ \\
\hline GA & 357.9 & 9.7 & 104.7 & 0.41 & $58.50 \%$ & $-5.40 \%$ \\
\hline NV & 157.2 & 10 & 108 & 0.4 & $74.60 \%$ & $-4.70 \%$ \\
\hline $\mathbf{A R}$ & 144.5 & 10.7 & 115.1 & 0.4 & $64.30 \%$ & $-4.70 \%$ \\
\hline $\mathbf{A L}$ & 216.3 & 8.9 & 95.7 & 0.38 & $59.20 \%$ & $-5.40 \%$ \\
\hline SC & 275.5 & 8.8 & 95.2 & 0.37 & $59.90 \%$ & $-5.80 \%$ \\
\hline ID & 137.9 & 12.7 & 136.5 & 0.36 & $77.00 \%$ & $-4.90 \%$ \\
\hline $\mathrm{CO}$ & 274.1 & 11.2 & 120.9 & 0.36 & $76.90 \%$ & $-4.60 \%$ \\
\hline KS & 87.3 & 11.6 & 125.1 & 0.36 & $74.00 \%$ & $-5.90 \%$ \\
\hline $\mathrm{NC}$ & 657.8 & 9.6 & 103.6 & 0.35 & $64.80 \%$ & $-6.80 \%$ \\
\hline UT & 192.8 & 10.9 & 117.1 & 0.34 & $74.70 \%$ & $-5.10 \%$ \\
\hline MO & 198.4 & 10.1 & 109 & 0.34 & $71.80 \%$ & $-6.00 \%$ \\
\hline $\mathbf{O H}$ & 273.5 & 13.8 & 148.3 & 0.33 & $79.00 \%$ & $-5.20 \%$ \\
\hline WI & 237.9 & 16.4 & 176.9 & 0.33 & $81.40 \%$ & $-4.60 \%$ \\
\hline CT & 61 & 13 & 140.3 & 0.32 & $77.60 \%$ & $-5.50 \%$ \\
\hline IN & 271.7 & 14 & 150.9 & 0.32 & $76.70 \%$ & $-5.60 \%$ \\
\hline MI & 284.5 & 16 & 172.7 & 0.32 & $81.80 \%$ & $-4.60 \%$ \\
\hline MT & 44.4 & 15 & 161.5 & 0.32 & $81.60 \%$ & $-4.60 \%$ \\
\hline NE & 128.6 & 14.8 & 158.8 & 0.32 & $78.90 \%$ & $-5.20 \%$ \\
\hline NH & 50.3 & 15.3 & 164.6 & 0.32 & $80.50 \%$ & $-4.70 \%$ \\
\hline PA & 264 & 12 & 129.7 & 0.32 & $78.00 \%$ & $-5.30 \%$ \\
\hline VT & 22 & 16.6 & 179.2 & 0.32 & $81.60 \%$ & $-4.80 \%$ \\
\hline OR & 169.6 & 13.4 & 143.7 & 0.32 & $76.90 \%$ & $-5.20 \%$ \\
\hline MN & 275.5 & 17 & 183.1 & 0.32 & $84.00 \%$ & $-4.00 \%$ \\
\hline $\mathbf{T N}$ & 243 & 7.6 & 82.1 & 0.32 & $66.00 \%$ & $-6.50 \%$ \\
\hline WV & 36.8 & 11.3 & 121.8 & 0.31 & $74.40 \%$ & $-5.90 \%$ \\
\hline SD & 58.9 & 12.9 & 138.5 & 0.29 & $81.10 \%$ & $-4.50 \%$ \\
\hline KY & 127.1 & 10.2 & 110.3 & 0.28 & $73.30 \%$ & $-6.60 \%$ \\
\hline ND & 132 & 17.4 & 187 & 0.28 & $83.90 \%$ & $-4.30 \%$ \\
\hline NJ & 155 & 12.2 & 131.3 & 0.28 & $75.20 \%$ & $-6.70 \%$ \\
\hline NM & 56.3 & 8.1 & 87.2 & 0.28 & $67.30 \%$ & $-6.20 \%$ \\
\hline AK & 11.4 & 13.8 & 148.7 & 0.28 & $88.20 \%$ & $-2.70 \%$ \\
\hline NY & 202 & 13.1 & 141.4 & 0.27 & $80.30 \%$ & $-5.20 \%$ \\
\hline ME & 52.8 & 10.9 & 117 & 0.27 & $83.40 \%$ & $-4.00 \%$ \\
\hline WY & 37.2 & 10.1 & 108.4 & 0.27 & $80.00 \%$ & $-4.30 \%$ \\
\hline
\end{tabular}


Table D-4 Savings in Life-Cycle Costs per Unit of Floor Area from Adoption of the 2012 IECC (10-Year)

\begin{tabular}{|c|c|c|c|c|c|}
\hline State & $\begin{array}{l}\text { Climate } \\
\text { Zone(s) }\end{array}$ & $\begin{array}{l}\text { Average Annual New Floor Area } \\
\qquad 1000 \mathrm{~m}^{2}\left(1000 \mathrm{ft}^{2}\right)\end{array}$ & LCC (\$ million) & $\$ / \mathrm{m}^{2}$ & $\$ / f^{2}$ \\
\hline VT & 6 & $123(1322)$ & 2.8 & 23.0 & 2.1 \\
\hline ME & 6,7 & $452(4862)$ & 8.5 & 18.8 & 1.7 \\
\hline CT & 5 & $435(4683)$ & 8.0 & 18.5 & 1.7 \\
\hline $\mathrm{NH}$ & 6 & $306(3291)$ & 5.7 & 18.5 & 1.7 \\
\hline OR & 4,5 & $1180(12706)$ & 20.2 & 17.1 & 1.6 \\
\hline NY & 5,6 & $1428(15374)$ & 23.5 & 16.5 & 1.5 \\
\hline MI & $5,6,7$ & $1647(17731)$ & 26.7 & 16.2 & 1.5 \\
\hline $\mathrm{AK}$ & 7,8 & $76(822)$ & 1.1 & 14.8 & 1.4 \\
\hline $\mathrm{HI}$ & 1 & $358(3855)$ & 5.1 & 14.4 & 1.3 \\
\hline $\mathrm{OH}$ & 5 & $1845(19858)$ & 26.6 & 14.4 & 1.3 \\
\hline $\mathrm{PA}$ & $4,5,6$ & $2036(21911)$ & 28.3 & 13.9 & 1.3 \\
\hline $\mathrm{NE}$ & 5 & $810(8715)$ & 10.7 & 13.2 & 1.2 \\
\hline ND & 6,7 & 706 (7599) & 9.2 & 13.0 & 1.2 \\
\hline $\mathrm{NJ}$ & 4 & $1181(12707)$ & 14.4 & 12.2 & 1.1 \\
\hline WI & 6 & 1345 (14 479) & 16.0 & 11.9 & 1.1 \\
\hline $\mathrm{SD}$ & 6 & $443(4766)$ & 5.0 & 11.7 & 1.1 \\
\hline IN & 4,5 & $1800(19380)$ & 20.9 & 11.6 & 1.1 \\
\hline MT & 6 & $275(2960)$ & 2.9 & 10.5 & 1.0 \\
\hline $\mathrm{MO}$ & 4 & $1820(19588)$ & 18.3 & 10.1 & 0.9 \\
\hline ID & 5,6 & $1010(10872)$ & 9.8 & 9.7 & 0.9 \\
\hline MN & 6,7 & 1504 (16 191) & 14.5 & 9.7 & 0.9 \\
\hline WV & 4,5 & $302(3249)$ & 2.9 & 9.7 & 0.9 \\
\hline $\mathrm{KS}$ & 4,5 & $698(7513)$ & 6.6 & 9.5 & 0.9 \\
\hline $\mathrm{CO}$ & 5,6 & $2267(24396)$ & 21.3 & 9.4 & 0.9 \\
\hline WY & 6 & $343(3696)$ & 3.2 & 9.4 & 0.9 \\
\hline UT & 5 & $1647(17728)$ & 15.0 & 9.1 & 0.8 \\
\hline $\mathrm{AL}$ & 2,3 & $2260(24324)$ & 17.6 & 7.8 & 0.7 \\
\hline $\mathrm{KY}$ & 4 & $1152(12405)$ & 8.7 & 7.6 & 0.7 \\
\hline $\mathrm{AZ}$ & 4,5 & $3345(36001)$ & 23.8 & 7.1 & 0.7 \\
\hline GA & 2,3 & $3419(36807)$ & 24.3 & 7.1 & 0.7 \\
\hline $\mathrm{NC}$ & 3,4 & 6346 (68 311) & 42.9 & 6.8 & 0.6 \\
\hline OK & 3 & $1719(18506)$ & 11.1 & 6.5 & 0.6 \\
\hline $\mathrm{AR}$ & 3 & $1256(13515)$ & 7.8 & 6.2 & 0.6 \\
\hline $\mathrm{NV}$ & 3 & $1457(15678)$ & 8.6 & 5.9 & 0.5 \\
\hline $\mathrm{SC}$ & 3 & $2895(31$ 159) & 16.8 & 5.8 & 0.5 \\
\hline $\mathrm{TX}$ & $2,3,4$ & 15189 (163 491) & 69.3 & 4.6 & 0.4 \\
\hline NM & 3,4 & $645(6942)$ & 2.7 & 4.3 & 0.4 \\
\hline MS & 3 & $1187(12775)$ & 4.2 & 3.6 & 0.3 \\
\hline FL & 1,2 & 8264 (88 955) & 26.3 & 3.2 & 0.3 \\
\hline $\mathrm{TN}$ & 3,4 & $2962(31879)$ & 9.2 & 3.1 & 0.3 \\
\hline LA & 2,3 & $2280(24545)$ & -0.1 & 0.0 & 0.0 \\
\hline
\end{tabular}

